\title{
The Holocene Glacial History of Dart Glacier, Southern Alps, New Zealand
}

\author{
Lisa Holly Dowling
}

\begin{abstract}
A thesis submitted to Victoria University of Wellington in partial fulfilment of requirements for the degree of Master of Science in Physical Geography
\end{abstract}

School of Geography, Environment and Earth Sciences Victoria University of Wellington 



\section{ABSTRACT}

Mountain glaciers are sensitive climate indicators, as climate variability drives mass changes that are expressed in glacier length fluctuations. These length changes are preserved in the geological record, thus offering the potential to generate new palaeoclimate proxy data that can be used to extend instrumental climate records. This study presents geomorphological mapping and cosmogenic ${ }^{10} \mathrm{Be}$ surface exposure dating of the Holocene moraines at Dart Glacier, New Zealand. These findings show that an early Holocene advance ( $\sim 6 \mathrm{~km}$ longer than present-day) took place $\sim 7817 \pm 336$ years ago. Moraine ages also show that a more restricted glacier readvance ( $\sim \mathrm{km}$ longer than present-day) occurred $\sim 321 \pm 44$ years ago. Through better constraining the timing and magnitude of Holocene glacier length changes, we extend the $\sim 100$-year history of observational records in the upper Dart valley.

Net retreat of Dart Glacier during the Holocene is consistent with other moraine chronologies from New Zealand, which supports existing hypotheses that suggest summer insolation was the dominant driver of multi-millennial climate change at southern mid-latitudes during the current interglacial. Individual moraine forming events at Dart Glacier also coincide with moraine ages from several other catchments in the Southern Alps and likely reflect shorter-term (decadal-centennial-scale) climatic changes. The new geological record constraints of length changes at Dart Glacier offer the opportunity to test such hypotheses more formally using physics-based modelling.

Connecting Holocene moraine records to historical glacier observations using ${ }^{10} \mathrm{Be}$ surface exposure dating requires consistently low background levels of this rare isotope. Systematic blank experiments show that concentrated analytical grade hydrofluoric acid and reused beakers are likely the largest contributors of ${ }^{10} \mathrm{Be}$ to the average process blank in the VUW Cosmogenic Laboratory. Based on these findings I recommend small methodological improvements that could be implemented to lower process blank ratios for routine application of ${ }^{10} \mathrm{Be}$ surface exposure dating to near-historic glacial landforms. 


\section{ACKNOWLEDGEMENTS}

Undertaking this research has been an incredible journey that I have shared with many people. Firstly, I would like to thank my supervisors, Shaun Eaves and Kevin Norton. Shaun, you have been an excellent mentor over the past three years. Thank you for always being so generous with your time and expertise, and for allowing me to be a part of this exciting project. Kevin, thank you for introducing me to the technique of cosmogenic nuclide dating, and for your encouragement and positivity throughout this project. I would also like to thank Lauren Vargo and Matt Ryan for their hard work during our unforgettable field expedition to Dart Glacier in 2017. Never again will we underestimate the intelligence and strength of kea! Thank you to the members of the VUW Cosmo group, particularly Claire Lukens, Ross Whitmore, Jamey Stutz, and our technicians Cassandra Trinh-Le and Luisa Ashworth - you were all immensely helpful and supportive during my time spent in the lab.

Special thanks to my family, Linda, Deanna, Sam and Dave for their emotional support over the past year and for making all those delicious dinners! Thank you to my wonderful flatmates, Alice, Wynn and Rose, for their kindness and understanding during the weeks leading up to my hand in. I am also grateful to my office mates and peers for supporting me through the challenging but rewarding experience of completing this thesis.

Finally, I would like to acknowledge Andrew Mackintosh, Drew Lorrey and Steve Tims for their involvement in the initial stages of designing this project. All sample analyses were carried out at Lawrence Livermore National Laboratory (LLNL) Center for Accelerator Mass Spectrometry (CAMS) by Alan Hidy and Susan Zimmerman. This research was funded by a National Geographic Waitt Grant. 


\section{TABLE OF CONTENTS}

ACKTRACT TOWLEDEMENTS

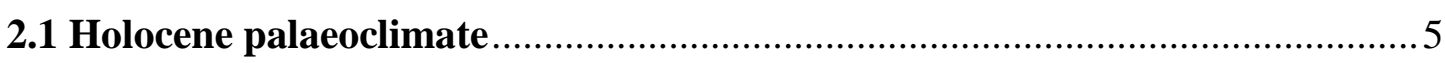

2.2 Mountain glaciers as palaeoclimate proxies .............................................. 8

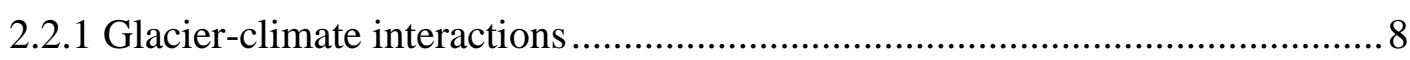

2.2.2 Controls on moraine formation and preservation ....................................... 11

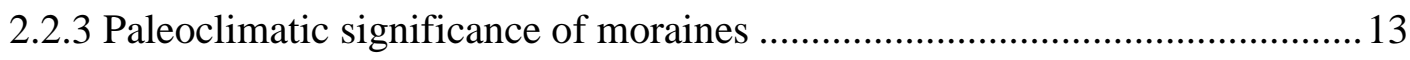

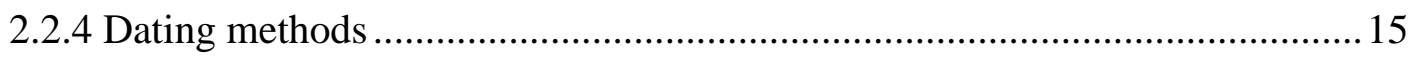

2.3 Cosmogenic ${ }^{10}$ Be surface exposure dating in glacial geomorphology ............. 16

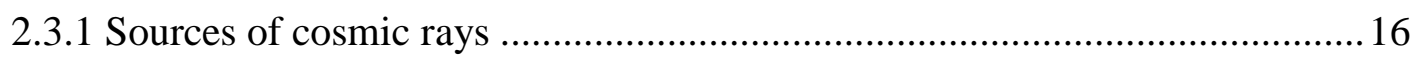

2.3.2 Cosmic ray interactions with Earth's geomagnetic field .............................. 16

2.3.3 Cosmic ray interactions with Earth's atmosphere ....................................... 18

2.3.4 Cosmic ray interactions with Earth's surface and nuclide production ...........2 21

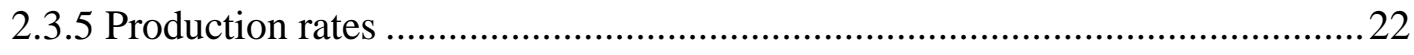

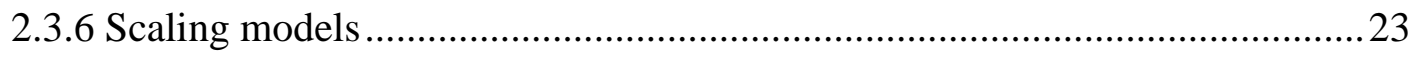

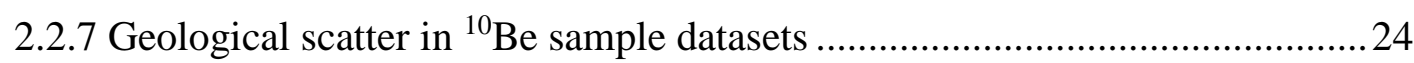

2.3.8 State-of-the-art of cosmogenic ${ }^{10} \mathrm{Be}$ surface exposure dating .......................26

2.4 Existing ${ }^{10}$ Be moraine chronologies in New Zealand ................................... 28

2.4.1 Pre-Holocene ${ }^{10} \mathrm{Be}$ moraine chronologies................................................. 28

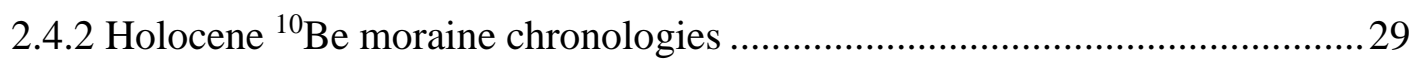

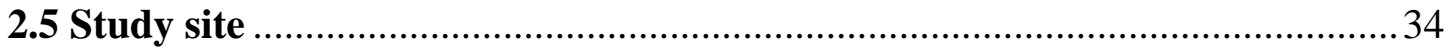

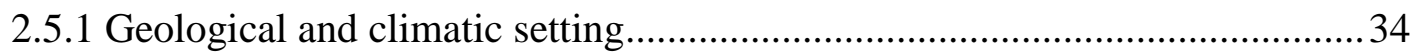

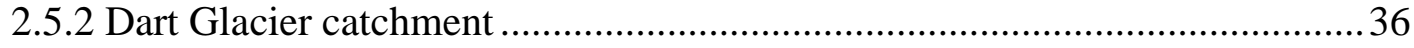

2.5.3 Observational record of glacier length changes at Dart Glacier ......................38

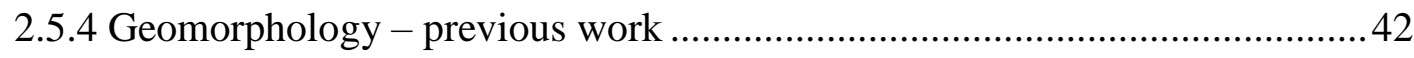

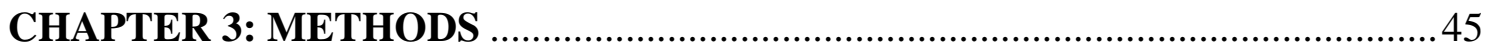

3.1 Geomorphological mapping of glacial landforms at Dart Glacier ................. 45 
3.1.1 General approach to geomorphological mapping ..................................... 45

3.1.2 Compilation of mapping resources and landform identification ...................49

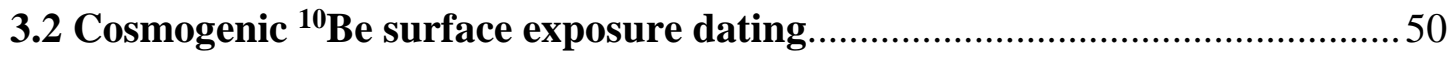

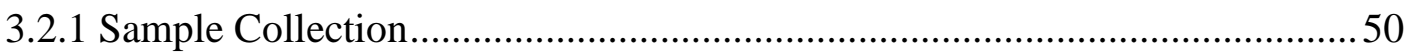

3.2.2 Physical quartz separation and cosmogenic ${ }^{10}$ Be preparation ....................... 51

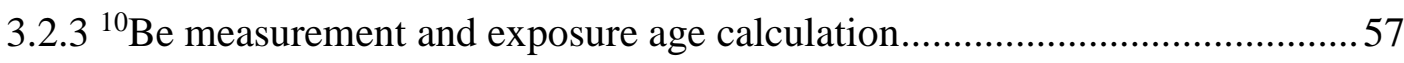

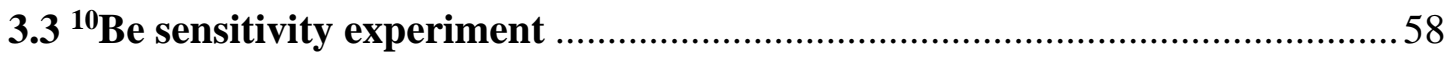

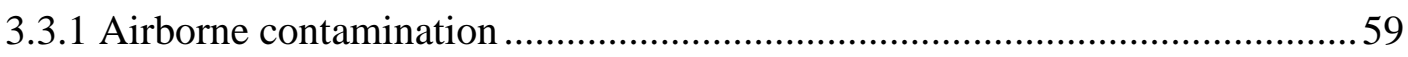

3.3.2 Contamination from reagents and the ${ }^{9} \mathrm{Be}$ carrier.....................................59

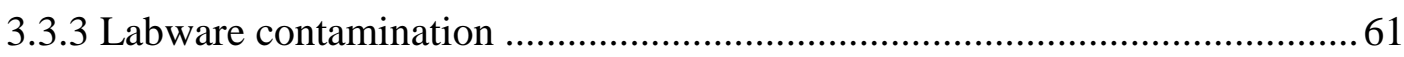

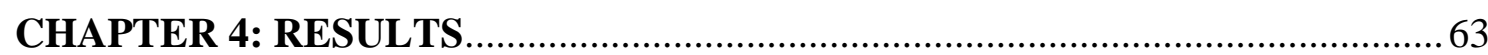

4.1 Glacial geomorphology of the upper Dart valley .......................................63

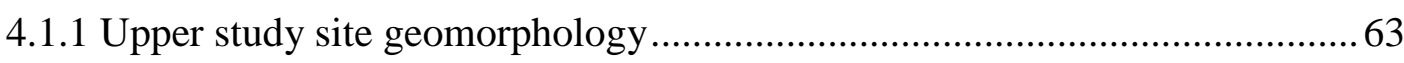

4.1.2 Lower study site and Dart Hut site geomorphology ....................................69

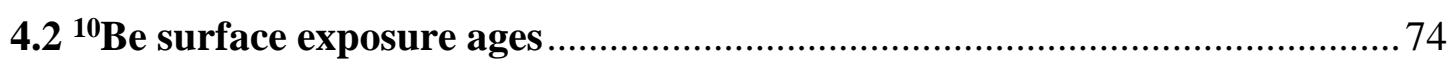

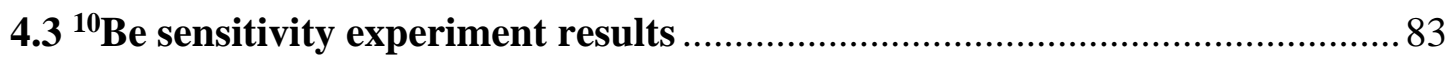

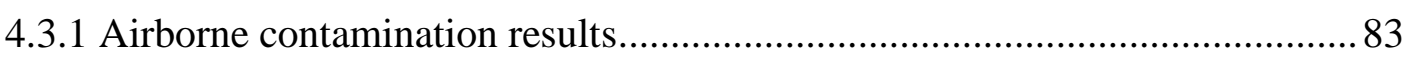

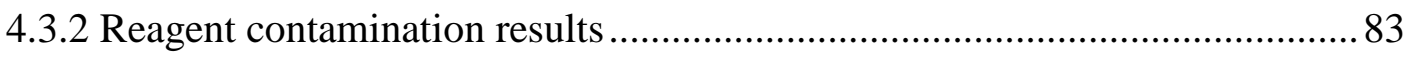

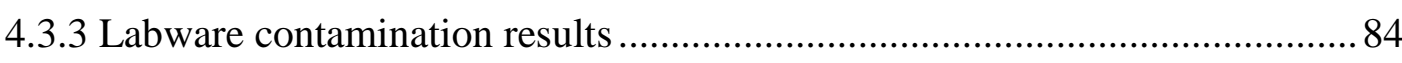

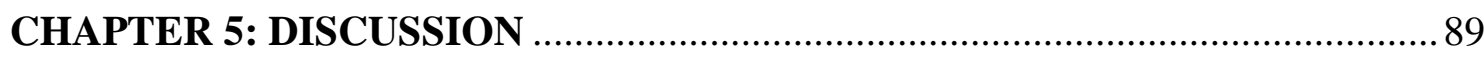

5.1 Magnitude and timing of glacier length changes at Dart Glacier ..................8 89

5.2 Holocene glacier length changes in the Southern Alps ..................................94

5.3 Drivers of the Holocene glacier length changes ............................................98

5.3.1 Potential non-climatic drivers of glacier length changes ............................. 98

5.3.2 The role of temperature and precipitation in glacier length changes..............99

5.3.3 Drivers of early Holocene glacier advance and Holocene net glacier retreat

5.3.4 Drivers of Little Ice Age glacier length changes .......................................... 104

5.4 Implications of ${ }^{10} \mathrm{Be}$ sensitivity experiment for future low concentration

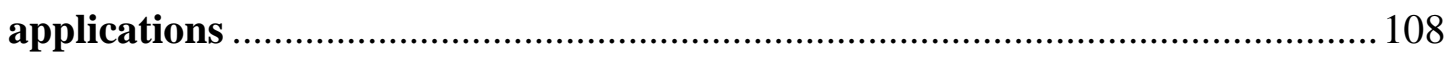

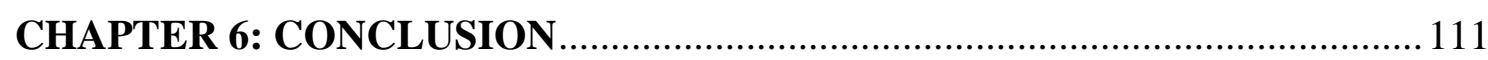

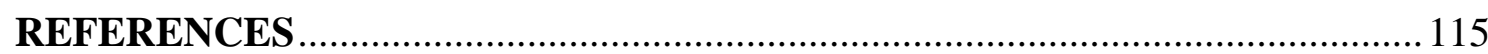

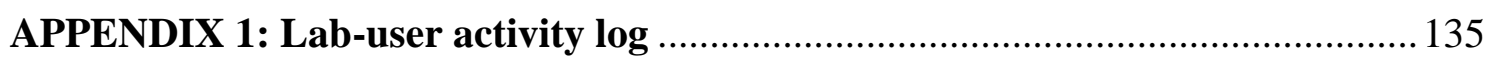

APPENDIX 2: Geomorphological map of the upper Dart valley ......................... 137 


\section{LIST OF FIGURES}

Figure 1.1 Oblique aerial photograph of Dart Glacier .... 4

Figure 2.1 Quaternary ice-core records from Greenland and Antarctica........................6

Figure 2.2 Image of an idealised mountain glacier

Figure 2.3 Historic length changes of New Zealand glaciers 11

Figure 2.4 The effect of the Earth's geomagnetic field on incoming cosmic rays ........ 18

Figure 2.5 The components of the secondary cosmic ray cascade in the atmosphere...20

Figure 2.6 ${ }^{10} \mathrm{Be}$ production with depth in quartz arenite. 22

Figure 2.7 Scaling cosmogenic nuclide production with latitude and altitude. 25

Figure 2.8 Illustrations demonstrating the various causes of geological scatter in exposure age datasets.

Figure 2.9 Map showing locations of sites in the central Southern Alps of New Zealand where there are existing Holocene moraine chronologies that have been developed using ${ }^{10} \mathrm{Be}$ surface exposure dating. 30

Figure 2.10 Mueller Glacier Holocene ${ }^{10} \mathrm{Be}$ moraine ages 32

Figure 2.11 Summary figure of the glacier-climate reconstruction at Whale Stream in Ben Ohau Range, central Southern Alps. 33

Figure 2.12 Location of Dart Glacier in the Southern Alps of New Zealand 35

Figure 2.13 Annotated aerial photograph of the Dart catchment showing the geometry of the glacier.

Figure 2.14 Historical photographs showing the lateral extent of Dart Glacier in AD1914 in the upper Dart valley

Figure 2.15 Historical map of the topography surrounding the Dart valley

Figure 2.16 Summary of the observational records documenting the former terminus positions of Dart Glacier from AD1915 to AD2007.

Figure 2.17 Previous geomorphic interpretations of glacial landforms at the upper study site

Figure 3.1 Sites for collection of moraine boulder samples for cosmogenic ${ }^{10} \mathrm{Be}$ surface exposure dating at Dart Glacier.

Figure 3.2 Flow chart adapted from Corbett et al. (2016) showing steps used for quartz separation and ${ }^{10} \mathrm{Be}$ preparation

Figure 4.1 Geomorphological map of the upper Dart valley 66

Figure 4.2 Upper study site geomorphology 
Figure 4.3 Images of geomorphic features at or near the upper study site ...................70

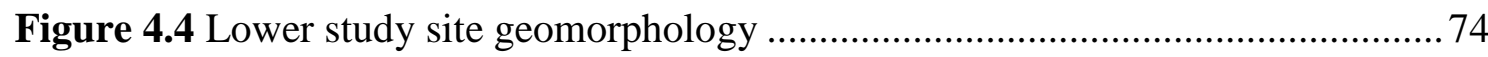

Figure 4.5 Images of geomorphic features at the lower study site.............................. 74

Figure 4.6 Sample exposure ages overlaid on the geomorphological map of the upper

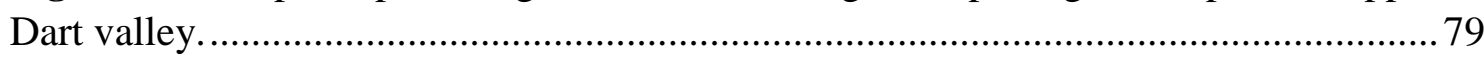

Figure 4.7 Images of sampled boulders and their associated exposure ages ................. 80

Figure 4.8 Camel plots and arithmetic mean ages $( \pm 1 \sigma)$ for individual moraines........ 81

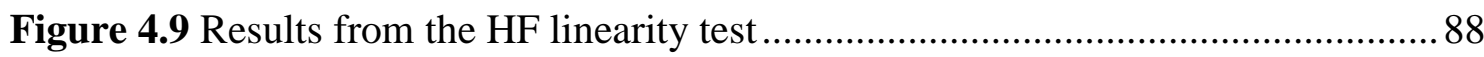

Figure 5.1 Recalibrated moraine ages using lichen diameters ..................................93

Figure 5.2 Compilation of Holocene moraine records in the Southern Alps.................95

Figure 5.3 Comparison of snowline derived temperature records with summer

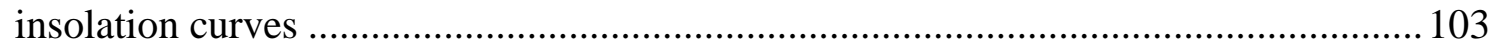

Figure 5.4 Interhemispheric variability in temperature extremes over the past millennium 


\section{LIST OF TABLES}

Table 3.1 Summary descriptions of the landform categories and types that were used to create the final geomorphological map

Table 3.2 Acid grades and concentrations used in the reagent contamination component of the ${ }^{10} \mathrm{Be}$ sensitivity experiment.

Table 4.1 ${ }^{10} \mathrm{Be} /{ }^{9} \mathrm{Be}$ ratios and ${ }^{10} \mathrm{Be}$ concentrations and all associated information with

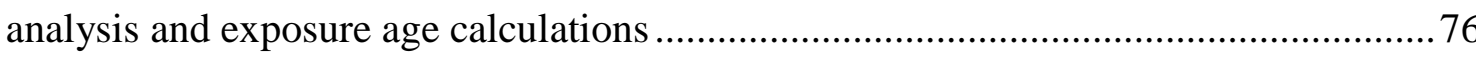

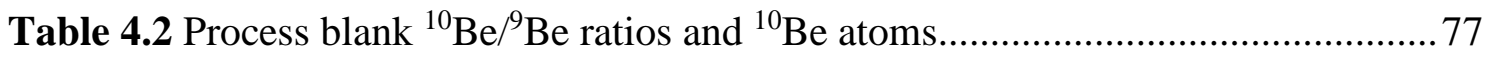

Table 4.3 Cosmogenic ${ }^{10} \mathrm{Be}$ exposure ages for the moraines in the Dart valley ............ 78

Table 4.4 Summary statistics for each moraine age dataset from a chi-squared outlier

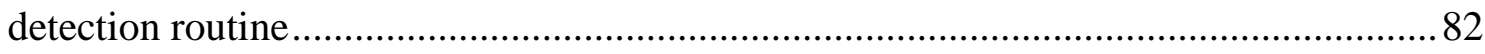

Table 4.5 ${ }^{10} \mathrm{Be} /{ }^{9} \mathrm{Be}$ ratios and ${ }^{10} \mathrm{Be}$ contents for ${ }^{10} \mathrm{Be}$ sensitivity experiment................. 86

Table 4.6 Percentage contribution of sources of ${ }^{10} \mathrm{Be}$ contamination to an average

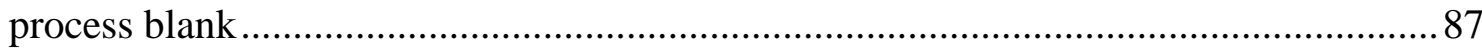




\section{CHAPTER 1: INTRODUCTION}

The Holocene epoch (11.7 ka to present-day) is defined by its relative climate stability that has facilitated the rise of human civilisation, which since the Industrial Revolution (mid-18 ${ }^{\text {th }}$ century) has had an increasingly significant impact on global climate (IPCC, 2013). As a result of these human activities, in particular, those involving the combustion of fossil fuels and land use changes, greenhouse gas concentrations have dramatically increased since the beginning of the industrial revolution (Ciais et al., 2013) and now exceed concentrations recorded in ice cores during the last 800,000 yrs (Loulergue et al., 2008; Lüthi et al., 2008; Schilt et al., 2010; Masson-Delmotte et al., 2013). This change in the composition of the atmosphere has consequently affected Earth's energy budget, causing atmospheric temperatures to warm over the past two centuries. There is compelling evidence for the influence of anthropogenic warming on the Earth's system due to observed changes in the atmosphere, terrestrial biosphere, oceans, and cryosphere (IPCC, 2013). For example, historical records of the global retreat of mountain glaciers during the $20^{\text {th }}$ and $21^{\text {st }}$ centuries are often promoted as visible evidence for anthropogenic climate change (Zemp et al., 2015). Our ability to detect and attribute these changes directly to anthropogenic change has proven difficult, as the climate can vary considerably both spatially and temporally due to the combined influences of natural internal climate variability and external forcings (e.g. orbital, solar and volcanic forcings) (Hartmann et al., 2013; Masson-Delmotte et al., 2013).

Currently, there is a global effort towards determining the extent to which the climate trends observed today are linked to anthropogenic or natural climate variability. In order to achieve this level of detection and attribution, we must first assess how and why the climate system has varied naturally during pre-industrial times. To-date reconstructions of the global climate during the Holocene may not accurately reflect natural climate variability in the Southern Hemisphere as the majority of palaeoclimate records are from the Northern Hemisphere (Mann et al., 2009; Marcott et al., 2013; Neukom et al., 2014). Therefore, there is a need to extend the existing short instrumental records in the Southern Hemisphere using palaeoclimate proxy data in order to assess the bounds of natural variability. Longer climate records can also be used to test global climate models which aim to simulate past and future climate responses to external forcings. 
One way to address this gap in Southern Hemisphere palaeoclimate records is to use glaciers as proxies for past changes in climate. Glaciers are exceptional recorders of climate as their mass balance changes, and ultimately their length fluctuations, are strongly dependent on changes in temperature and precipitation (Oerlemans, 2001). Therefore, pre-historic glacier fluctuations are recorded by moraines, which delineate former ice geometries and can therefore be used to reconstruct past glacier behaviour in response to changes in climate (Benn \& Evans, 2010; Mackintosh et al., 2017b). When accurately mapped and dated, moraines can also be used to constrain glacier and climate models used to test hypotheses surrounding the potential drivers of past climate variability (Oerlemans, 1997; Anderson \& Mackintosh, 2006; Schaefer et al., 2015; Doughty et al., 2017; Eaves et al., 2017; Koffman et al., 2017).

New Zealand provides an excellent location for glacier-climate reconstructions. Located in the Southern Hemisphere mid-latitudes $\left(34-47^{\circ} \mathrm{S}\right)$, the New Zealand landmass is well positioned to register changes in the prevailing westerly circulation that results from the interactions between the surrounding subtropical and sub-Antarctic air and water masses (Sturman \& Tapper, 2006; Lorrey \& Bostock, 2017). Furthermore, steep topography coupled with the temperate, maritime, high-precipitation setting means that local glaciers are highly responsive to changes in atmospheric temperature (Oerlemans \& Fortuin, 1992; Anderson et al., 2010; Anderson \& Mackintosh, 2012; Mackintosh et al., 2017a; Mackintosh et al., 2017b). Accurately constraining the timing and magnitude of the climate changes associated with geological records of past glacier length fluctuations requires a dense population of Holocene glacier reconstructions. However, to date only a small number of Holocene moraine records have been documented in New Zealand (Schaefer et al., 2009; Putnam et al., 2012; Kaplan et al., 2013).

Cosmogenic ${ }^{10} \mathrm{Be}$ surface exposure dating provides a powerful tool for accurately dating pre-historic glacial landforms (Gosse \& Phillips, 2001; Dunai, 2010; Ivy-Ochs \& Briner, 2014). Recent developments in accelerator mass spectrometry (AMS) have enabled precise measurement of samples with low ${ }^{10} \mathrm{Be}$ concentrations that pertain to very young landforms (Balco, 2011), although such applications are not yet routine. Low ${ }^{10} \mathrm{Be}$ concentration applications of surface exposure dating require careful consideration around laboratory pre-treatment of samples in order to maximise signal-to-noise ratios in samples and increase the overall accuracy of the ages (Hunt et al., 2008; Corbett et al., 2016). 
In this study, cosmogenic ${ }^{10} \mathrm{Be}$ surface exposure dating is applied to pre-historic moraines preserved in the proglacial foreland of Dart Glacier, situated in the Mt Aspiring region of the Southern Alps. Dart Glacier is $\sim 6 \mathrm{~km}$ long and comprises a wide accumulation zone and steep, narrow tongue (see Figure 1.1). Glacial modelling studies suggest that glaciers with this type of geometry have short response times and large length sensitivities, compared to those with more gradual slopes and uniform area-altitude distributions (Mackintosh et al., 2017a; Mackintosh et al., 2017b). Furthermore, Dart Glacier also receives high amounts of precipitation annually (Tait et al., 2006), meaning the glacier is very sensitive to temperature changes (Oerlemans \& Fortuin, 1992; Anderson et al., 2010; Anderson \& Mackintosh, 2012). There is also a rich observational record of the Dart Glacier that documents its length changes since the first direct observation in AD1914 (Bishop \& Forsyth, 1988; Ruddell, 1995). Additionally, the Dart valley contains wellpreserved moraine record that delineates the extent of former ice geometries (Sommerville et al., 1982). Overall, Dart Glacier provides an ideal study site for assessing Holocene glacier-climate fluctuations in New Zealand that has yet to be fully exploited.

The central aims of this study are: i) to better constrain the timing, magnitude, and climatic drivers of Holocene glacier length changes in New Zealand; and ii) to facilitate routine application of cosmogenic surface exposure dating to near-historic landforms in the VUW Cosmogenic Laboratory. To achieve these aims, I complete the following three objectives:

1. Document the distribution of glacial landforms in the upper Dart valley through detailed geomorphological mapping.

2. Develop a new moraine chronology at Dart Glacier using cosmogenic ${ }^{10} \mathrm{Be}$ surface exposure dating.

3. Quantify contributions of ${ }^{10} \mathrm{Be}$ to full-process blanks in the VUW Cosmogenic Laboratory through a systematic series of partial-process blank experiments. 


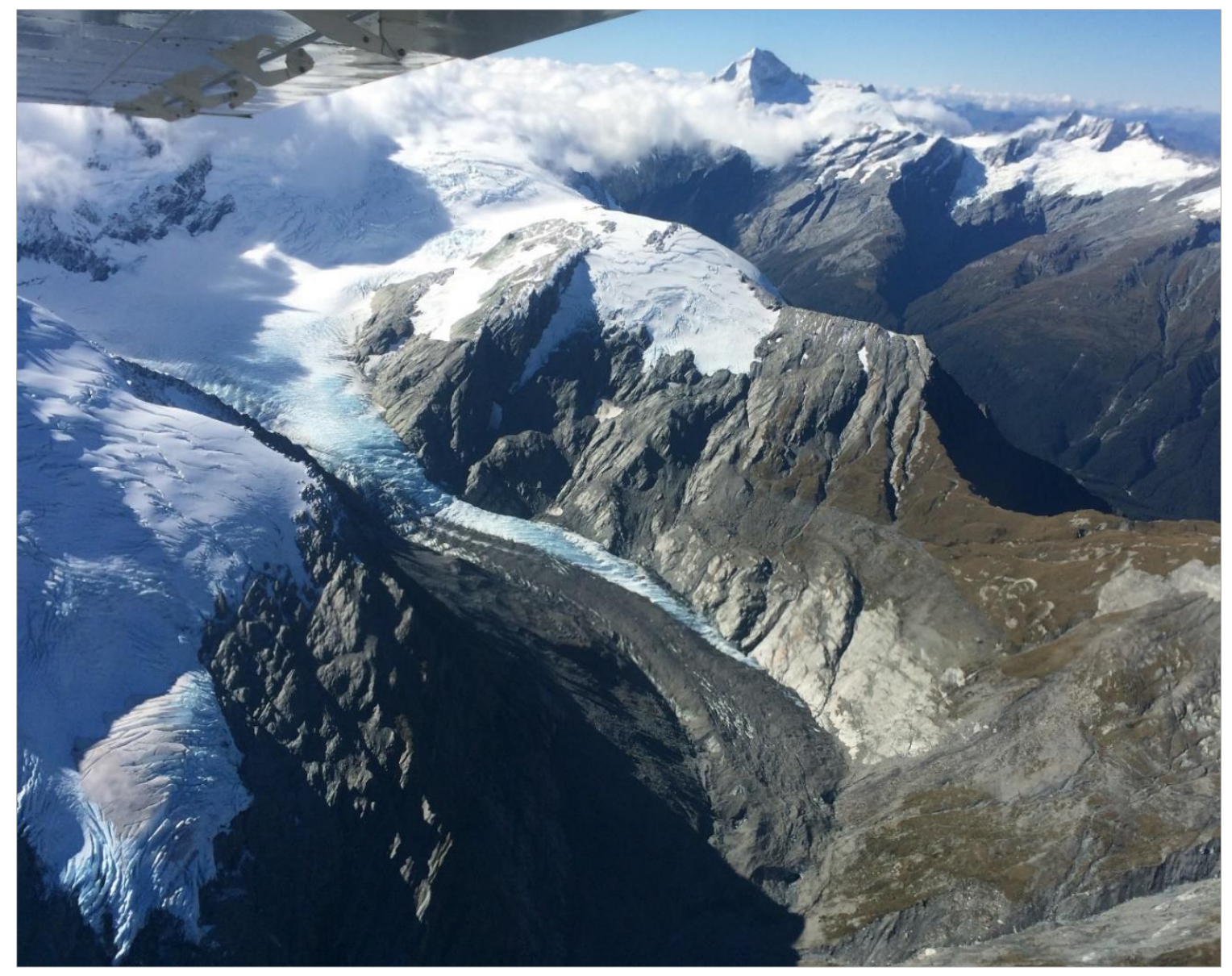

Figure 1.1 Oblique aerial photograph of Dart Glacier taken by A. Mackintosh during the End of Summer Snowline Survey in 2016. 


\section{CHAPTER 2: BACKGROUND}

\subsection{Holocene palaeoclimate}

The Holocene is a geological epoch that spans the last 11.7 kyrs (Walker et al., 2009). It is an interglacial, meaning that the climate is characteristically stable and warm compared to the unstable and cold climatic conditions of the last glacial (115 ka to $11.7 \mathrm{ka}$ ) (Walker et al., 2009; Lowe \& Walker, 2014). The contrasting climatic conditions of the Holocene and the last glacial are broadly demonstrated in ice core temperature records from Greenland and Antarctica (Figure 2.1). The climatic stability of the Holocene is similar to that of previous interglacials, however, the impact of humans on the environment sets the Holocene apart (Walker et al., 2009; Ruddiman, 2013; Lowe \& Walker, 2014). Stable climatic conditions of the Holocene allowed for human activities to become more widespread throughout the globe, leading to the rise of civilisations. More recently, landuse changes, population growth, and the 18th century Industrial Revolution, have led to an anomalous increase in greenhouse gas emissions that have had a significant impact on Earth's radiative balance, meaning humans are modifying the climate system (IPCC, 2013). Therefore, there is a need for longer and more highly resolved records of natural climate variability in order to detect the extent of anthropogenic climate change.

Understanding the drivers of natural climate variability during the Holocene provides an important 'baseline' for assessing anthropogenic climate change. Detection and attribution of human impact on the climate system is limited by short instrumental climate records, especially in the Southern Hemisphere. Palaeoclimate records, such as ice cores, lake and ocean sedimentological and biological proxies, mountain glaciers, tree-rings, and speleothems, can provide valuable insights into past climate variability prior to instrumental records. These archives allow us to compare the pre-industrial or 'natural' state of the climate with post-industrial climatic conditions. 


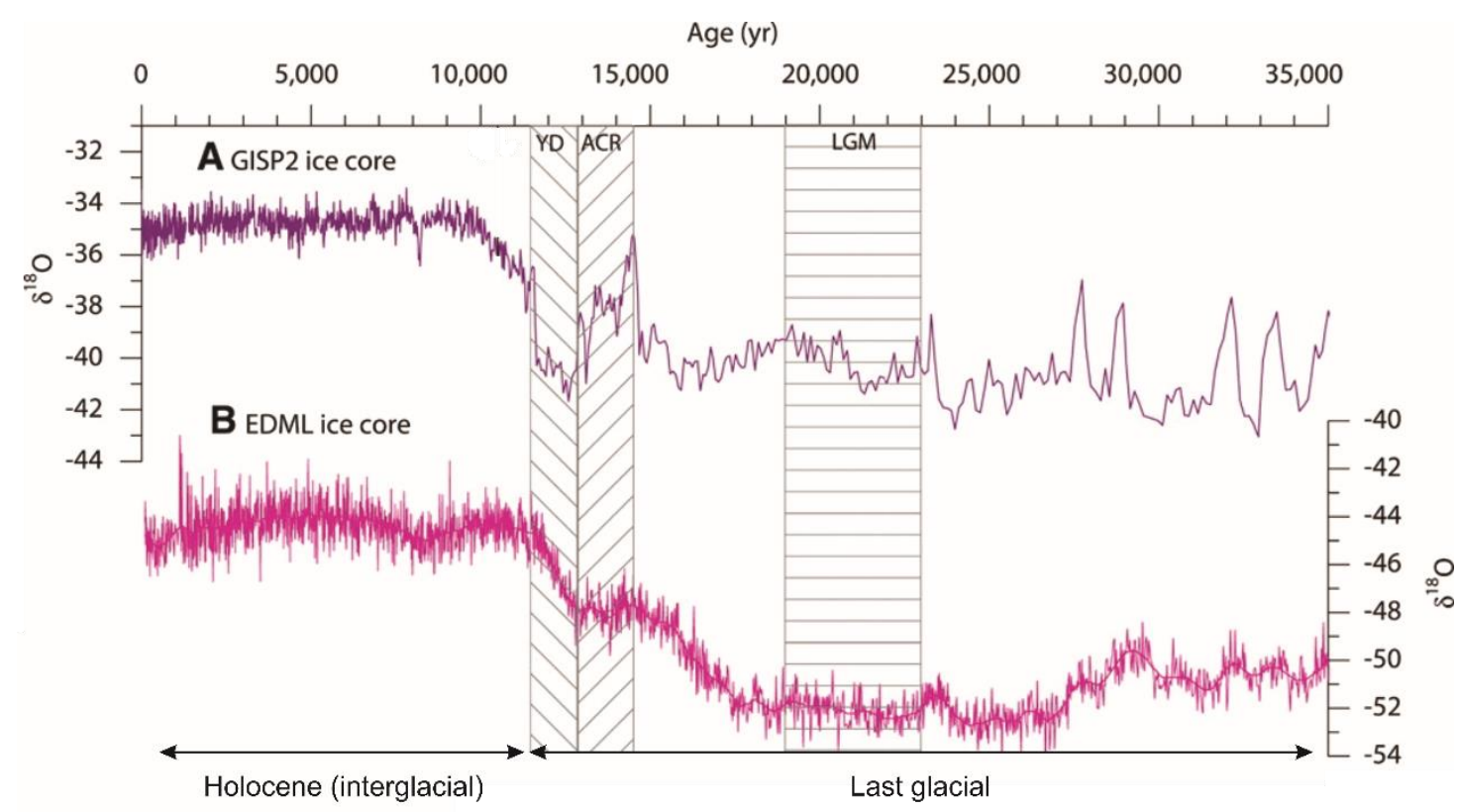

Figure 2.1 Quaternary ice-core records from Greenland and Antarctica. (A) Greenland Ice Sheet Project (GISP2) ice core $\delta^{18} O$ record (Grootes et al., 1993). (B) Antarctic European Project for Ice Coring in Antarctica (EPICA) Dronning Maud Land (EDML) ice core $\delta^{18} \mathrm{O}$ record (EPICA Community Members, 2006). Figure adapted from Barrows et al. (2007b).

Based on instrumental and palaeoclimate records we know that the climate varies naturally on a range of timescales due to the combined influence of different climate forcings. On long timescales, insolation changes and associated feedbacks in the Earth's climate system cause the climatic conditions to naturally switch from cold to warm phases over multimillennial timescales (1000-10,000 years) (Figure 2.1). The current understanding is that these phases, known as "Milankovitch cycles", are controlled by the periodicity of Earth's orbital parameters (eccentricity and precession) and axial tilt (obliquity) (Milankovitch, 1941; Hays et al., 1976). The combined effect of these astronomical variables causes the amount of radiation that is received at the top of Earth's atmosphere ('insolation') to vary both latitudinally and seasonally (Hays et al., 1976; Berger \& Loutre, 1991).

Superimposed on this long-term trend, the climate system changes on short-term (annual to millennial) timescales due to 'forced' climate variability associated with natural (nonanthropogenic) greenhouse gas, solar, and volcanic forcings which influence Earth's radiative balance (Robock, 2000; Lean, 2010; Ciais et al., 2013; Masson-Delmotte et al., 2013). Irrespective of external forcings, the climate varies on a range of spatial and temporal timescales as a result of internal climate variability which does not alter the 
Earth's energy budget but rather works to redistribute heat and energy around the globe (Hartmann et al., 2013). As a result of large-scale climate phenomena associated with ocean-atmosphere interactions, such as the El Nino Southern Oscillation (ENSO), internal climate variability can cause significant regional differences in climatic conditions on interannual to decadal timescales (Cane, 2005; Hartmann et al., 2013; Masson-Delmotte et al., 2013; Hartmann, 2016). Thus, forced climate variability is more likely to produce a globally-coherent climate signal compared to unforced internal climate variability which results in climatic conditions that are highly varied spatially.

As a result of these drivers, the climate varies spatially as well as temporally. Unlike in the Northern Hemisphere where more detailed instrumental and palaeoclimate records of climate variability exist, records are much shorter and fragmented in the Southern Hemisphere. More specifically, Northern Hemisphere palaeoclimate records suggest that temperatures were generally warm during the early Holocene and progressively cooled from the mid Holocene onwards until the $19^{\text {th }}$ century (e.g. Cuffey \& Clow, 1997; Hormes et al., 2001; Holzhauser et al., 2005; Joerin et al., 2006; Joerin et al., 2008; Ivy-Ochs et al., 2009; Goehring et al., 2011; Marcott et al., 2013). Multi-centennial warming and cooling events, including the Medieval Warm Period ( AD1000-1300) and 'Little Ice Age' ( 1450-1850), are also well-documented in observational and palaeoclimate records (Bradley \& Jonest, 1993; Broecker, 2001; Grove, 2004; Holzhauser et al., 2005). However, there is still large uncertainty surrounding the climatic conditions in the Southern Hemisphere during this time (Putnam et al., 2012; Lorrey \& Bostock, 2017). Consequently, our understanding of Holocene palaeoclimate is highly skewed towards the Northern Hemisphere (Mann et al., 2008; Mann et al., 2009; Marcott et al., 2013). The gaps in the Southern Hemisphere climate records ultimately restrict our ability to gain a complete understanding of how and why the climate has varied naturally throughout the Holocene. 


\subsection{Mountain glaciers as palaeoclimate proxies}

\subsubsection{Glacier-climate interactions}

Historical records of glacier length changes show that mountain glaciers are sensitive to changes in climate, especially temperature and precipitation (Oerlemans, 2001). This is because both variables play strong roles in determining glacier mass balance, which refers to the net gain and loss of ice in a glacier system over a fixed time span (usually a year) (Benn \& Evans, 2010). Temperate mountain glaciers predominantly gain mass at high elevations in the accumulation zone (Figure 2.2) through precipitation; air temperature determines whether precipitation falls as snow or rain (Mackintosh et al., 2017b). Snow also accumulates via wind-blown snow, refrozen meltwater, or avalanching of ice from surrounding topography (Benn \& Evans, 2010; Mackintosh et al., 2017b). Conversely, surface melt processes dominate in the ablation zone (Figure 2.2) that is located at lower elevations where the glacier loses mass. Melting in the ablation zone is determined primarily by solar (shortwave) radiation and air temperature (Oerlemans, 2001; Benn \& Evans, 2010; Mackintosh et al., 2017b). However, glaciers may also lose mass through sublimation, evaporation, wind scouring, and calving of icebergs at the terminus into water (e.g. pro-glacial lakes) (Benn \& Evans, 2010; Mackintosh et al., 2017b). Overall, in maritime settings glacier accumulation and ablation processes have been shown to be most sensitive to changes in temperature (Ohmura, 2001; Braithwaite et al., 2003; Oerlemans, 2005). That is, due to the high sensitivity of glacier mass balance to air temperatures, glaciers require large precipitation changes ( 40\%) to offset small temperature changes $\left(1^{\circ} \mathrm{C}\right)$ (Oerlemans, 2001; Anderson \& Mackintosh, 2006; Anderson et al., 2010; Mackintosh et al., 2017b).

The equilibrium line altitude (ELA) (also referred to as 'snowline') marks the transition point between the accumulation and ablation zones, where the two zones are in equilibrium and net annual mass balance is equal to zero (Figure 2.2; Benn \& Evans, 2010; Mackintosh et al., 2017b). Perturbations in climatic conditions, including changes in air temperature and/or precipitation, cause the ELA to increase or decrease, initiating a change in glacier mass balance. Glaciers grow in mass and increase in length when climate variables allow an extended period of positive mass balance (accumulation exceeds ablation and ELA lowers). Conversely, glaciers reduce in mass and decrease in length due to extended periods of negative mass balance (ablation exceeds accumulation 
and ELA increases). Therefore, changes in glacier thickness and length directly reflect integrated mass balance changes over time in response to climate variability.

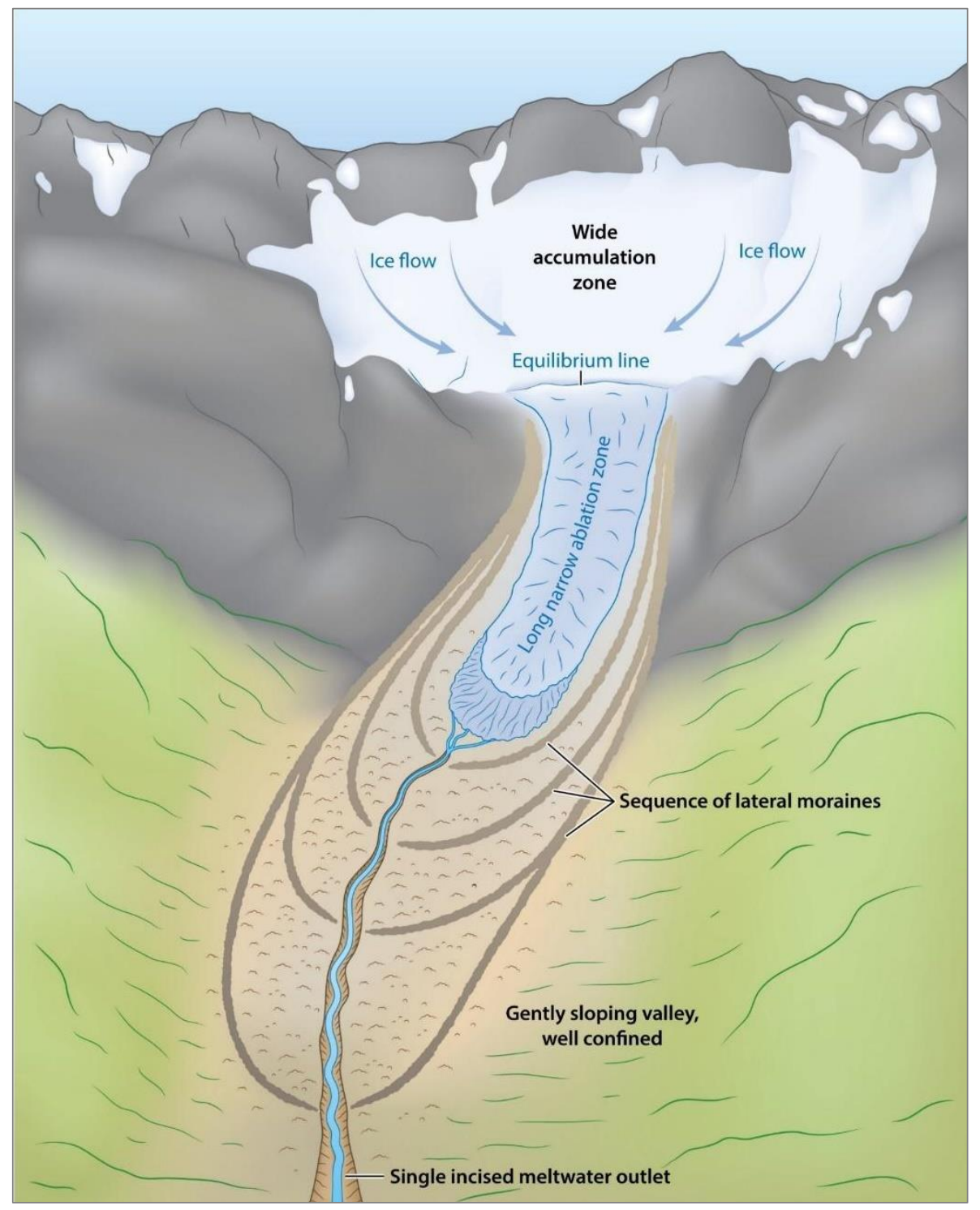

Figure 2.2 Image of an idealised mountain glacier showing the controls on moraine formation and preservation. The geometry is characteristic of a glacier with a fast response time where a sequence of lateral moraines was deposited by former glacier advance and subsequent retreat. The terminal moraines are being removed by a meltwater stream (see Section 2.2.2). Figure from Mackintosh et al. (2017b). 
Glaciers may not respond synchronously to changes in climate because of differences in response times. A glacier response time is the length of time taken for a glacier to undergo two-thirds of its volume adjustment following a change in mass balance (Jóhannesson et al., 1989; Oerlemans, 2001, 2005). Glacier response time is a theoretical concept that cannot be observed directly from field data as the climate is never constant, and is therefore best estimated using numerical models (e.g. Oerlemans, 1997). Climatic setting plays an important role in determining response times, as glaciers that receive high amounts of precipitation are more sensitive to changes in temperature compared to glaciers that receive low amounts of precipitation (Oerlemans \& Fortuin, 1992; Oerlemans et al., 1998; Anderson et al., 2010; Mackintosh et al., 2017a; Mackintosh et al., 2017b). Furthermore, the response time of a glacier is also dependent on its geometry which includes topographical factors such as altitude-area distribution, slope, and debris (Oerlemans \& Fortuin, 1992; Raper \& Braithwaite, 2009; Anderson et al., 2010; Anderson \& Mackintosh, 2012; Mackintosh et al., 2017b).

Monitored length changes of New Zealand glaciers over the last century provide good examples of differential glacier behaviour due to varied response times (Figure 2.3). Fox and Franz Josef glaciers located west of the Main Divide in the Southern Alps, are steep and relatively thin glaciers that receive high amounts of precipitation ( $\sim 10 \mathrm{~m}$ per year) (Anderson et al., 2008; Mackintosh et al., 2017a). Snow and ice are transported rapidly from wide accumulation zones through narrow valleys at rates up to $1 \mathrm{~km}$ per year (Oerlemans, 1997; Anderson et al., 2008; Mackintosh et al., 2017a). Consequently, Fox and Franz Josef glaciers have fast mass turnover rates and short response times $(\sim 20$ years), which are reflected in their frequent (decadal-scale) advances (Figure 2.3) (Oerlemans, 1997; Anderson et al., 2008; Mackintosh et al., 2017a). In contrast, Tasman Glacier is a large, gently sloping glacier with a more uniform area-altitude distribution. The glacier is also insulated by a thick layer of debris and terminates via calving into a pro-glacial lake that formed in the 1980s (Mackintosh et al., 2017a). Resultantly, Tasman Glacier responds more slowly to climate change (Warren \& Kirkbride, 2003; Anderson \& Mackintosh, 2012; Mackintosh et al., 2017a). As shown in Figure 2.3, Tasman Glacier did not fluctuate in the same way as Fox and Franz Josef glaciers during the $20^{\text {th }}$ century, despite being exposed to the same climatic conditions. Rather, Tasman Glacier has retreated continuously since the 1980s (Mackintosh et al., 2017a). This comparison 
demonstrates how adjacent mountain valley glaciers can respond very differently to the same climate signal.

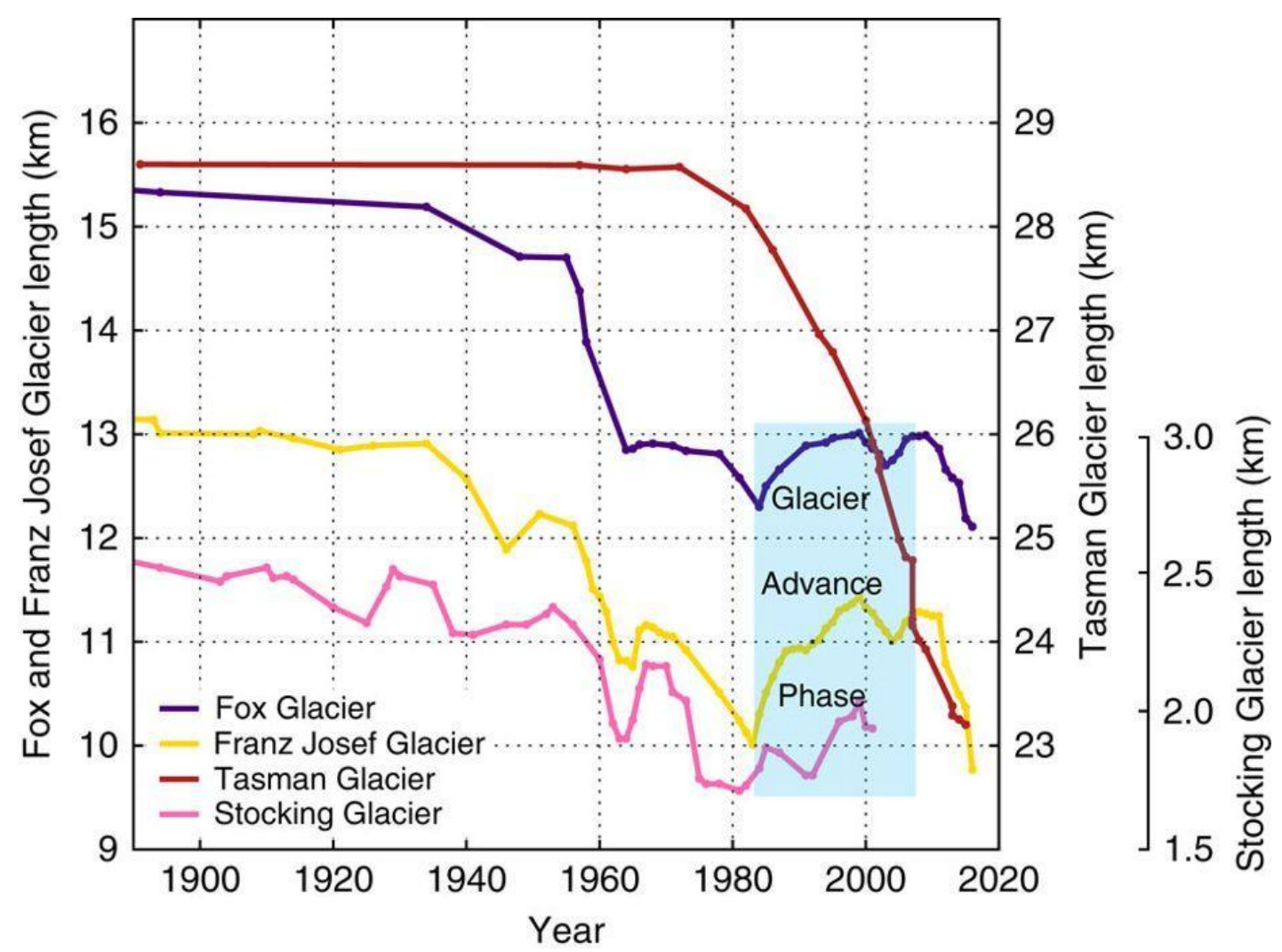

Figure 2.3 Historic length changes of New Zealand glaciers during the $20^{\text {th }}$ and $21^{\text {st }}$ centuries including Fox, Franz Josef, Tasman and Stocking glaciers. Note all glaciers retreated during the $20^{\text {th }}$ century, however, Fox, Franz Josef and Stocking glaciers readvanced periodically between 1983 and 2008 (Mackintosh et al., 2017a).

\subsubsection{Controls on moraine formation and preservation}

As a glacier flows downslope, sediment is derived and entrained through glacial erosion. Glaciers erode landscapes through different mechanisms such as plucking, abrasion, subglacial stream erosion, and chemical weathering processes at the glacier bed (Herman \& Braun, 2008; Herman et al., 2015). Sediment can also be contributed to the glacier from the surrounding topography via mass-movement processes. This material is then transported englacially (within the glacier), subglacially (at the glacier bed) or supraglacially (at the ice surface), supplying material for moraine formation (Benn \& Evans, 2010). 
Moraines are broadly defined as a landform that is comprised of ice-deposited (glaciogenic) sediment or till deposited at lateral and basal glacier margins (Benn \& Evans, 2010). When a glacier length remains stable, moraines build-up at the ice margins to form discrete ridge-type features. The shape and size of moraines is determined by factors such as glacial sediment load, meltwater volume, the direction of ice flow, flow velocity, glacier geometry, and topographic setting (Benn \& Evans, 2010). Therefore, larger moraines do not necessarily equate to prolonged glacier standstills and stable climatic conditions (Mackintosh et al., 2017b). Ridges deposited at the glacier terminus form terminal moraines, whereas material deposited parallel to the glacier form lateral moraines (Figure 2.2). Terminal and lateral moraines define the limit of a glacier advance (Benn \& Evans, 2010), therefore, when these features are preserved in the landscape they can be used to infer former ice-marginal positions for glacier-climate reconstructions (see Section 2.2.3). Successive advance and retreat can form moraine sequences potentially providing insights into longer-term climate variability.

Moraines are also modified after deposition by various processes that affect their preservation. Over time, the shape of a moraine changes due to degradation caused by periglacial activity (freeze-thaw), sub-aerial exposure, and topographic diffusion (Applegate et al., 2012). Moraines, particularly terminal moraines, are often destroyed by meltwater systems and outwash plains which also form during glacier retreat (Figure 2.2). Consequently, former ice-marginal positions must be inferred from lateral moraines (e.g. Putnam et al., 2010a; Eaves et al., 2016; Shulmeister et al., 2018). Moraines may also be altered by tectonic and mass-movement processes which often occur in glaciated mountain valleys (Barrell et al., 2011).

Glacier response time and length sensitivity can also play an important role in determining both moraine formation and preservation. Glaciers with short response times may respond to both high-frequency (interannual to decadal) and low-frequency (multidecadal to centennial) climate perturbations, whereas glaciers with slow response times are more likely to respond to only low-frequency changes (Mackintosh et al., 2017b). Both types of glaciers can demonstrate broadly similar behaviour, and comparable moraine sequences can be preserved in adjacent mountain valleys (Mackintosh et al., 2017b). However, fast-flowing glaciers may exhibit "obliterative overlap" of older moraines as a result of regular fluctuations, thus resulting in more discontinuous moraine records 
(Gibbons et al., 1984; Mackintosh et al., 2017b). Furthermore, glaciers also have different length sensitivities which can have an important influence on how moraine sequences are arranged spatially in mountain valleys. That is, glaciers with large length sensitivities tend to have relatively spread out moraine sequences (e.g. Figure 2.2; Eaves et al., 2019), whereas glaciers with lower length sensitivities tend to deposit compound moraine sequences through the repeated deposition of till at the same site during glacier advance and retreat (Mackintosh et al., 2017b). It is therefore important to consider the effect of individual glacier response times and glacier length sensitivities on both moraine formation and preservation when comparing moraine records in adjacent mountain valleys.

\subsubsection{Paleoclimatic significance of moraines}

Because mountain glaciers are intimately linked to climate, moraines can be used to reconstruct past glacier-climate variability. Reconstructing glacial histories from the geological record requires: (i) well-preserved glacial geomorphology; and (ii) accurate dating methods that are applicable to centennial timescales. Moraine records in different mountain valleys can be compared on regional and global scales to infer the timing and spatial extent of past climatic changes. Moraine chronologies can be situated in the context of continuous palaeoclimate records (e.g. tree-ring, speleothem or lake records) to confirm the regional or global extent of climate signals. Glacier-climate reconstructions can then be used to create hypotheses about potential drivers of past glacier and climatic change. These hypotheses may also be tested using ELA reconstructions (e.g. Porter, 1975) and physics-based glacier model and/or climate model experiments (e.g. Oerlemans, 1997; Anderson \& Mackintosh, 2006; Schaefer et al., 2015; Doughty et al., 2017; Eaves et al., 2017). Therefore, when accurately mapped and dated, moraines have the potential to reveal information about the timing, magnitude, and climatic drivers of past glacier behaviour.

Glaciers and moraines have been discussed as highly trusted indicators of climate, but this may not always be the case. For example, several studies suggest that debris covered glaciers are less suitable for paleoclimate reconstructions as their moraines may have resulted from non-climatically driven glacier advances (Warren \& Kirkbride, 2003; Shulmeister et al., 2009; Reznichenko et al., 2011; Reznichenko et al., 2012). Depending on thickness, sediment covering the terminus or ablation zone can either increase or 
reduce the rate of ice melt beneath the debris cover. Thus, debris cover alters how sensitive glacier mass balance and length changes are to climate perturbations (Purdie \& Fitzharris, 1999; Warren \& Kirkbride, 2003; Anderson \& Mackintosh, 2012; Mackintosh et al., 2017b). Furthermore, it has been hypothesised that in the event of a large rock fall event, the large amount of debris covering the ice can insulate the glacier from prevailing climatic conditions, thus resulting in glacier advance and subsequent moraine formation irrespective of climate (Shulmeister et al., 2009; Reznichenko et al., 2011). The paleoclimatic significance of moraine chronologies at Mt Cook (Tasman, Mueller and Hooker glaciers) and Franz Josef Glacier (Waiho Loop) have been questioned due to the potential for rock fall driven glacier advance (Tovar et al., 2008; Shulmeister et al., 2009; Reznichenko et al., 2011).

Because the climate can vary on a wide range of timescales (annual to millennial), moraine records may form in response to stochastic, interannual climate variability that can induce glacier length changes (Balco, 2009; Roe, 2011; Anderson et al., 2014; Doughty et al., 2017; Mackintosh et al., 2017b; Eaves et al., 2019). This can have important implications for palaeoclimate reconstructions based on moraine records, which rely on the assumption that moraines formed during long term changes in mean climate (temperature and/or precipitation). The potential for interannual climate variability to form moraines during the Last Glacial Maximum (LGM) ( 18-30 ka) was assessed by Anderson et al. (2014) for glaciers of the Colorado Front Range, United States. Similarly, Doughty et al. (2017) used numerical modelling to establish whether interannual climate variability alone could provide sufficiently cold temperatures to force the Cameron Glacier, located in the central Southern Alps of New Zealand, to its former late glacial and Holocene moraine positions. Both studies found that interannual climate variability alone could not be responsible for causing glaciers to advance to their former moraine positions. Rather, glacier advance and moraine formation were likely in response to a combination of both interannual variability and long-term climate change. Doughty et al. (2017) also acknowledge that varying glacier response times are an important determinant of whether glaciers are sensitive to interannual climate variability. For example, glaciers with longer response times, such as Cameron Glacier (response time $\sim 70$ years) and Brewster Glacier (response time $~ 50$ years) are less susceptible to interannual climate variability compared to glaciers with short response times (e.g. Franz Josef; 20 years) (Doughty et al., 2017; Mackintosh et al., 2017b). Therefore, it is 
beneficial for glacier-climate reconstructions, particularly on glaciers with short response times, to determine whether moraines are formed by stochastic length changes in response to interannual climate variability, before interpreting that moraines are formed in response to glacier length changes caused by an externally forced regional or global climate signal.

\subsubsection{Dating methods}

Glacier-climate reconstructions have long been limited by the ability to obtain reliable moraine chronologies. Until recently, moraine ages were derived using dating techniques such as weathering rind thickness (Chinn, 1981; Birkeland, 1982; Gellatly, 1984), Schmidt hammer measurements (Winkler, 2000, 2004; Goudie, 2006; Winkler, 2014), lichenometry (Burrows \& Orwin, 1971; Burrows \& Maunder, 1975; Gellatly, 1982; Sommerville et al., 1982), or soil and vegetation development (Burrows, 1973; Wardle, 1973; Birkeland, 1981). In most circumstances, these techniques require calibration of time-dependent variables using surfaces of a known age or surfaces dated using absolute dating such as cosmogenic surface exposure dating. At sites where surface ages are unknown, methods that have been calibrated at different sites are often applied, thus introducing age uncertainties due to differing climatic, lithological, and altitudinal settings between sites. More precise methods such as tephrochronology, luminescence dating, and radiocarbon dating have been used to constrain the timing of moraine formation. However, use of these techniques is highly situational. For example, radiocarbon dating is dependent on the preservation of organic material such as cases where wood is found fossilised in the moraine deposit due to the glacier advancing over a forested landscape (e.g. Burrows, 1980, 1989; Denton \& Hendy, 1994; Barclay et al., 2009). Additionally, these techniques can often only provide bracketing (maximum or minimum) age constraints for the timing of moraine formation (e.g. Denton \& Hendy, 1994; Eaves et al., 2016).

In recent decades, cosmogenic ${ }^{10} \mathrm{Be}$ surface exposure dating has emerged as a powerful technique that can be used to accurately date moraines. Unlike other techniques, ${ }^{10} \mathrm{Be}$ surface exposure dating can directly determine the timing of moraine formation. Section 2.3 provides an overview of cosmogenic ${ }^{10} \mathrm{Be}$ surface exposure dating and Section 2.4 highlights the recent application of the technique in New Zealand. 


\subsection{Cosmogenic ${ }^{10} \mathrm{Be}$ surface exposure dating in glacial geomorphology}

Cosmogenic nuclides are rare isotopes produced at Earth's surface from elements in minerals due to their interaction with cosmic radiation (Gosse \& Phillips, 2001). An array of cosmogenic nuclides are produced at Earth's surface including ${ }^{3} \mathrm{He},{ }^{21} \mathrm{Ne},{ }^{10} \mathrm{Be},{ }^{26} \mathrm{Al}$, ${ }^{36} \mathrm{Cl}$ and ${ }^{14} \mathrm{Cl}$. Because cosmogenic nuclides are preferentially produced at the surface, they can provide quantitative constraints of the flux or residence time of geological materials. The application of cosmogenic surface exposure dating in glacial geomorphology is particularly useful in glacier-climate reconstructions. More specifically, surface exposure dating of moraine boulders can be used to constrain the timing of the onset of glacier retreat (Balco, 2011; Ivy-Ochs \& Briner, 2014). The theory for interpreting cosmogenic data is outlined here as well as the existing limitations of surface exposure dating in glacial geomorphology.

\subsubsection{Sources of cosmic rays}

Cosmic rays are sourced from supernova explosions that occur outside of our solar system but within our galaxy (Gosse \& Phillips, 2001). Cosmic rays are accelerated by shock waves, and travel through surrounding interstellar gas. These primary cosmic rays consist of positively charged, high energy particles (typically ranging $\sim 0.1$ to $10 \mathrm{GeV}$ ). The majority of cosmic rays entering Earth's atmosphere consist of protons (83\%) and alpha particles (13\%) with the remainder being heavier nuclei and electrons (Gosse \& Phillips, 2001; Dunai, 2010). The flux of incoming primary cosmic rays reaching Earth is highly dependent on their kinetic energy and factors such as the shape and intensity of the Earth's geomagnetic field.

\subsubsection{Cosmic ray interactions with Earth's geomagnetic field}

Cosmic ray interactions with Earth's geomagnetic field play an important role in determining the eventual production of cosmogenic nuclides at Earth's surface. The geomagnetic field is dominated by its dipole component which modulates nuclide production by shielding and deflecting primary cosmic rays, sending them on different trajectories (Figure 2.4; Dunai, 2010). To a lesser extent solar activity also modulates the primary cosmic ray flux through the turbulence of solar winds generated during solar cycles (Lifton et al., 2005). Both factors can cause cosmic ray energies entering Earth's 
atmosphere, and cosmogenic nuclide production, to vary spatially and temporally (Lifton et al., 2014).

Cosmic rays can only penetrate Earth's magnetic field if their energies exceed the "cutoff rigidity" (Gosse \& Phillips, 2001; Dunai, 2010). The cut-off rigidity describes the critical energy $(\mathrm{GeV})$ required for a charged particle to penetrate the magnetic field. The cut-off rigidity also has an inverse relationship with geomagnetic latitude (Figure $2.4 \&$ 2.7A). Near the equator, the geomagnetic field lines are positioned approximately perpendicular to incident cosmic rays, therefore high rigidities $(>10 \mathrm{GeV})$ are required to penetrate the magnetic field in the tropics (Figure 2.4; Gosse \& Phillips, 2001). Near the poles, cosmic rays travel approximately parallel to the field lines, which allows all cosmic ray rigidities to enter Earth's atmosphere (Figure 2.4), although cosmic rays with very low energies $(>0.6 \mathrm{GeV})$ are limited by solar modulation (Lifton et al., 2005). Consequently, only higher energy particles penetrate through to the upper atmosphere at the geomagnetic equator, so higher latitudes receive cosmic rays with a wider spectrum of energies (Gosse \& Phillips, 2001). The net effect of cosmic ray interactions with the geomagnetic field is that cosmogenic nuclide production rates are lower at the equator compared to the production rates at the poles (Gosse \& Phillips, 2001; Dunai, 2010; Dunai \& Lifton, 2014).

Along with this spatial variability, temporal variability in geomagnetic field strength is an important factor to consider when determining the production of cosmogenic nuclides at Earth's surface, particularly in geological dating applications (see Section 2.3.6). Cosmogenic nuclide production is not sensitive to temporal variability in the geomagnetic field at high latitude $\left(>65^{\circ}\right)$ (Dunai \& Lifton, 2014). However, the influence of temporal variations in the geomagnetic field on cosmogenic nuclide production becomes increasingly noticeable at high altitude and low latitude. Therefore, in geological applications at lower latitudes, temporal variations in the geomagnetic field need to be considered through scaling methods which account for changes in nuclide production through time (See 2.3.6; Balco et al., 2008; Dunai \& Lifton, 2014; Lifton et al., 2014). 


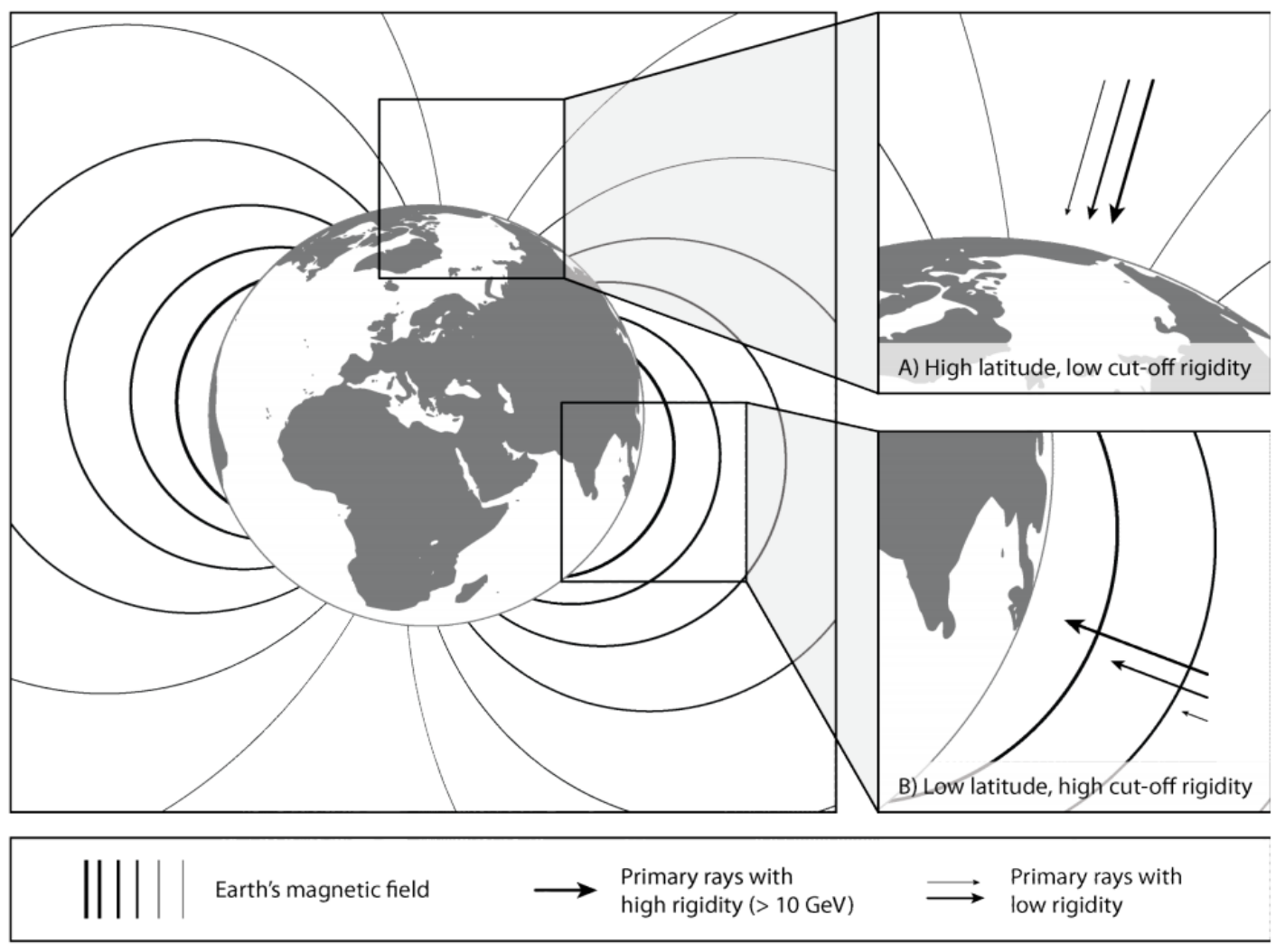

Figure 2.4 The effect of the Earth's geomagnetic field on incoming cosmic rays. Figure from Darvill (2013).

\subsubsection{Cosmic ray interactions with Earth's atmosphere}

Upon entering Earth's atmosphere, inelastic collisions or 'spallation reactions' take place between primary cosmic ray particles and target nuclei, producing a secondary cascade of particles (Figure 2.5; Dunai \& Lifton, 2014). In the upper atmosphere, these secondary particles can be divided into three main components that are defined by their relative energies. These include the nucleonic component (protons, alpha particles, and neutrons), the mesonic component (pions, muons, antimuons, kaons, neutrinos, electrons, and positrons), and the electromagnetic component (electrons, positrons, and photons) (Figure 2.5; Dunai, 2010; Dunai \& Lifton, 2014). Spallation reactions occur in the nucleonic component, where protons and neutrons are sputtered off the target nucleus (e.g. oxygen or nitrogen) and go on inducing spallation in other target nuclei, maintaining the nuclear cascade in Earth's atmosphere (Figure 2.5; Gosse \& Phillips, 2001; Dunai, 2010). Thus, the nuclear cascade composition changes from being proton-dominated at the top of the atmosphere to being neutron-dominated at sea level. Because of the high energy nuclear reactions, the nucleonic component dominates the total secondary cosmic ray flux and is 
responsible for the majority of the production of cosmogenic ${ }^{10} \mathrm{Be}$ at Earth's surface (Dunai, 2010; Dunai \& Lifton, 2014). However, cosmogenic ${ }^{10} \mathrm{Be}$ is also produced via muon capture reactions (see Section 2.3.4).

Secondary particles produced at the top of the atmosphere decrease exponentially in energy and abundance with increasing atmospheric depth, thus fewer interactions occur towards the Earth's surface (Figure 2.5; Masarik \& Beer, 1999; Stone, 2000; Gosse \& Phillips, 2001). This relationship is described by the following equation:

$$
N(d)=N_{0} e^{-d / \Lambda}
$$

where $\mathrm{N}_{0}$ as the number of nucleons at the top of the atmosphere, $\mathrm{d}$ is atmospheric depth $\left(\mathrm{g} \mathrm{cm}^{-2}\right)$ and $\Lambda$ is the attenuation length $\left(\mathrm{g} \mathrm{cm}^{-2}\right)$. The attenuation length is the thickness of mass (e.g. rock or air) required to attenuate the cosmic ray flux by a factor of $\mathrm{e}^{-1}$ (Gosse $\&$ Phillips, 2001). The attenuation length changes in accordance with the energy of the incoming cosmic ray flux and thus geomagnetic latitude (or cut-off rigidity). That is, the cosmic ray flux is more strongly attenuated at the equator (higher cut-off rigidity) than at the poles (Section 2.3.2). However, this difference dampens with increasing atmospheric depth as cosmic rays approach sea level (Equation 1). Ultimately, variations in the attenuation of the secondary cosmic rays through the atmosphere causes the cosmogenic production rates at Earth surface to vary with both latitude and altitude (Lal, 1991; Stone, 2000). 
THE ATMOSPHERIC NUCLEAR CASCADE

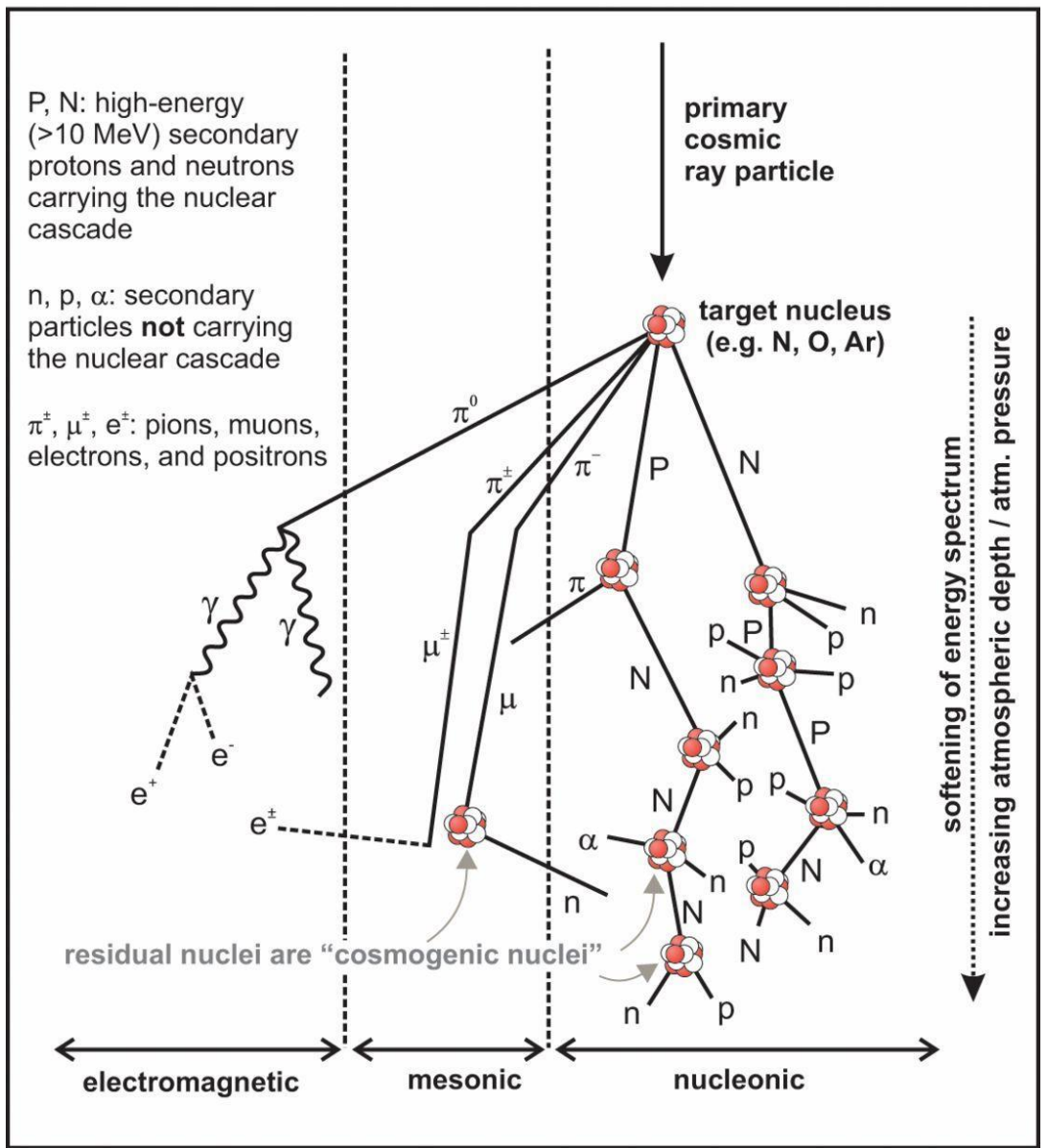

Figure 2.5 The components of the secondary cosmic ray cascade in the atmosphere. Nuclear reactions occurring in the atmosphere produce meteoric cosmogenic nuclides and secondary particles. These secondary particles are mostly neutrons which go on to produce most of the cosmogenic nuclides at Earth's surface. Also denotes the 'softening of the energy spectrum' with increasing atmospheric depth. Abbreviations: neutrons (n), protons ( $p)$ (upper case letters for particles carrying the nuclear cascade), alpha particle $(\alpha)$, electrons or positron ( \pm \pm$)$, gamma-ray photons $(\gamma)$, pion $(\pi)$ and muons $(\mu \pm)$. The electromagnetic component is irrelevant to cosmogenic nuclide production. Figure from Dunai and Lifton (2014).

Meteoric ${ }^{10} \mathrm{Be}$ is produced in the atmosphere through spallation and muon capture reactions (Gosse \& Phillips, 2001). Meteoric ${ }^{10} \mathrm{Be}$ is transported to the Earth's surface via aerosol dispersion and has various useful applications (e.g. Willenbring \& von Blanckenburg, 2010; Yokoyama et al., 2016). In in situ applications (e.g. surface exposure dating) meteoric ${ }^{10} \mathrm{Be}$ contamination must be removed during the stages of physical quartz separation and ${ }^{10} \mathrm{Be}$ extraction (see Section 3.2.2). 


\subsubsection{Cosmic ray interactions with Earth's surface and nuclide production}

The attenuation of cosmic ray particles in solid Earth follows generally the same principles as in the atmosphere. The main difference is that rock has a higher density than the atmosphere. Additionally, cosmic rays interact with elements in a target mineral. In this case, ${ }^{10} \mathrm{Be}$ is produced due to the cosmic ray interactions with oxygen and silicon in quartz. Because of the variations in cosmic ray particle energies (i.e. nucleonic vs. mesonic components), there are two main mechanisms which produce cosmogenic ${ }^{10} \mathrm{Be}$ in quartz: (i) through spallation reactions and (ii) by muon capture reactions.

Spallation reactions result in the shattering of the target nucleus and immediate successive nucleus disintegration that forms lighter particles (protons or neutrons) leaving a residual cosmogenic nuclide (e.g. a ${ }^{10} \mathrm{Be}$ atom) (Gosse \& Phillips, 2001). Like cosmic rays travelling through the atmosphere, high energy particles involved in spallation reactions decrease approximately exponentially with the depth below Earth's surface. Most spallation reactions occur in the upper $\sim 2-3 \mathrm{~m}$ of rock surface (Figure 2.6) (Dunne et al., 1999; Gosse \& Phillips, 2001; Dunai \& Lifton, 2014).

At Earth's surface muons are weakly attenuated, therefore muon capture reactions only produce cosmogenic ${ }^{10} \mathrm{Be}$ at depth. Decelerated or stopped negative muons with low energies may fall into electron shells of atoms where they are captured by the nucleus, producing cosmogenic nuclides (Gosse \& Phillips, 2001). Negative muon capture reactions account for a low percentage $(\sim 2 \%)$ of the total ${ }^{10} \mathrm{Be}$ that is produced at the surface but account for the majority of ${ }^{10} \mathrm{Be}$ production deeper in the rock surface (Figure 2.6; Gosse \& Phillips, 2001; Balco, 2017c). Because these reactions do not produce significant amounts of ${ }^{10} \mathrm{Be}$ at the surface, muons have little importance in ${ }^{10} \mathrm{Be}$ surface exposure dating applications. 


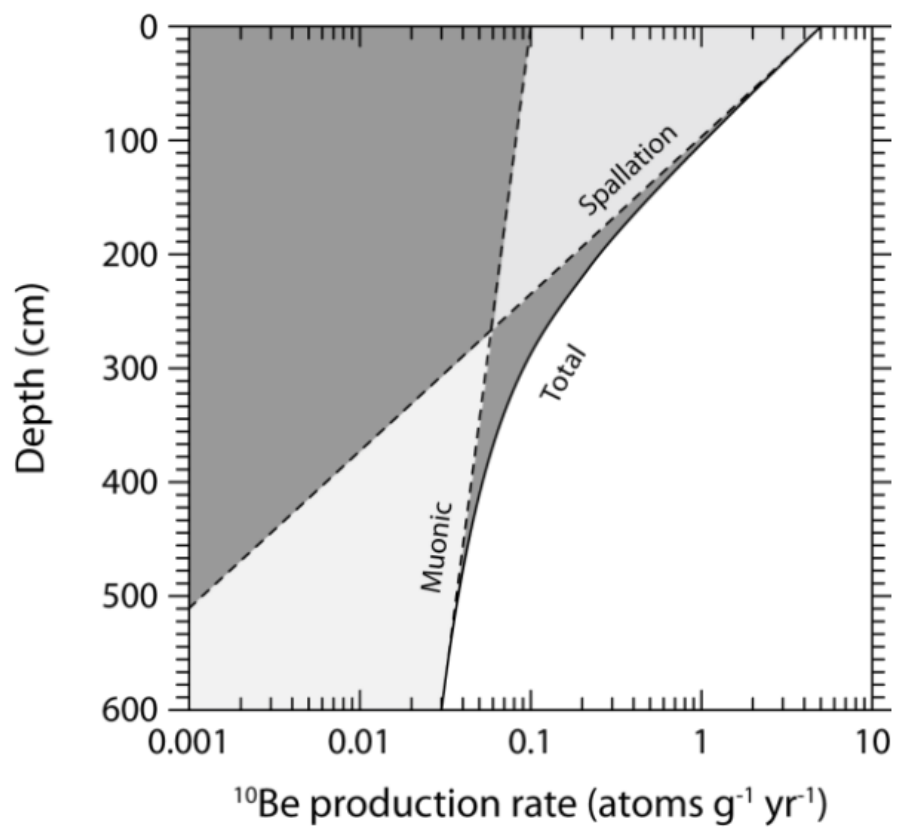

Figure $2.6{ }^{10}$ Be production with depth in quartz arenite. Spallation reactions occurring in the upper 2-3 m accounts for the majority of ${ }^{10}$ Be production at Earth's surface; muon capture reactions account for a higher percentage of ${ }^{10}$ Be production below $\sim 3 \mathrm{~m}$. Figure from Darvill (2013) adapted from Gosse and Phillips (2001).

\subsubsection{Production rates}

To use cosmogenic nuclides in surface exposure dating, accurate knowledge of their production rates at Earth surface integrated throughout the exposure history of a sample is required. The production rate can be defined as the rate at which a cosmogenic nuclide is produced in a specific mineral. Production rates are measured in atoms per gram of the target material (e.g. quartz) per year (at $\left.\mathrm{g}^{-1} \mathrm{yr}^{-1}\right)$ (Gosse \& Phillips, 2001).

Production rates of in situ cosmogenic nuclides have typically been derived using numerical model simulations of the secondary cosmic ray cascade interacting with Earth's surface which predict neutron capture cross-sections (i.e. the probability of a given incident neutron interacting with a target atom) (Masarik \& Beer, 1999; Gosse \& Phillips, 2001; Dunai, 2010). These production rates are refined through geological calibrations which are calculated by measuring nuclide concentrations in surfaces with a known exposure duration. Ideally, these surfaces have not undergone any prior exposure, erosion, or intermittent burial. Existing calibration surfaces include landslides, glacially eroded bedrock, moraines, lava flows or shoreline features (e.g. Nishiizumi et al., 1989; 
Licciardi et al., 1999; Kubik \& Ivy-Ochs, 2004; Eaves et al., 2015; Lifton et al., 2015). Depending on the nature of the surface, independent age constraints are derived from techniques such as radiocarbon dating, luminescence, or dendrochronology. A cosmogenic nuclide production rate is calculated from the measured nuclide concentrations in a sample, divided by the independent age of the surface. For example, Putnam et al. (2010b) determined the first direct estimation of ${ }^{10} \mathrm{Be}$ production in the central Southern Alps of New Zealand using radiocarbon ages from an early Holocene debris-flow deposit in the Macaulay valley. Choosing suitable production rate calibration sites requires robust independent age control and for this reason, the geographical distribution of these sites is limited.

\subsubsection{Scaling models}

Established local production rates are scaled to account for the variations in the cosmic ray flux and production of cosmogenic nuclides (Figure 2.7) at specific sample sites. Existing scaling models (Stone, 2000; Dunai, 2001; Lifton et al., 2005; Desilets et al., 2006; Balco et al., 2008; Lifton et al., 2014) account for the difference in production rates with altitude, latitude, and time to varying degrees. Generally, exposure ages calculated using different scaling schemes are very similar, however, large differences between models begin to emerge at high altitude and low latitude (Figure 2.7; Balco et al., 2008; Dunai \& Lifton, 2014; Lifton et al., 2014; Borchers et al., 2016). These variations arise as scaling schemes established based on neutron monitors, such as the Du (Dunai, 2001), Li (Lifton et al., 2005) and De (Desilets \& Zreda, 2003; Desilets et al., 2006) scaling models, tend to overestimate scaling factors (Figure 2.7A) and are therefore now considered to be outdated (Lifton et al., 2014; Borchers et al., 2016). Differences in the parameterisation of the geomagnetic field can also cause scaling methods to diverge at high altitude and low latitude; that is, whether scaling schemes account for changes in the geomagnetic field through time (Figure 2.7A). The LSD (Lifton et al., 2014) and Lm (Balco et al., 2008) scaling models are generally favoured over the St (Lal, 1991; Stone, 2000) scaling model as they account for changes in cosmogenic production rate due to variations in both geomagnetic field intensity and solar activity.

Exposure age calculators (e.g. Marrero et al., 2016; Martin et al., 2017) allow for scaling factors to be applied to production rates by non-specialists. These calculators are often used in association with online databases (e.g. ICE-D http://calibration.ice-d.org/) that 
contain global compilations of local production rates and calibration datasets. Calculators allow for comparisons of exposure ages produced using different scaling models (Balco et al., 2008; Marrero et al., 2016). It is best practice to report ages from a range of scaling factors to illustrate the sensitivity of a given sample site to the choice of scaling method.

\subsubsection{Geological scatter in ${ }^{10} \mathrm{Be}$ sample datasets}

In theory, all moraine boulders on a single moraine crest should yield identical (within analytical uncertainty) exposure ages. In practice, this is often not the case as several geological factors can cause scatter in ${ }^{10} \mathrm{Be}$ exposure age datasets (Briner et al., 2005; Barrows et al., 2007b). First, ${ }^{10} \mathrm{Be}$ surface exposure dating assumes that no nuclides have been inherited from previous exposure of moraine boulders. However, the reset of the cosmogenic "clock" is not always certain, and, if incomplete, can produce much older exposure ages than the true exposure duration (Figure 2.8b; Balco, 2011; Heyman et al., 2011; Ivy-Ochs \& Briner, 2014). The ability to detect inheritance in the field is limited, however, striae on moraine boulders can provide evidence of the possible removal of inherited ${ }^{10} \mathrm{Be}$ through subglacial/englacial erosion. Boulder surfaces that are eroded or buried after deposition can yield lower cosmogenic nuclide concentrations and younger ages than the true exposure duration (Figure 2.8c; Balco, 2011; Heyman et al., 2011; IvyOchs \& Briner, 2014). Therefore, for surface exposure dating more resistant minerals (e.g. quartz), or surfaces with visibly less evidence of weathering and erosion, are typically sampled.

When applying cosmogenic nuclide analyses, outliers caused by inheritance and boulder movement, burial, exhumation or erosion, can be avoided through following a strict sampling strategy (see Section 3.2.1) or may be identified by increasing the number of boulders sampled on a feature (Balco, 2011). Multiple isotope analysis using a combination of ${ }^{10} \mathrm{Be}$ and ${ }^{26} \mathrm{Al}$ or ${ }^{10} \mathrm{Be}$ and ${ }^{14} \mathrm{C}$ (Ivy-Ochs \& Briner, 2014) can also reveal some of these complexities in surface exposure histories (e.g. Bierman et al., 1999; Miller et al., 2006; Goehring et al., 2011). 


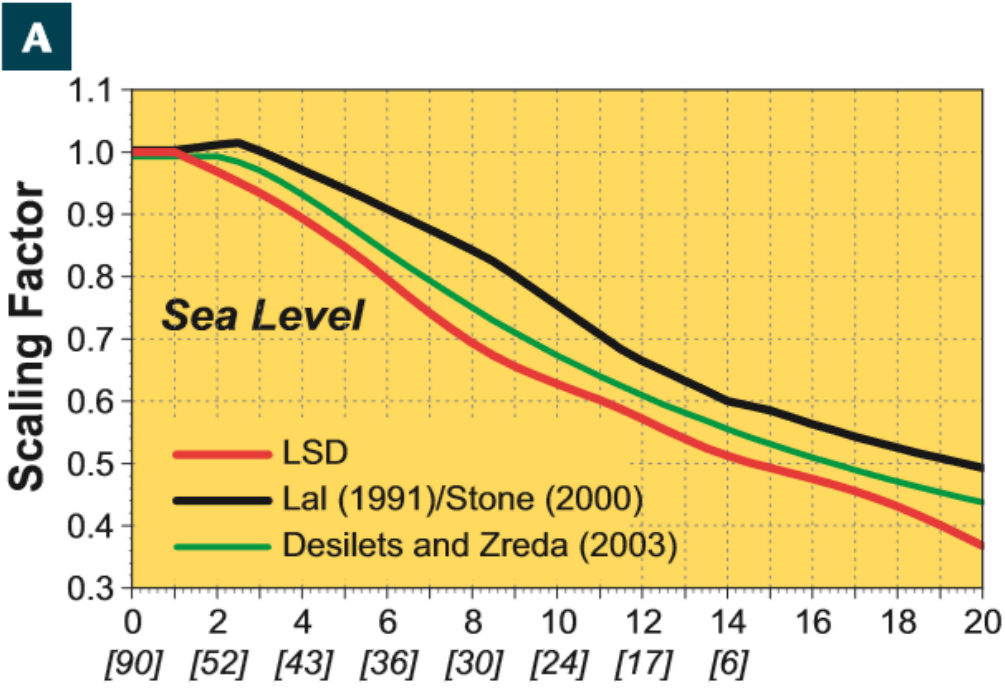

$\mathbf{R}_{\mathrm{c}}(\mathrm{GV})$

[Geomagnetic Latitude $\left({ }^{\circ} \mathrm{N}\right)$ ]

\section{B}

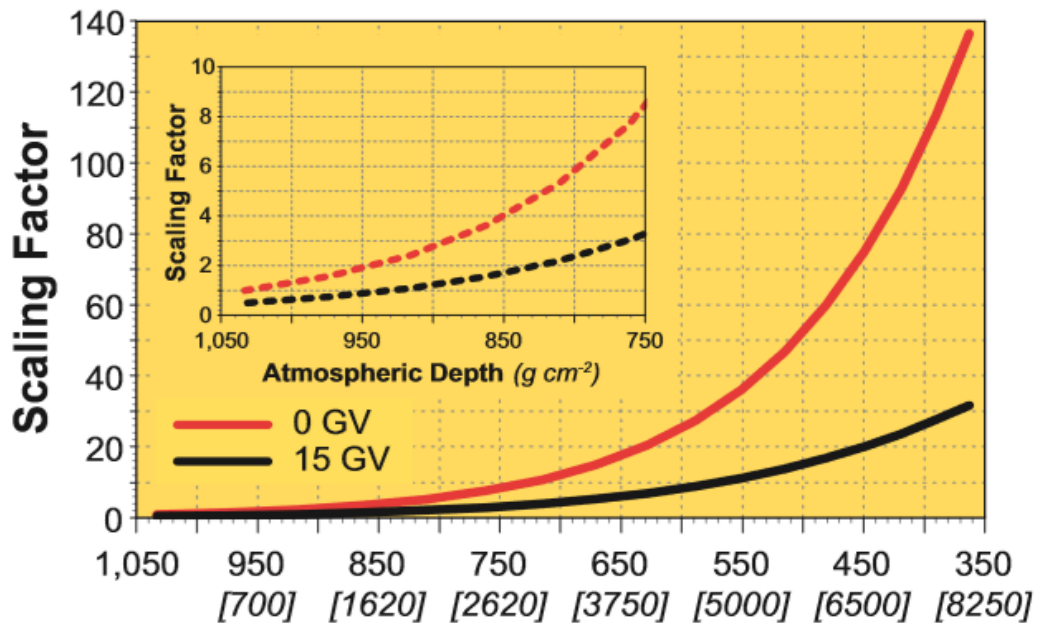

Atmospheric Depth $\left(\mathrm{g} \mathrm{cm}^{-2}\right)$

[Altitude $(m)$ ]

Figure 2.7 Scaling cosmogenic nuclide production with latitude and altitude. (A) Demonstrates scaling factors accounting for varied cosmogenic nuclide production with increasing cut-off rigidity $\left(R_{c}\right)$ and decreasing geomagnetic latitude. Also includes a comparison of LSD (Lifton et al., 2014), De (Desilets \& Zreda, 2003; Desilets et al., 2006), and St (Lal, 1991; Stone, 2000) scaling models which shows how neutron monitorbased scaling schemes (e.g. De) overestimate nuclide production at lower latitudes. The discrepancy between the LSD and St models is explained by differing treatment of variations in the geomagnetic field. (B) Demonstrates scaling factors accounting for varied cosmogenic nuclide production with increasing atmospheric depth and decreasing altitude. Altitudinal scaling is greater at the poles $(0 \mathrm{GV}$; red) compared to the equator (15 GV; black) due to the wider range of cosmogenic ray energies at the top of the atmosphere. Cosmic rays at the poles do not have sufficient energies to continue the nuclear cascade, therefore the amount of scaling required decreases closer to sea level (Dunai \& Lifton, 2014). 


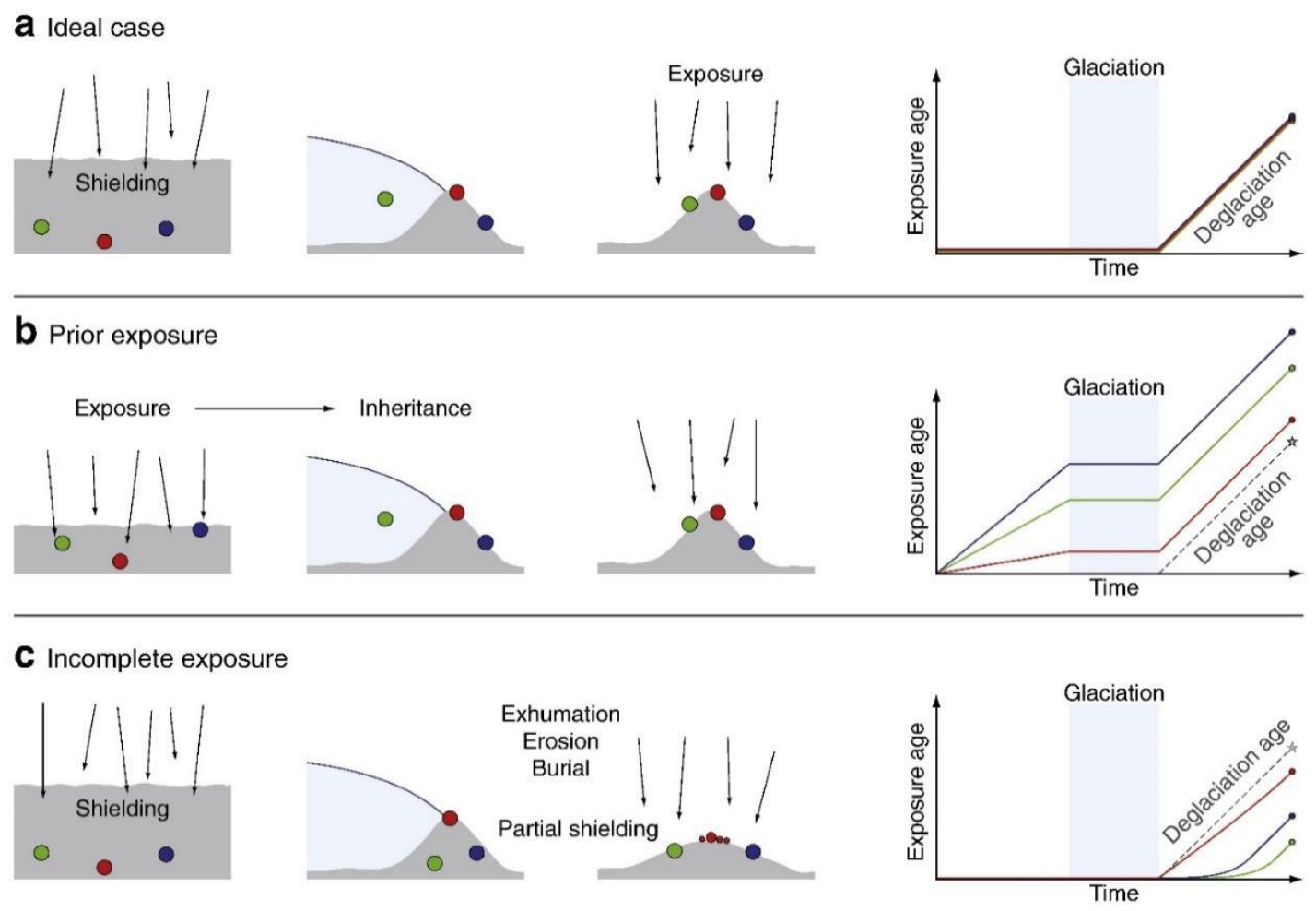

Figure 2.8 Illustrations demonstrating the various causes of geological scatter in exposure age datasets. (a) Shows the ideal case where samples are shielded prior to deglaciation and then constantly exposed to cosmic rays post-deglaciation. (b) Sample exposure prior to deglaciation may produce an older age than the true exposure age due to inherited cosmogenic nuclides. (c) Samples may be affected by processes such as exhumation, erosion and/or burial after initial exposure which can produce a younger age than the true exposure age due to incomplete exposure. Figure from Ivy-Ochs and Briner (2014) adapted from Heyman et al. (2011).

\subsubsection{State-of-the-art of cosmogenic ${ }^{10} \mathrm{Be}$ surface exposure dating}

In recent decades, advances in the measurement of cosmogenic in situ ${ }^{10} \mathrm{Be}$ have led to significant developments in geomorphological applications (Balco, 2011). Advances have been made in studies that push the limits of the techniques, such as applications in environments where cosmogenic ${ }^{10} \mathrm{Be}$ content is very low (e.g. Schaefer et al., 2009; Shakun et al., 2018). Surface exposure dating of near-historic landforms (exposure in the last several 100 years) requires measuring ${ }^{10} \mathrm{Be}$ concentrations above laboratory and machine background levels. Recent studies have shown that dating young moraines is possible (e.g. Licciardi et al., 2009; Schaefer et al., 2009; Schimmelpfennig et al., 2014), however, obtaining these measurements can be challenging due to the limitations of AMS and the potential for background ${ }^{10} \mathrm{Be}$ to be introduced in laboratory preparation. 
When measuring low Be content, careful consideration of ways to optimise ${ }^{10} \mathrm{Be}$ measurement is required. Firstly, an AMS with low detection limits is required to precisely detect small amounts of ${ }^{10} \mathrm{Be}$. Recent measurements at Lawrence Livermore National Laboratory (LLNL) show that it is possible to precisely measure process blank ${ }^{10} \mathrm{Be} /{ }^{9} \mathrm{Be}$ ratios as low as $10^{-16}$ (equivalent to $10^{3}$ to $10^{4}{ }^{10} \mathrm{Be}$ atoms) making it possible to obtain precise measurements from samples with low ${ }^{10} \mathrm{Be}$ content (Rood et al., 2010; Corbett et al., 2016). Measurement precision is based on the total number of ${ }^{10} \mathrm{Be}$ atom counts from a sample, where more counts equate to lower uncertainties (Rood et al., 2013; Schimmelpfennig et al., 2014; Corbett et al., 2016). Therefore, along with sensitive AMS facilities, sufficiently large sample masses $\left(\sim 60-80 \mathrm{~g}\right.$ of pure quartz) can increase ${ }^{10} \mathrm{Be}$ measurement precision. ${ }^{10} \mathrm{Be}$ measurements also require samples with high purity as elemental impurities (such as aluminium and titanium) can suppress AMS ion beams (Hunt et al., 2008; Corbett et al., 2016).

${ }^{10} \mathrm{Be}$ measurements are corrected using laboratory process blanks which accounts for background ${ }^{10} \mathrm{Be}$ contamination that is introduced through stages of sample preparation. In order to maximise signal-to-noise ratios in low ${ }^{10} \mathrm{Be}$ samples, low process blanks are required (Licciardi et al., 2009; Corbett et al., 2016). Small changes in laboratory procedures have been shown to improve background ${ }^{10} \mathrm{Be}$ contamination. For example, changing from a commercial ${ }^{9} \mathrm{Be}$ carrier, to a ${ }^{9} \mathrm{Be}$ carrier made from deeply-mined phenakite which contains lower amounts of background ${ }^{10} \mathrm{Be}$, can allow for the detection of significantly lower ${ }^{10} \mathrm{Be}$ concentrations (see Section 3.2) (Hunt et al., 2008; Corbett et al., 2016). Other sources of ${ }^{10} \mathrm{Be}$ contamination may be introduced at various stages of chemical preparation. Sensitivity experiments can be carried out to isolate and minimise the various sources of background ${ }^{10} \mathrm{Be}$ (see Section 3.3). 


\subsection{Existing ${ }^{10}$ Be moraine chronologies in New Zealand}

\subsubsection{Pre-Holocene ${ }^{10} \mathrm{Be}$ moraine chronologies}

In New Zealand, many studies have successfully produced high-precision moraine chronologies using cosmogenic ${ }^{10} \mathrm{Be}$ surface exposure dating in order to constrain the timing of Quaternary glaciation. These chronologies are on timescales ranging from 130 ka (e.g. Putnam et al., 2013) to 100-200 yrs (e.g. Schaefer et al., 2009). Pre-Holocene (prior to $11.7 \mathrm{ka}$ ) ${ }^{10} \mathrm{Be}$ moraine studies have focussed on understanding late Quaternary glacier-climate fluctuations in the Southern Alps in the South Island of New Zealand (Shulmeister et al., 2005; Schaefer et al., 2006; Putnam et al., 2010b; Shulmeister et al., 2010; Barrows et al., 2013; Putnam et al., 2013; Barrell, 2014; Rother et al., 2014; Rother et al., 2015; Schaefer et al., 2015; Koffman et al., 2017; Shulmeister et al., 2018). These studies show that Last Glacial Maximum (LGM) moraine complexes formed 30-18 ka. Glacier model-based temperature reconstructions, constrained by mapped and dated moraines in the Southern Alps suggest that temperatures were $6-7^{\circ} \mathrm{C}$ cooler than present day during the LGM (Golledge et al., 2012; McKinnon et al., 2012; Putnam et al., 2013; Rowan et al., 2013) followed by rapid glacier retreat 18-15 ka (Barrows et al., 2013; Eaves et al., 2017). Subsequently, several late glacial readvances occurred around $\sim 14.5-12.5$ ka coinciding with the Antarctic Cold Reversal (Figure 2.11; Ivy-Ochs et al., 1999; Barrows et al., 2007b; Kaplan et al., 2010; Putnam et al., 2010a; Putnam et al., 2010b; Koffman et al., 2017). Glacier modelling and ELA reconstructions suggest that late glacial readvances around $\sim 13 \mathrm{ka}$ required a temperature reduction of $2-3^{\circ} \mathrm{C}$ relative to present-day (Anderson \& Mackintosh, 2006; Doughty et al., 2013; Kaplan et al., 2013; Doughty et al., 2017; Koffman et al., 2017). After which temperatures increased by $\sim 1{ }^{\circ} \mathrm{C}$ between $13 \mathrm{ka}$ and $11.7 \mathrm{ka}$ causing gradual glacier retreat which continued into the early Holocene (Kaplan et al., 2010; Putnam et al., 2012; Kaplan et al., 2013; Doughty et al., 2017; Koffman et al., 2017). These studies set the scene for glacier extents and palaeotemperatures $\left(1-2^{\circ} \mathrm{C}\right.$ below present-day) in New Zealand at the beginning of the Holocene (11.7 ka). 


\subsubsection{Holocene ${ }^{10} \mathrm{Be}$ moraine chronologies}

To-date there are a limited number of Holocene ${ }^{10} \mathrm{Be}$ moraine chronologies in New Zealand, and the majority of these glacier-climate reconstructions have been carried out in the restricted region of the central Southern Alps (Figure 2.9; Schaefer et al., 2009; Putnam et al., 2012; Kaplan et al., 2013; Koffman et al., 2017). Past Holocene ${ }^{10}$ Be glacial reconstructions have tried to shed light on the debated existence and timing of a Southern Hemisphere 'Little Ice Age' which took place in the Northern Hemisphere between AD1450-1850 (Grove, 2004). Previous chronological studies of moraines that use alternative dating methods (e.g. tree-rings, radiocarbon ages, lichenometry, weathering rind thicknesses, and Schmidt hammer measurements) suggest that a cooling event took place in New Zealand during the same time frame as the termination of the Northern Hemisphere Little Ice Age ( AD1850) (e.g. Burrows, 1973, 1975; Winkler, 2000). Treering and speleothem records (e.g. Cook et al., 2002; Lorrey et al., 2008) suggest that cooling took place in New Zealand much earlier in the Little Ice Age during the period $\sim \mathrm{AD} 1500-1700$.

Schaefer et al. (2009) produced a high-precision moraine chronology from the Mt Cook region of the central Southern Alps, focusing on the well-preserved moraine sequence at Mueller Glacier with complementary samples from the moraines at Hooker and Tasman glaciers. The moraine chronology includes some of the youngest ${ }^{10} \mathrm{Be}$ surface exposure ages reported to-date. Mean exposure ages from Mueller Glacier (Figure 2.10) suggest several moraine formation events took place during the Holocene. The outermost feature yields an exposure age of $\sim 6400$ years. The timing of smaller glacier terminations inboard of this feature is dated at $~ 3200$ and $~ 2000$ years. Further inboard there is a prominent $\sim 570$-year-old moraine, as well as smaller moraines that formed $\sim 400, \sim 270$ and $\sim 220$ years ago. The innermost moraine produced a mean exposure age of $\sim 160$ years, which overlaps with historical records of the glacier. Exposure ages from moraines at Hooker and Tasman Glaciers suggest additional glacier advances took place $\sim 1000, \sim 1400$ and 1650 years ago. Note that these ages were calculated using the ${ }^{10} \mathrm{Be}$ production rate calibrated by Balco et al. (2009) and have not been recalculated using the New Zealand ${ }^{10}$ Be production rate established by Putnam et al. (2010b). Putnam et al. (2012) present a complementary ${ }^{10} \mathrm{Be}$ moraine chronology from Cameron Glacier, draining the Arrowsmith Range in the central Southern Alps, approximately $85 \mathrm{~km}$ northeast of Mt Cook (Figure 2.9). Cosmogenic ${ }^{10} \mathrm{Be}$ ages from the Cameron Glacier moraine complex 
capture earlier more extensive advances that occurred $\sim 11 \mathrm{ka}$ through to $\sim 7 \mathrm{ka}$. These two high-resolution Holocene ${ }^{10} \mathrm{Be}$ moraine chronologies are supported by several moraine ages collected from the Rakaia valley (Koffman et al., 2017) and the Ben Ohau Range at Whale Stream (Kaplan et al., 2013). The broad trend captured by existing Holocene ${ }^{10} \mathrm{Be}$ moraine ages is presented in Figure 2.11.

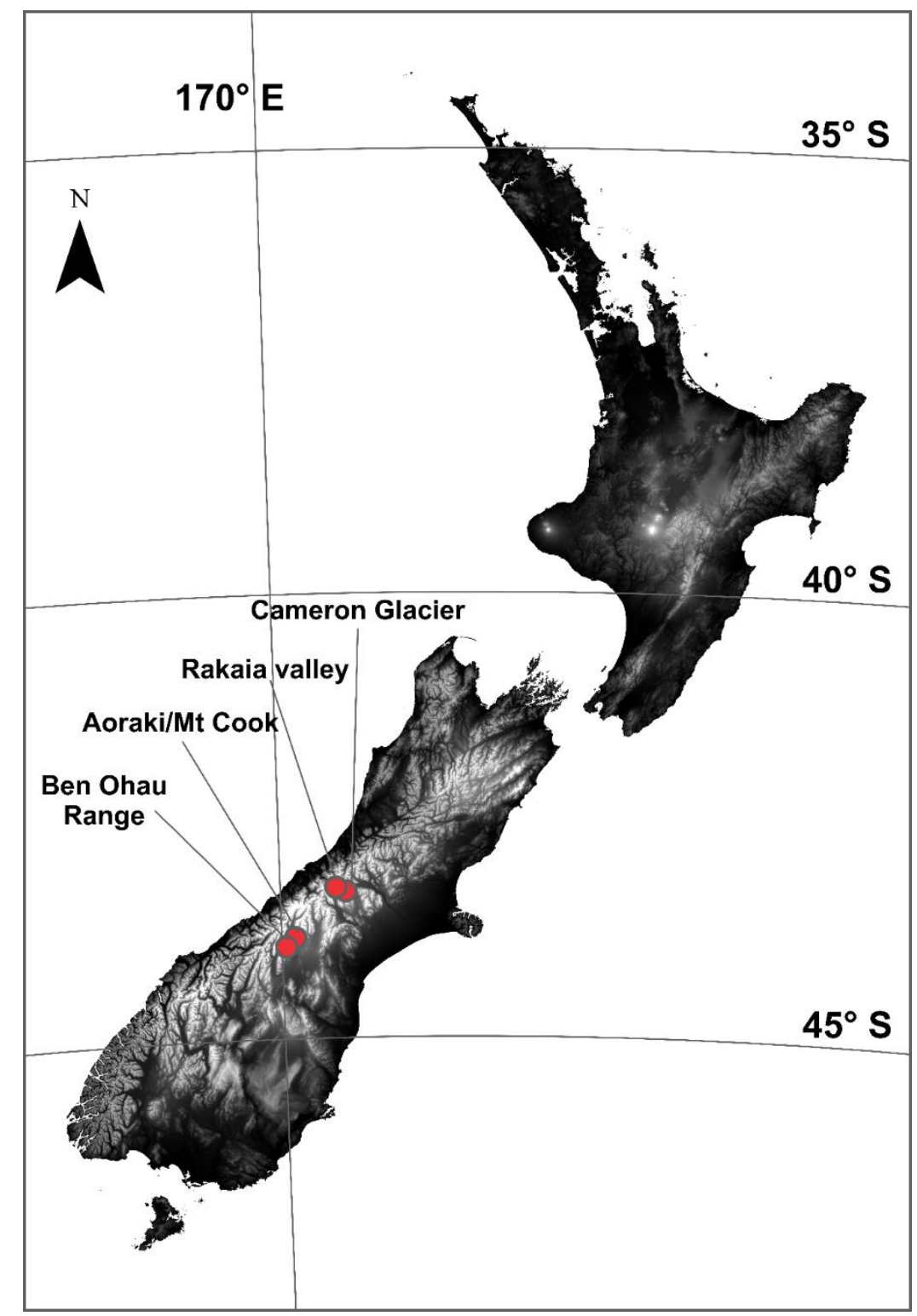

Figure 2.9 Map showing locations of sites in the central Southern Alps of New Zealand where there are existing Holocene moraine chronologies that have been developed using ${ }^{10}$ Be surface exposure dating (Schaefer et al., 2009; Putnam et al., 2012; Kaplan et al., 2013; Koffman et al., 2017). 
Overall, existing ${ }^{10} \mathrm{Be}$ moraine chronologies in the central Southern Alps show that glaciers have retreated since the early-mid Holocene with episodic glacier fluctuations occurring in the late Holocene (Figure 2.11). The trend of net glacier retreat is well supported by several palaeoclimate reconstructions, from which it has been suggested that local summer insolation may play an important role in determining Holocene climate variability in the Southern Hemisphere (Figure 2.11; McGlone et al., 2010b; van den Bos et al., 2018). Evidence of minor glacier advances during the Little Ice Age also suggests that New Zealand glaciers may have responded to a globally-coherent climate forcing during this time period (Schaefer et al., 2009; Putnam et al., 2012).

Cosmogenic ${ }^{10} \mathrm{Be}$ surface exposure dating is a more direct technique for obtaining Holocene moraine ages compared to other more indirect dating methods discussed in Section 2.2.4. However, there is a need to improve the spatial extent of ${ }^{10} \mathrm{Be}$ moraine chronologies in order to constrain the timing and magnitude of Holocene glacier length changes in New Zealand. As highlighted in Section 2.2.2, there are several factors that can influence the formation and preservation of moraines meaning that glacier-climate reconstructions are discontinuous palaeoclimate records and can only provide a 'snapshot' of past climatic conditions. Thus, there is a need to compare moraine chronologies (and other palaeoclimate proxy records) from sites across New Zealand. New moraine chronologies from different locations may validate or challenge the emerging pattern of Holocene glacier length changes recorded in the few existing studies in the central Southern Alps. Additionally, new chronologies may help to produce new testable hypotheses surrounding the drivers of Holocene glacier length changes in New Zealand. Furthermore, of the existing minimal Holocene glacier-climate records, few have focussed on the potential for ${ }^{10} \mathrm{Be}$ moraine chronologies to extend observational records of glacier length changes to supplement instrumental climate records. Therefore, there is also a need to further improve upon the capabilities of ${ }^{10} \mathrm{Be}$ surface exposure dating to produce high-resolution moraine chronologies from near-historic moraines that can directly extend observational records (see Section 2.3.8). 


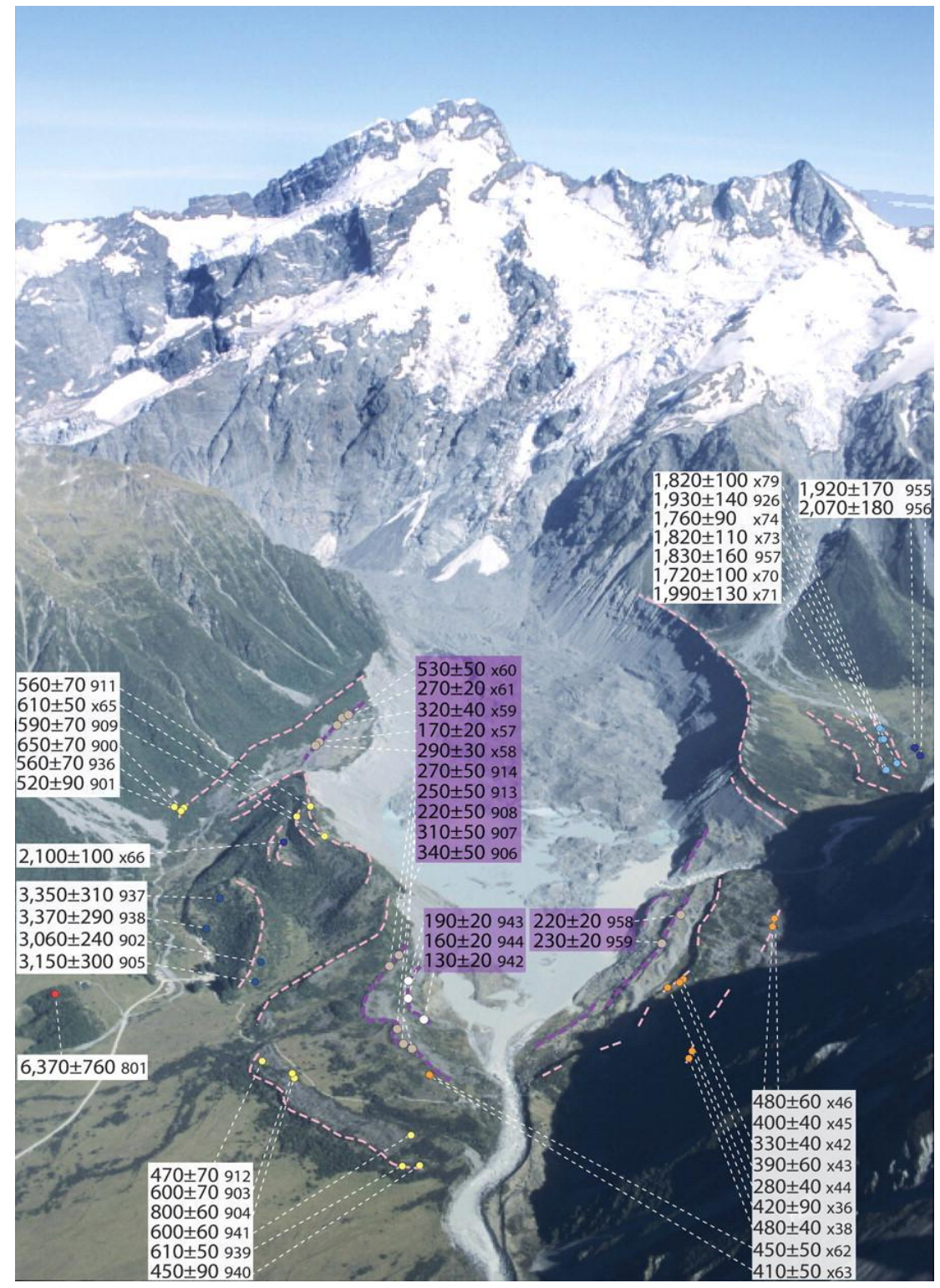

Figure 2.10 Mueller Glacier Holocene ${ }^{10}$ Be moraine ages (annotated oblique aerial photograph from Schaefer et al., 2009). 


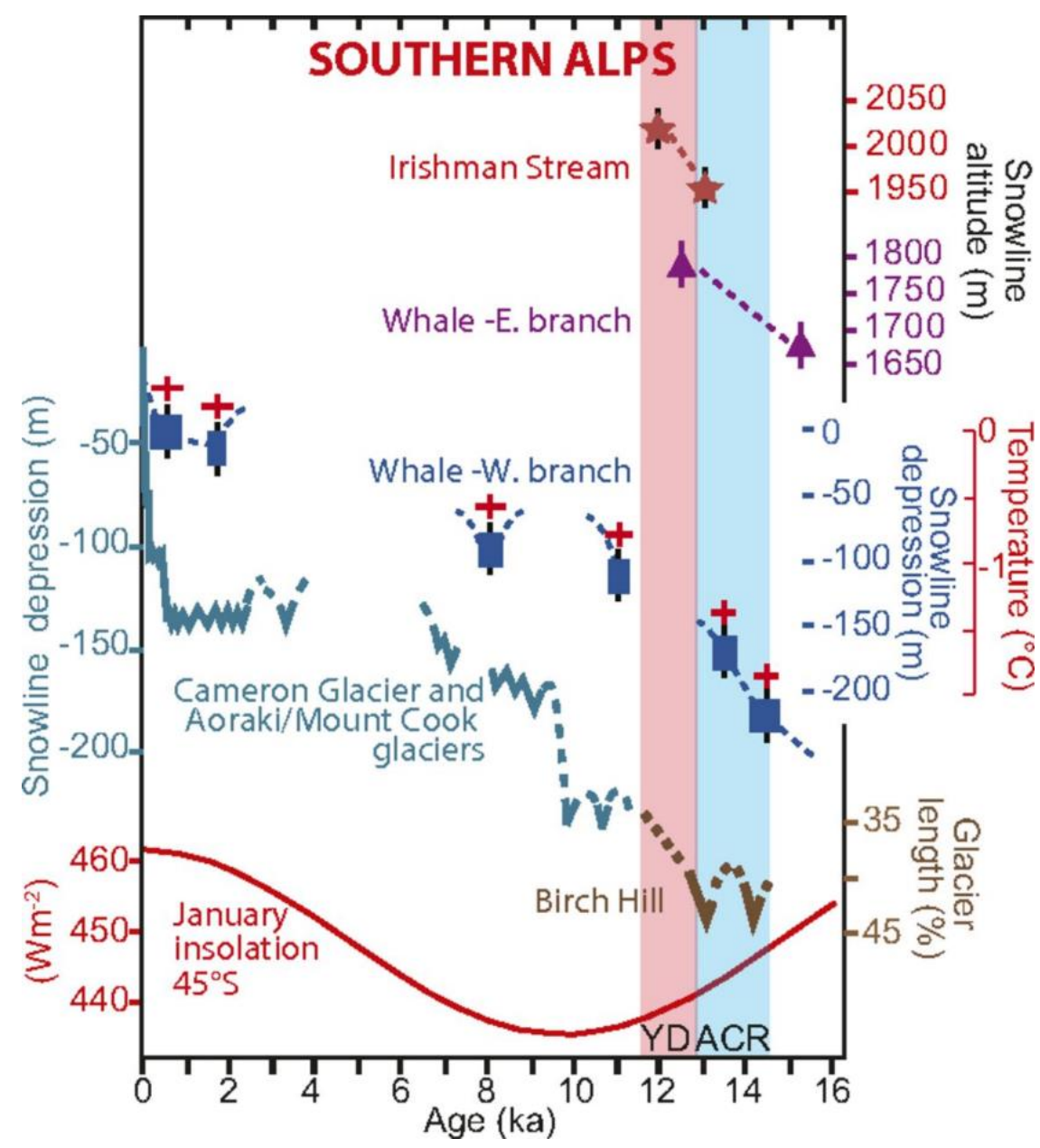

Figure 2.11 Summary figure of the glacier-climate reconstruction at Whale Stream in Ben Ohau Range, central Southern Alps (see Figure 2.9). The figure shows snowline and/or glacier length changes based on moraines from the east and west branches of Whale Stream. These results are compared with snowline and/or glacier length changes interpreted from existing late glacial and Holocene ${ }^{10}$ Be moraine chronologies from the central Southern Alps, New Zealand including: Cameron Glacier-Aoraki/Mount Cook moraines (Schaefer et al., 2009; Putnam et al., 2012), Birch Hill moraines (Putnam et al., 2010a), and Irishman Stream moraines (Kaplan et al., 2010). Insolation curve from Berger and Loutre (1991). Abbreviations: YD-Younger Dryas; ACR-Antarctic Cold Reversal. Figure from Kaplan et al. (2013). 


\subsection{Study site}

\subsubsection{Geological and climatic setting}

Dart Glacier $\left(44.45^{\circ} \mathrm{S}, 168.61^{\circ} \mathrm{E}\right)$ is situated in the Mt Aspiring/Tititea region of the Southern Alps of New Zealand (Figure 2.12). The Southern Alps form a northeastsouthwest trending mountain range that reflects the ongoing uplift that coincides with the active plate boundary between the Pacific and Australian plates with numerous peaks exceeding $2500 \mathrm{~m}$ along the main drainage divide ('Main Divide'). The presence of the active plate boundary in this landscape results in variations in lithology either side of the Main Divide. Torlesse greywacke is the most common lithology east of the Main Divide. Lithologies become increasingly metamorphosed west of the Main Divide and are predominantly schists (Barrell et al., 2011). Otago schist is the dominant lithology found in the Mt Aspiring region (Craw, 1984).

New Zealand's temperate maritime climate is a product of the interactions between the surrounding subtropical and sub-Antarctic air and water masses. Because of these interactions, westerly wind belts prevail over New Zealand. The circumpolar westerly atmospheric circulation affects the central and southern portions of New Zealand, while seasonally the subtropical anticyclonic belts extend over the North Island (Sturman \& Tapper, 2006). The Southern Alps create a barrier to the prevailing westerlies, producing an orographic precipitation regime. Consequently, in the central Southern Alps mean annual precipitation west of the Main Divide increases from $\sim 3 \mathrm{~m}$ at the coast to at least $\sim 10$ m close to the divide (Henderson \& Thompson, 1999). Precipitation then decreases to $\sim 1 \mathrm{~m}$ on the eastern side of the Main Divide. Overall, this orographic effect brings about high annual rainfall to the west and drier conditions to the east.

Changes in the intensity and location of the westerly wind belts can occur on annual to decadal timescales due to large-scale climate phenomena such as El Nino Southern Oscillation (ENSO) and Southern Annular Mode (SAM). El Nino events are associated with enhanced southwesterly circulation that brings cold and wet climatic conditions across New Zealand, while La Nina events are associated with more settled climatic conditions (Kidson \& Renwick, 2002; Ummenhofer \& England, 2007). ENSO activity can also work in conjunction with SAM phases which also influence precipitation and temperature in New Zealand (Gong \& Wang, 1999; Renwick \& Thompson, 2006; Ummenhofer et al., 2009). Negative SAM phases are associated with strong 
southwesterly air flow over New Zealand, whereas during positive SAM phases westerly wind belts contract towards the poles (Kidston et al., 2009). Consequently, these phenomena are known to have a strong regional influence on climate variability, glacier mass balance, and ultimately glacier length changes in New Zealand (Fitzharris et al., 1997; Purdie et al., 2011; Mackintosh et al., 2017a).

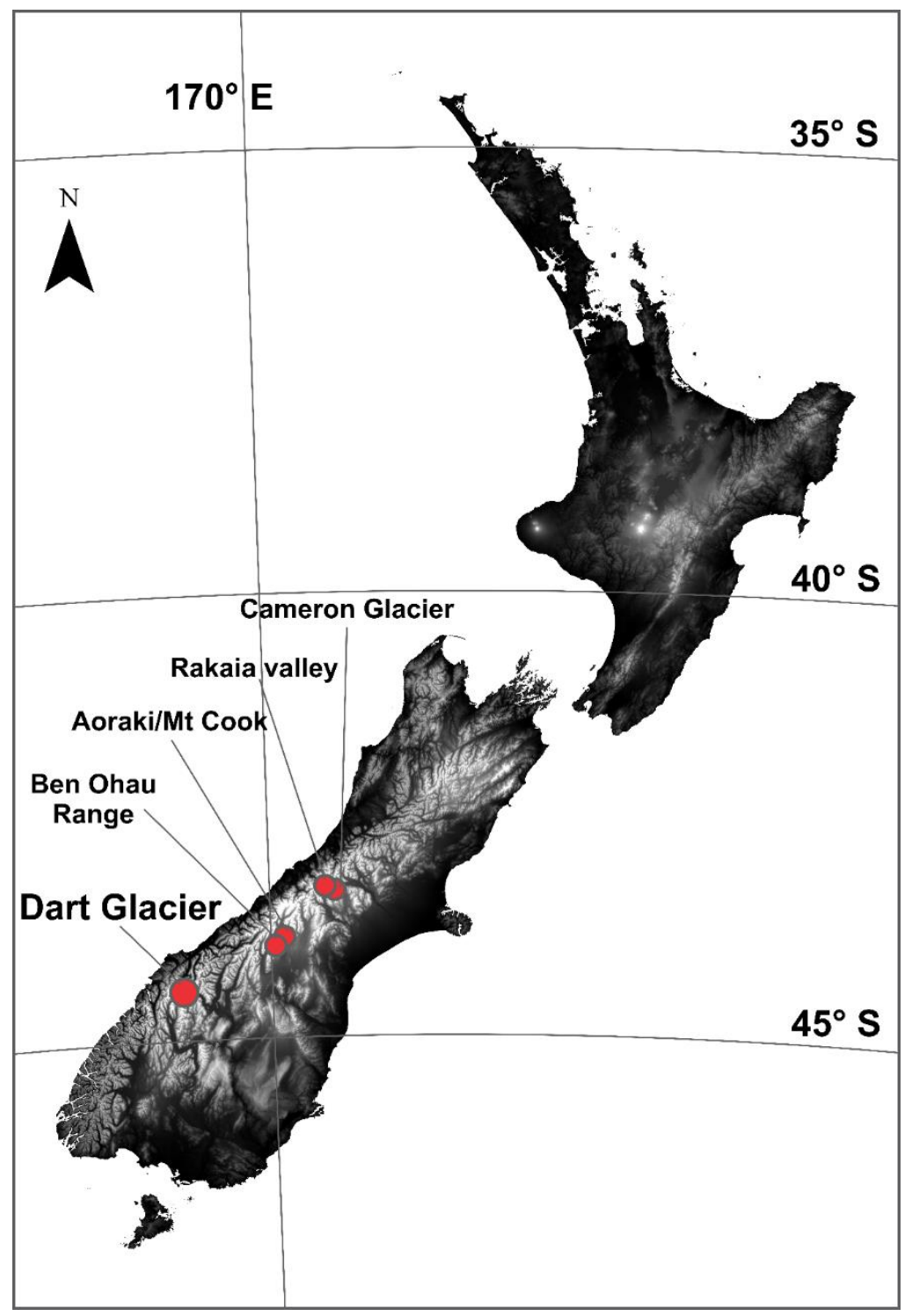

Figure 2.12 Location of Dart Glacier in the Southern Alps of New Zealand and the locations of existing Holocene moraine chronologies that have been developed using ${ }^{10} \mathrm{Be}$ surface exposure dating. 


\subsubsection{Dart Glacier catchment}

Dart Glacier is $\sim 6 \mathrm{~km}$ long and has a wide accumulation zone and narrow tongue that extends into the Dart valley (Figure 2.13). The accumulation zone is surrounded by mountainous terrain that contributes ice, snow, and rock via ice streams and avalanching. The lower portion of the glacier is covered in supraglacial debris (Figure 2.13). The equilibrium line altitude was last measured at $\sim 1700 \mathrm{~m}$ above sea level (asl) by Bishop and Forsyth (1988) (Figure 2.13). The accumulation zone and tongue are separated by a steep icefall (Figure 2.13). A meltwater channel, that forms the Dart River, begins at the glacier terminus. The present-day glacier is restricted to the upper valley; however, the Dart valley extends $\sim 60 \mathrm{~km}$ to Lake Wakatipu. This study is set in the upper $\sim 10 \mathrm{~km}$ of the Dart valley where there is extensive evidence for past glaciation, including moraines and glaciofluvial outwash plains, in the foreland of the present-day glacier terminus and on the surrounding valley walls (Sommerville et al., 1982; Bishop \& Forsyth, 1988). Dart glacier receives $\sim 5 \mathrm{~m}$ of precipitation annually (Tait et al., 2006) and ablates rapidly at a rate of 2-5 cm per day (equivalent to $\sim 3-7 \mathrm{~m}$ in a 150-day melt season) (Bishop \& Forsyth, 1988). The Dart Glacier is similar to Franz Josef and Fox glaciers, in terms of both its climatic setting and topography, meaning the glacier has a relatively fast response time to mass balance changes (Oerlemans, 1997; Anderson et al., 2006; Anderson et al., 2008; Purdie et al., 2014; Mackintosh et al., 2017a). The sensitivity of Dart Glacier to climate has been confirmed through close field observations between AD1975-1987, which suggest that long term glacier length changes closely reflect atmospheric temperature records (Bishop \& Forsyth, 1988). 


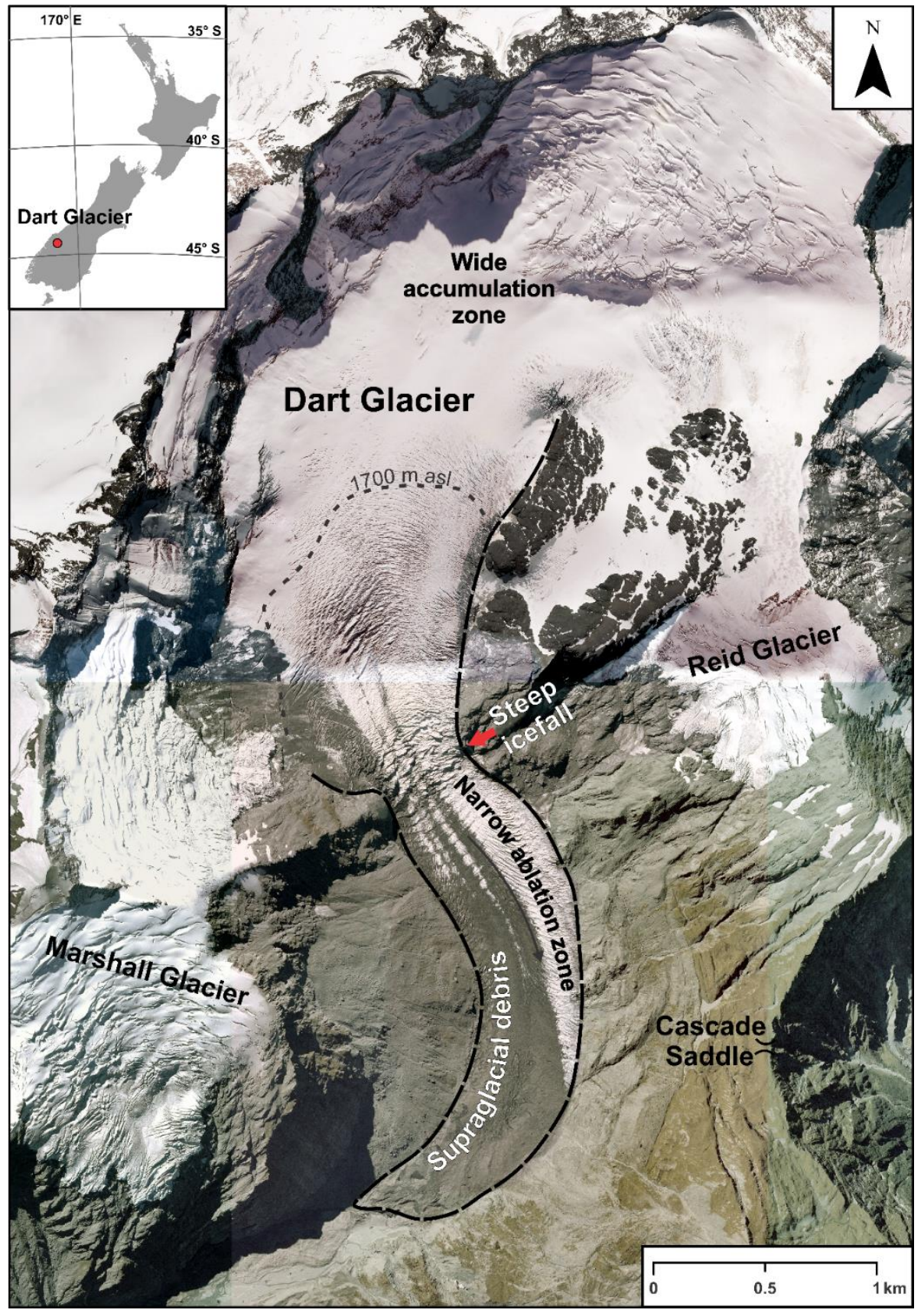

Figure 2.13 Annotated aerial photograph of the Dart catchment showing the geometry of the glacier. The approximated position of the 1988 ELA position is denoted by the dashed contour line at $1700 \mathrm{~m}$ asl as measured by Bishop and Forsyth (1988). 


\subsubsection{Observational record of glacier length changes at Dart Glacier}

Dart Glacier has a rich observational record of glacier length changes that span the last century, including historical photographs (e.g. Figure 2.14) and maps from topographical surveys of the Dart valley (e.g. Figure 2.15). Ruddell (1995) and Bishop and Forsyth (1988) provide extensive compilations of these historical records. Former terminus positions interpreted from these historical records show that Dart Glacier has retreated $\sim 3.5 \mathrm{~km}$ from its historical AD1915 terminus position to its AD2007 terminus position (Figure 2.16). There is some overlap between the observational and geological records as the AD1914 moraine is captured in historical photos and maps (e.g. Figure 2.16) and at present-day is shown by a lateral moraine in the upper region of the Dart valley. The well-preserved pre-historic moraine record delineates former glacier terminus positions that are not captured by the observational record. 

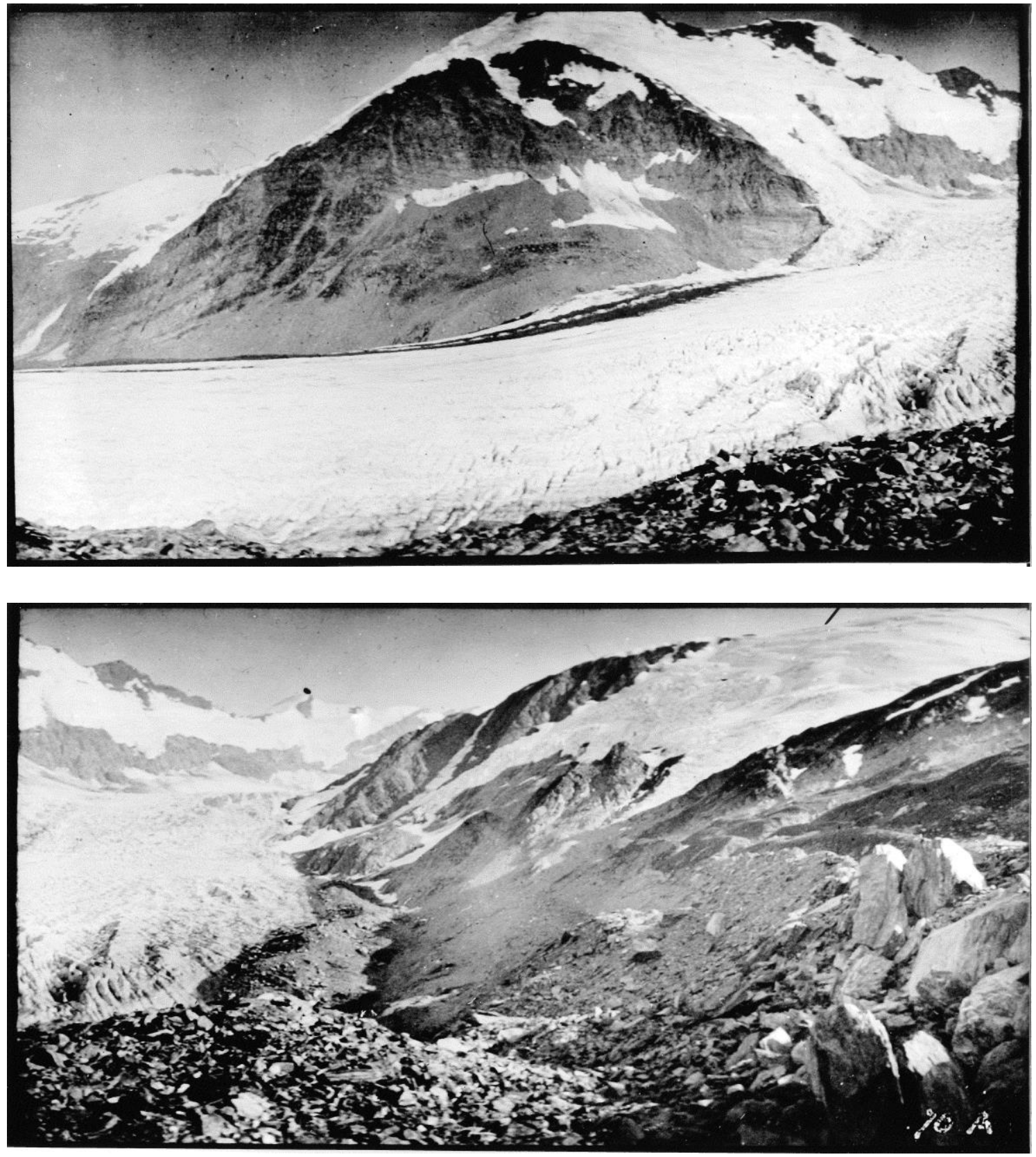

Figure 2.14 Historical photographs showing the lateral extent of Dart Glacier in AD1914 in the upper Dart valley. Top image: shows the landslide on the west side of the icefall (ablation zone) that is still present today. Bottom image: shows ice level and formation of AD1914 moraine on the eastern upper valley wall between the Dart Glacier and Cascade Saddle (Photo: B. Head, 1914). 


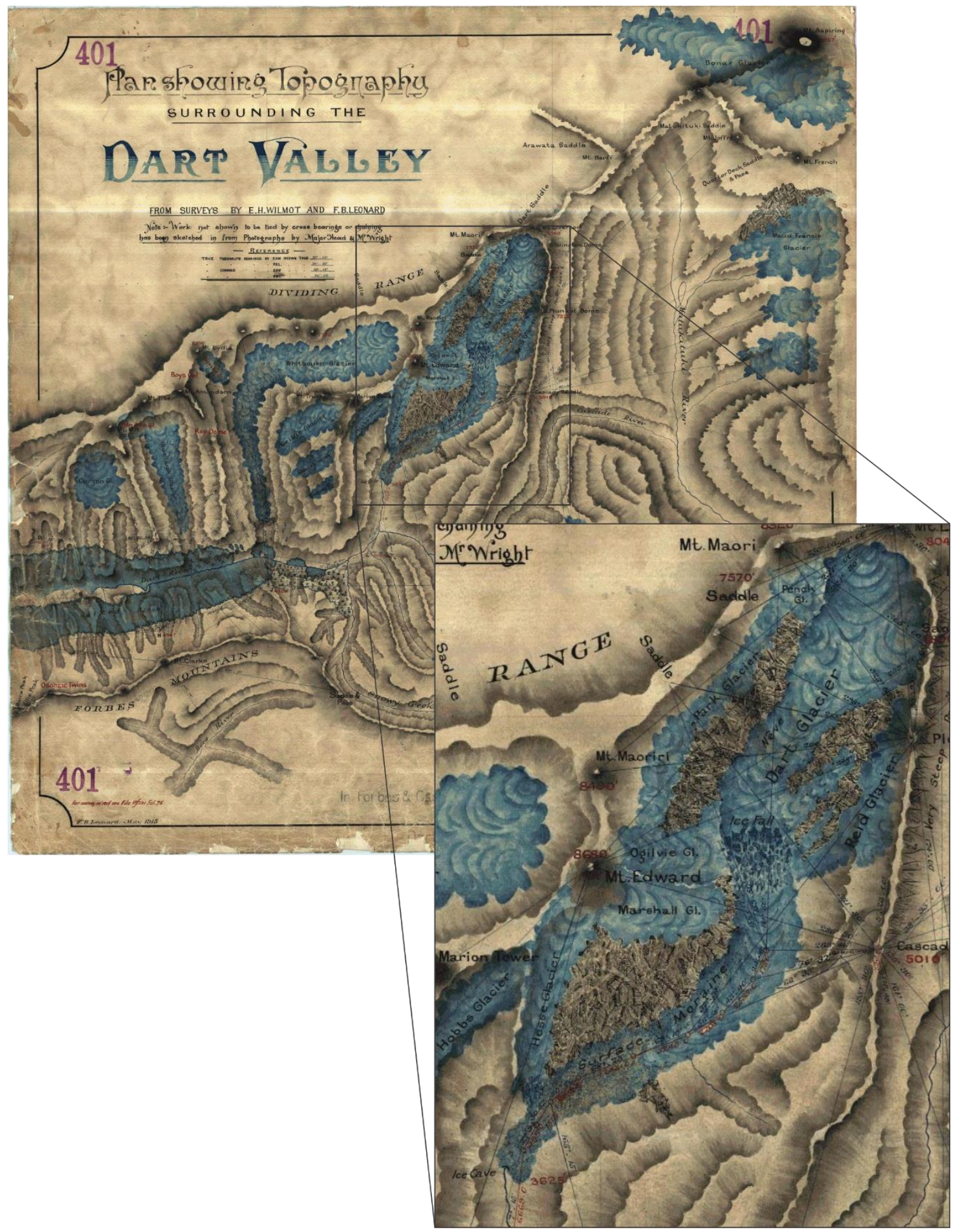

Figure 2.15 Historical map of the topography surrounding the Dart valley created from a topographical survey by E.H. Wilmot and F.B. Leonard in 1915. 


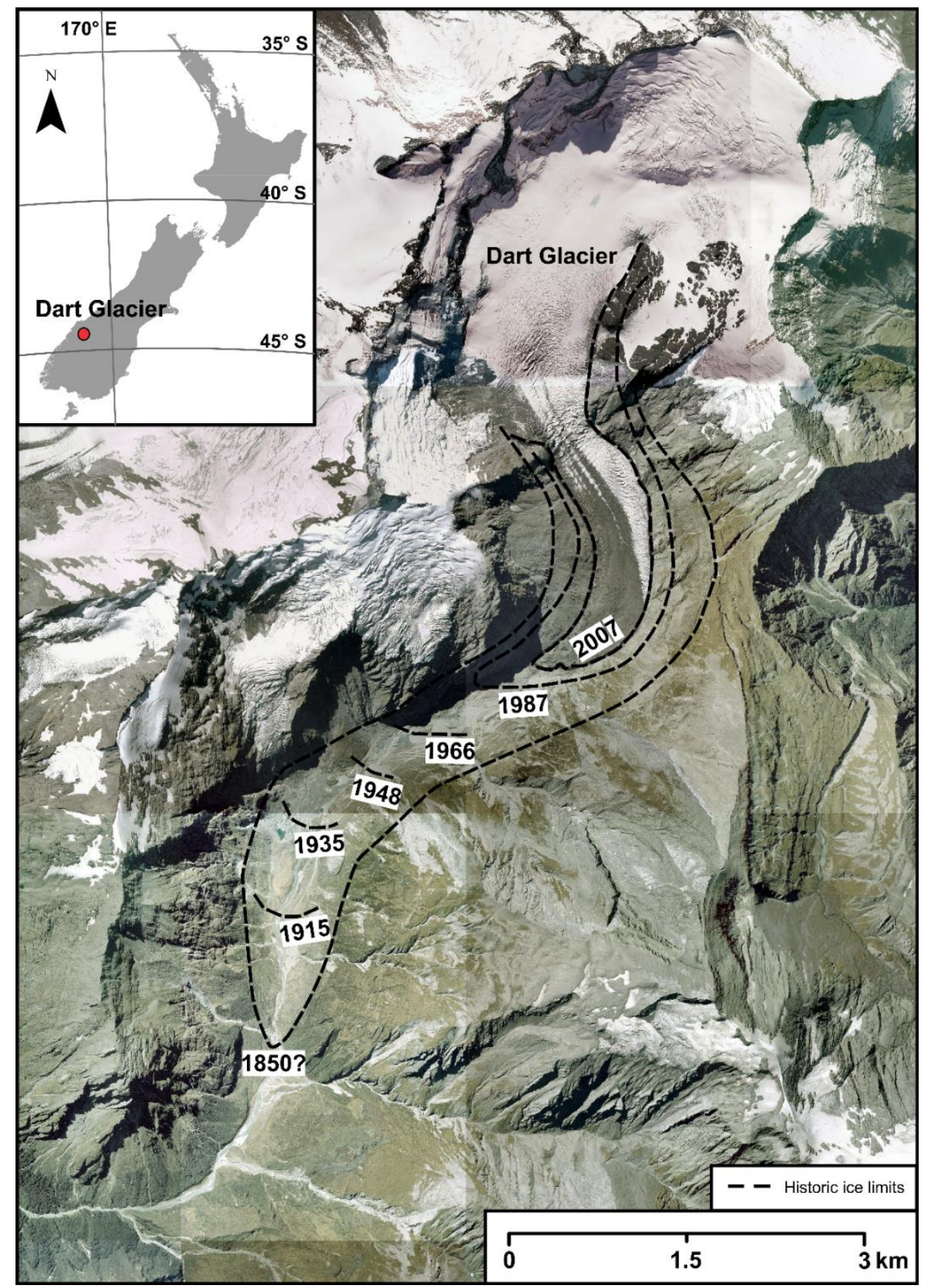

Figure 2.16 Summary of the observational records documenting the former terminus positions of Dart Glacier from AD1915 to AD2007 (records from Bishop \& Forsyth, 1988; Ruddell, 1995). Note that these terminus positions are neither advance positions or existing moraines, except for the $\sim A D 1850$ ice extent that was proposed by Sommerville et al. (1982). 


\subsubsection{Geomorphology - previous work}

Dart Glacier has a well-preserved moraine record, revealing a pattern of pre-historic glacier length changes and ice surface lowering. Several lateral moraines have been identified in the upper region of the Dart valley, perched on the eastern wall between the Dart Glacier and Cascade Saddle (Figure 2.17). A prominent moraine ridge called the U8 moraine, located $\sim 200 \mathrm{~m}$ up the valley wall from the present ice surface at $\sim 1450 \mathrm{~m}$ asl (see Figure 2.17) was attributed the age of $\sim$ AD1850 in a lichenometry study carried out by Sommerville et al. (1982). This study identified ten additional bedrock and sediment ridges at their 'upper study site' both inboard and outboard of the U8 moraine and interpreted these as being glacial in origin (Figure 2.17). Sommerville et al. (1982) identified very similar geomorphology on the eastern wall at their 'lower study site'. However, the geomorphic features at the upper and lower study sites are separated by a large landslide deposit, therefore it is uncertain whether these features formed during the same glacier advance. Sommerville et al. (1982) estimated the ages for nine of the ridges identified at the upper and lower study sites using lichenometry. These age estimates range between 70 and 250 years (relative to AD1982).

Lichenometry ages attributed to the moraines at Dart Glacier by Sommerville et al. (1982) were estimated measuring thalli of lichen (Rhizocarpon geographicum) and then by applying the lichen growth curve established at Lyell Glacier in the upper Rakaia Valley by Burrows and Maunder (1975). The lack of local calibration curve creates a potential source of uncertainty in the Dart moraine lichenometry ages. Furthermore, Sommerville et al. (1982) acknowledge that their application of the lichenometry curve to these surfaces provides minimum age constraints. Since the 1980s, several lichen growth curves have been recalibrated, suggesting that previous growth curves had significantly underestimated the ages of moraines prior to the historical record (Gellatly, 1982; Burrows et al., 1990). This finding further casts uncertainty on the lichenometry age estimations for the moraines at Dart Glacier. Cosmogenic ${ }^{10} \mathrm{Be}$ surface exposure dating of the glacial features at Dart Glacier has the potential to verify the previously attributed ages.

McColl and Davies (2013) propose that the area inboard of the U8 moraine (Figure 2.17) on the eastern valley wall is moving due to deep-seated gravitational slope 
deformation (DSGSD). This study suggests that DSGSD is squeezing the glacier, causing the tongue to appear laterally constrained and identifies blocky, up-hill facing scarps that reflect bedrock foliation. Similar features formed by DSGSD are common on high relief, previously glaciated terrain. For example, on Mueller Rockslide on the Sealy Range at Mt Cook, DSGSD associated with glacier debuttressing has caused the formation of scarps, blocky topography, and widely spaced joints that align with the distinctly-bedded greywacke bedrock (McColl \& Davies, 2013). The interpretations of the geomorphology at Dart Glacier made by McColl and Davies (2013) could have important implications for correct identification of moraines and for the application of cosmogenic ${ }^{10} \mathrm{Be}$ surface exposure dating, as any gradual movement of the moraines perched on the eastern valley side may cause surface lowering and boulder movement. However, unlike at Mueller Glacier, the inferences made at Dart Glacier were based on satellite imagery (SPOT and Google Earth). Ground-truthing is required to more accurately classify the features described by McColl and Davies (2013) and to assess whether these slopes are actively moving due to DSGSD. 


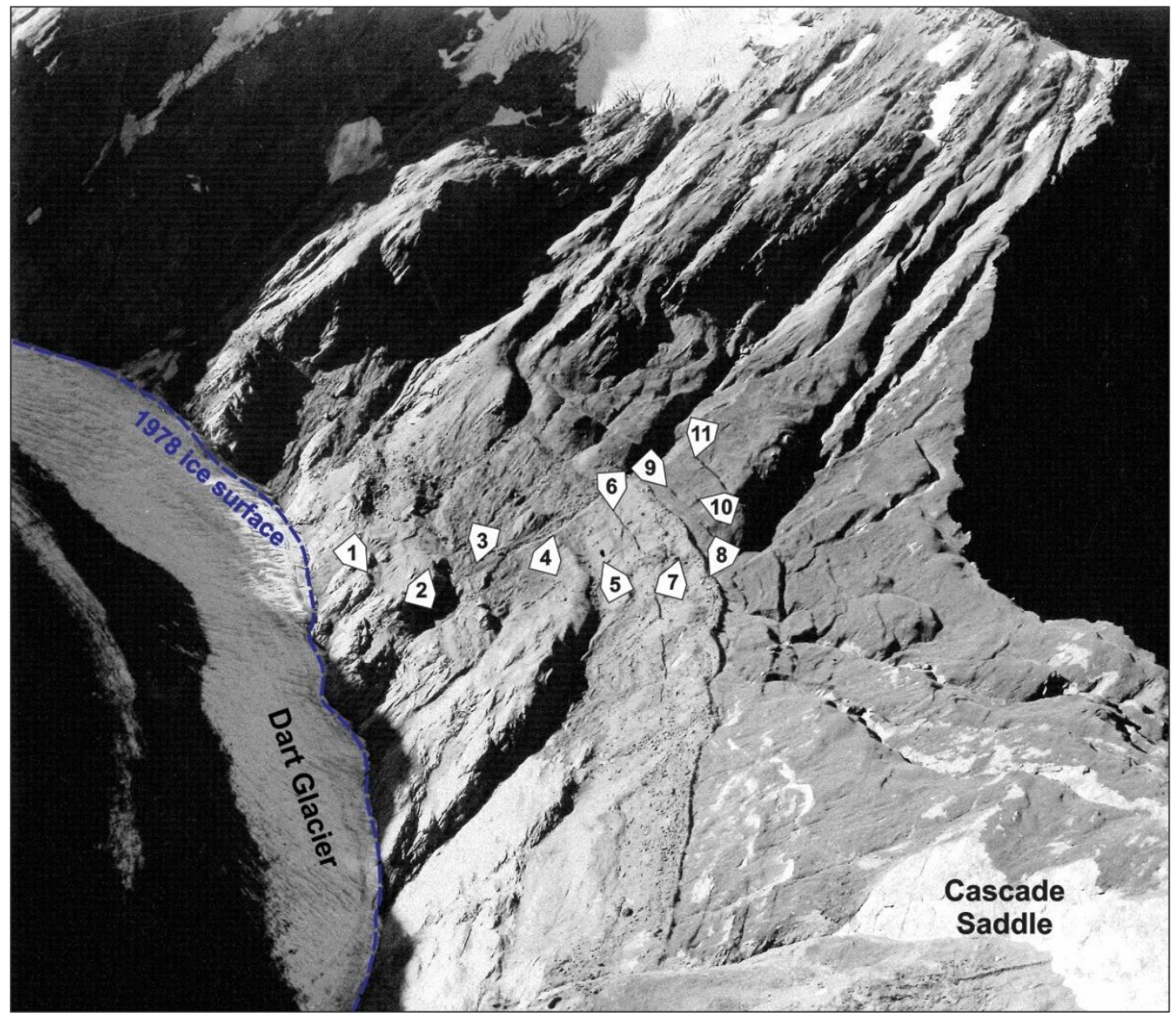

Figure 2.17 Previous geomorphic interpretations of glacial landforms at the upper study site (U1-U11) made by Sommerville et al. (1982). Photograph taken by D.L. Homer (Geological Survey, 1978). 


\section{CHAPTER 3: METHODS}

\subsection{Geomorphological mapping of glacial landforms at Dart Glacier}

\subsubsection{General approach to geomorphological mapping}

Geomorphological mapping is the identification and usage of surface topographic features (position, shape, and texture) to determine the process-origins of different landforms (Barrell et al., 2011). In this study, glacial landforms, such as moraines, were specifically targeted in order to constrain the magnitude of past length changes of Dart Glacier. Because of the active tectonic and hydrological setting of the Southern Alps, the glacial landforms in the Dart valley have been modified over various timescales (see Section 2.2.2). Therefore, surrounding mass-movement and fluvial landforms were also identified and mapped to assess their influence on the preservation of pre-historic glacial landforms. Irregular surfaces such as landslide debris and outcropping bedrock can have similar morphological characteristics to moraines (e.g. Hewitt, 1999; McColl \& Davies, 2011), further justifying the importance of mapping the surrounding geomorphological features in the Dart valley.

The geomorphological mapping approach applied at Dart Glacier builds on the approach used by Barrell et al. (2011) to map the glacial geomorphology in the central South Island, New Zealand. Barrell et al. (2011) primarily based their landform interpretations on vertical aerial photographs and field observations that were drawn onto topographic base maps (NZ Topo50 map series) and then digitised as lines (e.g. streams) or polygons (e.g. moraine ridge) using ArcGIS software. This approach was also undertaken in the Dart valley, as consistency was important in order to make the geomorphological map of the Dart valley directly comparable with existing maps. The recent critique of the Barrell et al. (2011) approach (e.g. Reznichenko et al., 2016; Hedding et al., 2018) was addressed through ground-truthing in the field (see Section 3.1.3) and the use of an extensive compilation of mapping resources to ensure the correct identification of glacial landforms.

The geomorphology at Dart Glacier was mapped using five broad landform categories: (i) bedrock terrain, (ii) glacial landforms, (iii) fluvial landforms, (iv) mass-movement landforms, and (v) other landforms. Table 3.1 provides a brief description of each 
landform category and the landform types mapped within each category. The glacial landforms have been mapped with the highest detail, whereas all other landform mapping was more generalised.

Table 3.1 Summary descriptions of the landform categories and types that were used to create the final geomorphological map (see Appendix 2). Table adapted from Barrell et al. (2011).

\begin{tabular}{|c|c|c|c|}
\hline $\begin{array}{l}\text { Landform } \\
\text { Category }\end{array}$ & $\begin{array}{l}\text { Description of } \\
\text { landform category }\end{array}$ & Landform type & $\begin{array}{l}\text { Description of landform } \\
\text { type }\end{array}$ \\
\hline \multirow[t]{3}{*}{ Bedrock } & \multirow[t]{3}{*}{$\begin{array}{l}\text { Any landform } \\
\text { consisting of } \\
\text { bedrock; may also } \\
\text { include erosional } \\
\text { features such as } \\
\text { benches or glacially } \\
\text { modified bedrock. }\end{array}$} & Bedrock terrain & $\begin{array}{l}\text { Topography consisting of } \\
\text { parent bedrock where there } \\
\text { is insufficient evidence for } \\
\text { glacial erosion. General } \\
\text { bedrock terrain is } \\
\text { frequently covered in soil } \\
\text { and vegetation and } \\
\text { dissected through fluvial or } \\
\text { gravitational erosion } \\
\text { processes. }\end{array}$ \\
\hline & & $\begin{array}{l}\text { Ice-sculpted } \\
\text { bedrock }\end{array}$ & $\begin{array}{l}\text { Bedrock with altered } \\
\text { surface texture due to past } \\
\text { glacial erosion. Surfaces } \\
\text { contain irregular rises and } \\
\text { textures which are } \\
\text { accentuated by weathering, } \\
\text { striations, stream incision, } \\
\text { and pockets of till. Bedrock } \\
\text { on previously glaciated } \\
\text { valley sides is often smooth } \\
\text { and broadly planar. }\end{array}$ \\
\hline & & Bedrock bench & $\begin{array}{l}\text { Discrete landforms that } \\
\text { exhibit ridge morphologies } \\
\text { and are predominantly } \\
\text { comprised of bedrock, as } \\
\text { opposed to unlithified } \\
\text { sediment. In this study, the } \\
\text { bedrock benches are } \\
\text { assumed to be structural } \\
\text { landforms that reflect the } \\
\text { orientation of bedrock } \\
\text { foliation. }\end{array}$ \\
\hline
\end{tabular}




\begin{tabular}{|c|c|c|c|}
\hline \multirow[t]{3}{*}{ Glacial } & \multirow[t]{3}{*}{$\begin{array}{l}\text { Depositional or } \\
\text { erosional features } \\
\text { formed directly } \\
\text { during the } \\
\text { processes of glacier } \\
\text { advance and/or } \\
\text { retreat. }\end{array}$} & Till & $\begin{array}{l}\text { Any landform and area } \\
\text { largely consisting of till. } \\
\text { These landforms have } \\
\text { irregular surface textures } \\
\text { and are heavily dissected } \\
\text { by stream incision, } \\
\text { particularly on valley sides. }\end{array}$ \\
\hline & & Moraine ridge & $\begin{array}{l}\text { Continuous or semi- } \\
\text { continuous discrete ridges } \\
\text { comprising till deposited at } \\
\text { ice margins during glacier } \\
\text { standstills. Moraine ridges } \\
\text { typically reflect the shape } \\
\text { of former ice geometries } \\
\text { and have distinct crests } \\
\text { with large embedded } \\
\text { boulders. These features } \\
\text { always have ice-contact } \\
\text { slopes that face the present } \\
\text { or former glacier. }\end{array}$ \\
\hline & & Ice-contact slope & $\begin{array}{l}\text { A slope comprising till that } \\
\text { was deposited against a } \\
\text { wall of glacier ice. Ice- } \\
\text { contact slopes delineate } \\
\text { former ice margins and } \\
\text { often coincide with the ice- } \\
\text { proximal slopes of } \\
\text { moraines. }\end{array}$ \\
\hline \multirow[t]{2}{*}{ Fluvial } & \multirow[t]{2}{*}{$\begin{array}{l}\text { Depositional or } \\
\text { erosional features } \\
\text { formed in } \\
\text { association with a } \\
\text { river or stream. }\end{array}$} & Outwash surface & $\begin{array}{l}\text { Planar surfaces that form } \\
\text { on the flood plains of } \\
\text { glacial meltwater systems } \\
\text { and consist of glaciofluvial } \\
\text { sediment. }\end{array}$ \\
\hline & & Alluvial fan & $\begin{array}{l}\text { Convex, fan-shaped } \\
\text { landforms which comprise } \\
\text { fluvially transported } \\
\text { sediment (alluvium) } \\
\text { derived from the valley } \\
\text { slopes. These features } \\
\text { occur when a stream } \\
\text { transporting sediment } \\
\text { deposits this material where } \\
\text { the channel is less confined. }\end{array}$ \\
\hline
\end{tabular}




\begin{tabular}{|c|c|c|c|}
\hline Mass-movement & $\begin{array}{l}\text { Formed during } \\
\text { gravitational slope } \\
\text { movement. }\end{array}$ & Landslide & $\begin{array}{l}\text { Irregular surfaces that form } \\
\text { on sloped terrain as large } \\
\text { amounts of unconsolidated, } \\
\text { slope-derived sediment is } \\
\text { transported under the } \\
\text { influence of gravity. }\end{array}$ \\
\hline \multirow[t]{6}{*}{ Other landforms } & \multirow[t]{6}{*}{$\begin{array}{l}\text { All geomorphic } \\
\text { features that do not } \\
\text { fit in the other four } \\
\text { landform category } \\
\text { descriptions. }\end{array}$} & Active river bed & $\begin{array}{l}\text { River bed or the episodic } \\
\text { floodplain of glacial } \\
\text { meltwater system. }\end{array}$ \\
\hline & & Stream & $\begin{array}{l}\text { Channels transporting } \\
\text { water downstream. The } \\
\text { main stream sits within the } \\
\text { active river bed and is fed } \\
\text { by glacial meltwater and } \\
\text { additionally by tributaries } \\
\text { that incise the surrounding } \\
\text { valley walls. }\end{array}$ \\
\hline & & Water body & $\begin{array}{l}\text { Permanent or seasonal } \\
\text { water body. Kettle holes or } \\
\text { tarns are closed depressions } \\
\text { in outwash surfaces, } \\
\text { moraines, or bedrock } \\
\text { benches. }\end{array}$ \\
\hline & & Glacier & $\begin{array}{l}\text { Ice or snow that makes up } \\
\text { the main glacier, hanging } \\
\text { glaciers or ice patches } \\
\text { covering the upper valley } \\
\text { walls. }\end{array}$ \\
\hline & & \begin{tabular}{|l|} 
Supraglacial \\
debris
\end{tabular} & $\begin{array}{l}\text { Debris that covers the } \\
\text { glacier ice; typically found } \\
\text { in the ablation zone but also } \\
\text { in the accumulation zone as } \\
\text { a result of avalanching. }\end{array}$ \\
\hline & & \begin{tabular}{|l|} 
Dead ice \\
\end{tabular} & $\begin{array}{l}\text { Ice that once made up the } \\
\text { glacier terminus that is } \\
\text { insulated by a thick layer of } \\
\text { debris. The surrounding ice } \\
\text { has melted during glacier } \\
\text { retreat, leaving behind a } \\
\text { mound of ice buried by } \\
\text { debris. }\end{array}$ \\
\hline
\end{tabular}




\subsubsection{Compilation of mapping resources and landform identification}

Landform identification in the Dart valley was based on a wide compilation of mapping resources which allowed for cross-checking between sources, minimising the uncertainty associated with attributing landform types and defining landform boundaries. Crosschecking also allowed for less generalisation of the geomorphic detail in the upper Dart valley. However, as noted by Barrell et al. (2011) generalisation of some intricate details is essential in mapping in order to clearly present all identified landforms at typical geomorphological map scales $(1: 25,000$ to $1: 100,000)$.

Similar to Barrell et al. (2011), aerial photography (Otago 0.75m Rural Aerial Photos 2004-2011) and NZ Topo50 series maps were used as base maps for the initial identification of the landform types in the Dart valley (LINZ, 2018). Geomorphic observations of these landforms were made in the field regarding landform morphology and preservation, as well as the source of landform material (e.g. glacially vs fluvially derived material). Global positioning system (GPS) surveying was carried out in the field to locate the positions (latitude, longitude and elevation) of glacial landforms (specifically moraines) and sample sites. In addition to these resources, landform types and shapes were refined using a digital elevation model (DEM) $(8 \mathrm{~m})$ and a DEM ( $<1 \mathrm{~m}$ resolution) derived via structure-from-motion techniques using a low elevation aerial photo survey (provided by Dr Brian Anderson, Victoria University of Wellington). Numerous oblique photographs of glacial landforms and surrounding geomorphology were taken in the field. Historical photographic and cartographic records spanning the last century (see Section 2.5.3) also allowed for further corroboration of the mapped geomorphology.

Once identified, landforms were digitised in ArcGIS. Landform types are represented by lines and polygons that are uniquely defined by a distinct symbol, colour, and/or texture. Glacial landforms with inferred different ages (i.e. outwash surfaces) are also represented using different colours. Landforms are displayed using the New Zealand Transverse Mercator (NZTM) projection. These features are presented on a hillshade created using the DEM $(8 \mathrm{~m})$ with topographic contours provided at $100 \mathrm{~m}$ intervals. The final geomorphic map is displayed at 1:25,000 scale (Appendix 2). The mapping limits are also defined by a solid black line where all geomorphology was predominantly mapped within the limits of the Dart Glacier catchment. 


\subsection{Cosmogenic ${ }^{10}$ Be surface exposure dating}

\subsubsection{Sample Collection}

Moraine boulders preserved in the Dart valley consists of high-grade metamorphic schist, which provided quartz-rich moraine boulder samples required for ${ }^{10} \mathrm{Be}$ surface exposure dating. The integrity of samples collected for surface exposure dating relies on the following assumptions: (i) moraines have correctly been identified (i.e. formed in direct association with glacial activity); (ii) sampled landforms have not been subjected to post-depositional processes causing erosion, burial or movement of boulders; and (iii) sampled boulders have not inherited cosmogenic nuclides from previous periods of exposure.

To best uphold these assumptions a strict boulder selection and sampling procedure was followed, adapted from Putnam et al. (2013). Large boulders embedded in the crests of moraines were targeted to reduce the possibility that boulders have moved since deposition. Preference was given to boulders with flat-topped surfaces, and minimal signs of weathering or sediment and vegetation cover to ensure that sampled surfaces have not been subject to burial or erosion (see Figure 2.8 in Section 2.3.7). Boulders in close-proximity to active geomorphic features such as steep terrain, landslide or fan deposits and incising streams/rivers were avoided when sampling to minimise the likelihood of post-depositional boulder movement or erosion (Figure 2.8 and Section 2.3.7). Striated boulders were desirable, as these features provide evidence of subglacial/englacial erosion and thus removal of inherited ${ }^{10} \mathrm{Be}$. However, no obvious striae were found on these schist boulders.

Quartz veins situated on the boulder surfaces were sampled using a hammer and chisel. Boulder dimensions were measured at each sample site along with written descriptions of the geomorphic context and boulder appearance (e.g. evidence of weathering). To determine topographic shielding of incoming cosmic rays, the angle of the surrounding skyline was surveyed using a clinometer and compass, along with the strike and dip of each sample surface. The location (latitude and longitude) and elevations of each sample were surveyed using either a Trimble GeoXH or Garmin eTrex GPS system (relative to WGS1984 datum) (Table 4.1). The collection of this contextual sample information was important to ensure that the sampling procedure was consistent, and the discussed assumptions were upheld. 
The prominent moraine ridges in the upper Dart valley labelled 'AD1850' (Bishop \& Forsyth, 1988) or U8 and L8, respectively (Sommerville et al., 1982) were targeted for sampling (Figure 3.1). The samples collected from the U8 moraine (Sommerville et al., 1982) at the upper study site (Figure 3.1) were labelled with the prefix 'DU'. All samples collected from the L8 moraine (Sommerville et al., 1982) at the lower study site (Figure 3.1) were labelled with the prefix 'DL'. Because these two sites are separated by a large landslide deposit, this sampling strategy would help to determine whether these prominent ridges formed contemporaneously or represent two distinct moraines features with independent ages. To constrain the timing of earlier past glacier fluctuations in the Dart valley, samples were also collected from previously undescribed moraine remnants identified during field mapping in the vicinity of Dart Hut, situated $\sim 6 \mathrm{~km}$ from the present-day glacier terminus (Figure 3.1). Samples taken from the Dart Hut site were labelled with the prefix ' $\mathrm{DH}$ '.

\subsubsection{Physical quartz separation and cosmogenic ${ }^{10} \mathrm{Be}$ preparation}

Schist samples were brought back to Victoria University of Wellington (VUW) for standard physical and chemical processing required for in situ cosmogenic ${ }^{10} \mathrm{Be}$ surface exposure dating (Kohl \& Nishiizumi, 1992; Stone, 1998). Of the twentyfive schist samples collected from the Dart valley, sixteen were fully processed in the ${ }^{10} \mathrm{Be}$ preparation laboratory at VUW following standard laboratory procedures for quartz separation/purification and ${ }^{10} \mathrm{Be}$ extraction. These procedures were adapted from von Blanckenburg et al. (1996), von Blanckenburg et al. (2004) and Norton et al. (2008) and are summarised in steps 1 to 27 of Figure 3.2. 


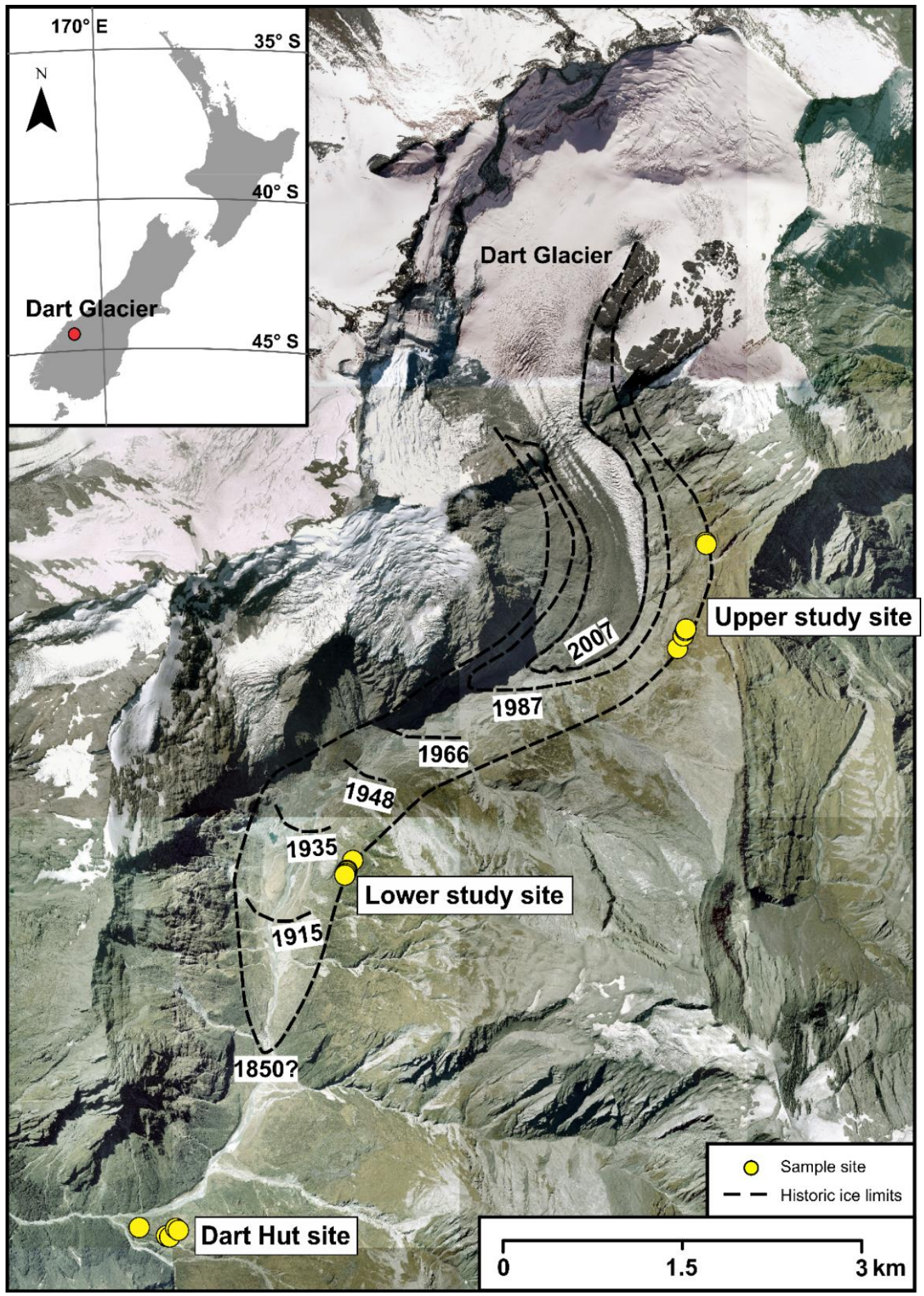

Figure 3.1 Sites for collection of moraine boulder samples for cosmogenic ${ }^{10}$ Be surface exposure dating at Dart Glacier. Samples were taken from the upper study site (U8 moraine), lower study site (L8 moraine) and at the Dart Hut site. Historical glacier length changes from AD1915 to AD2007 are also included to show how this sampling strategy will provide a moraine chronology that extends the observational record. 


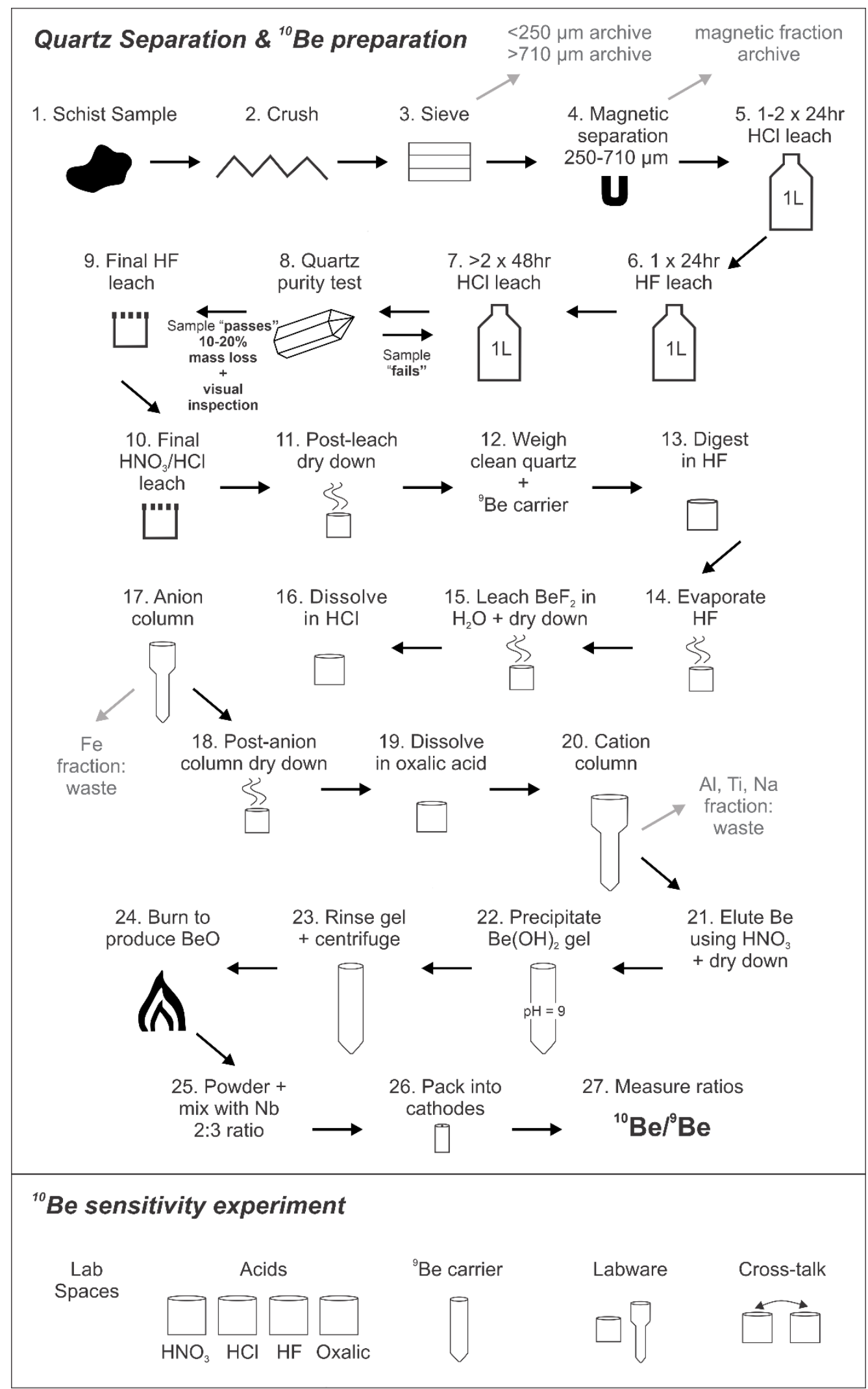

Figure 3.2 Flow chart adapted from Corbett et al. (2016) showing steps used for quartz separation and ${ }^{10} \mathrm{Be}$ preparation. Sources of ${ }^{10} \mathrm{Be}$ contamination tested in the ${ }^{10} \mathrm{Be}$ sensitivity experiment are also included (see Section 3.3). 


\subsubsection{Quartz separation and purification}

Physical descriptions of sample thickness and appearance were made before the sample was crushed using a jaw crusher to $<1 \mathrm{~mm}$ grain size. Samples were then sieved into four fractions using a mechanical sieve shaker: $>710 \mu \mathrm{m}, 710-500 \mu \mathrm{m}$, 500-250 $\mu \mathrm{m}$, and $<250 \mu \mathrm{m}$. Once sieved, the 500-250 $\mu \mathrm{m}$ fraction was rinsed in glass beakers to remove any finer particulates and organic material. Once rinsed, samples were transferred into metal dishes and dried in the oven overnight at $50^{\circ} \mathrm{C}$. Samples were then cleaned using a hand magnet to remove the highly magnetic mineral fraction. Isodynamic magnetic separation was used to remove the remaining magnetic mineral content. Magnetic separation was repeated by systematically adjusting the amperage until 100-150 g of 500-250 $\mu \mathrm{m}$ non-magnetic material (majority quartz) was obtained.

Approximately $100 \mathrm{~g}$ of the non-magnetic fraction from each sample was added to $1 \mathrm{~L}$ bottles and were then exposed to a series of acid leaches (steps 5 to 7 in Figure 3.2). First, $800 \mathrm{ml}$ of $10 \% \mathrm{HCl}$ was added to each sample to remove organic matter, carbonates, and weathering products such as oxides coating the outer surfaces of minerals. One hundred $\mathrm{ml}$ of $10 \% \mathrm{HCl}$ was initially added and left uncapped overnight to allow any strong reactions to occur. The remaining $700 \mathrm{ml}$ of $10 \% \mathrm{HCl}$ was added and the sample bottles were placed tightly capped in a heated water bath for $24 \mathrm{hrs}$. The samples were regularly agitated to ensure all grains were exposed to acid. The $\mathrm{HCl}$ solution was then decanted and samples were rinsed four times with milliQ $\mathrm{H}_{2} \mathrm{O}$. The same leaching process was then carried out using $800 \mathrm{ml}$ of $2.5 \%$ hydrofluoric acid $(\mathrm{HF})$ and $1 \%$ nitric acid $\left(\mathrm{HNO}_{3}\right)$ solution to remove any remaining impurities adhering to the quartz grains. Samples were then leached in $2.5 \% \mathrm{HF}$ for $1 \times 24 \mathrm{hrs}$ and at least 2 x $48 \mathrm{hrs}$. Samples were rinsed five times with milliQ $\mathrm{H}_{2} \mathrm{O}$ and dried in the oven at $50^{\circ} \mathrm{C}$ in between successive HF leaches. Samples were also weighed between leaches to keep track of the mass loss. HF leaches were continued until all visible impurities had been removed from the sample. Quartz purity was determined through visual inspection using a reflecting binocular microscope and total mass loss of the sample (usually $\sim 15-20 \%$ required). 


\subsubsection{Beryllium extraction}

Each $350 \mathrm{ml}$ Savillex beaker (lid and jar) was precisely weighed before $\sim 60-80 \mathrm{~g}$ (see Table 4.1) of pure quartz sample was added. Final quartz leach procedures were carried out on each sample to ensure that all impurities (including meteoric ${ }^{10} \mathrm{Be}$ ) had been removed (steps 9 and 10 in Figure 3.2). To begin this procedure, 7M HF was added ensuring each sample was covered with $\sim 5 \mathrm{~mm}$ of excess liquid. The beakers were capped and placed on a hotplate $\left(120^{\circ} \mathrm{C}\right)$ for $\sim 1 \mathrm{hr}$. The beakers were removed, allowing the contents to cool, before the HF was decanted, and samples were rinsed five times with milliQ $\mathrm{H}_{2} \mathrm{O}$. Aqua Regia (1:3 molar mixture of $15 \mathrm{M}$ $\mathrm{HNO}_{3}: 12 \mathrm{M} \mathrm{HCl}$ ) was added ensuring the sample was covered with $\sim 5 \mathrm{~mm}$ of excess liquid. The beakers were left open for $\sim 30$ minutes to ensure all brown gas formed during the initial reaction was gone. The beakers were then capped and placed on a hotplate $\left(120^{\circ} \mathrm{C}\right)$ for $2 \mathrm{hrs}$. The samples were then rinsed four to five times with milliQ $\mathrm{H}_{2} \mathrm{O}$ and left overnight ( $\left.\sim 12 \mathrm{hrs}\right)$ to dry down on a hotplate.

The dried samples were then precisely weighed. Each sample was then spiked with $\sim 0.89 \mu \mathrm{g}$ of ${ }^{9} \mathrm{Be}$ carrier (in-house $305 \mathrm{ppm}{ }^{9} \mathrm{Be}$ solution). Precise weights of the carrier added to each sample were recorded (see Table 4.1 in Section 4.2). ${ }^{9} \mathrm{Be}$ carrier was added to each sample because there is not enough Be in total to measure via AMS. Process blanks were also prepared at the same time as the ${ }^{9} \mathrm{Be}$ carrier additions. The blanks were treated the same as samples throughout the remainder of the Be extraction procedure (steps 13 to 26 in Figure 3.2).

Approximately $300-400 \mathrm{ml}$ of concentrated (28M) HF was added to the samples to digest the quartz. Due to the large sample masses ( $60-80 \mathrm{~g})$, a combination of both open and closed beaker dissolution was used. During open beaker dissolution concentrated HF was added to the samples in $~ 60 \mathrm{ml}$ increments; in between additions the HF was evaporated by placing the beakers uncapped on a hotplate $\left(120^{\circ} \mathrm{C}\right)$. The beakers were arranged on the hotplate at least one beaker width apart to avoid cross-contamination between reacting samples. Once the sample had at least halved in mass, the remaining sample was completely dried and weighed to determine the volume of HF required for closed beaker dissolution. To determine this volume the mid-dissolution sample weights were multiplied by five and rounded. The beakers were then capped and placed on the hotplate for 
approximately two to three days ( $\sim 65 \mathrm{hrs})$ until the quartz was completely dissolved. Lids were then removed from the beakers allowing the remaining solution to evaporate completely, forming a thin fluoride cake $\left(\mathrm{BeF}_{2}\right)$ in the bottom of each beaker.

Prior to ion exchange chromatography, $\mathrm{BeF}_{2}$ was leached from the samples using milliQ $\mathrm{H}_{2} \mathrm{O}$ as $\mathrm{BeF}_{2}$ is more soluble in water compared to many other fluorides (Stone, 1998). Ten ml of milliQ $\mathrm{H}_{2} \mathrm{O}$ was added to each beaker to cover the samples. Samples were left to rest for $\sim 10$ minutes to allow the $\mathrm{BeF}_{2}$ to leach into the water. Samples (supernate and solids) were pipetted into $50 \mathrm{ml}$ centrifuge tubes and centrifuged for 5 minutes at 3500 revolutions per minute (rpm). The supernate was decanted into the cleaned original beakers (wiped using a kimwipe and rinsed three times with milliQ $\left.\mathrm{H}_{2} \mathrm{O}\right)$. Samples were then dried down on a hotplate $\left(\sim 120^{\circ} \mathrm{C}\right)$. Once evaporated, $10 \mathrm{ml}$ of $6 \mathrm{M} \mathrm{HCl}$ was used to redissolve the samples, which were then transferred into $15 \mathrm{ml}$ centrifuge tubes and centrifuged in preparation for iron $(\mathrm{Fe})$ columns.

Iron was removed from the samples using $15 \mathrm{ml}$ Eichrom columns containing $2 \mathrm{ml}$ of Biorad AG1-X8 100-200 mesh (anion) resin. Five $\mathrm{ml}+5 \mathrm{ml}$ of $0.3 \mathrm{M} \mathrm{HCl}$ was added to each column to clean the resin, followed by $2 \mathrm{ml}+2 \mathrm{ml}+2 \mathrm{ml}$ of $6 \mathrm{M} \mathrm{HCl}$ for resin conditioning. Samples in $10 \mathrm{ml} 6 \mathrm{M} \mathrm{HCl}$ and $2 \mathrm{ml}+2 \mathrm{ml}+2 \mathrm{ml} 6 \mathrm{M} \mathrm{HCl}$ were used to elute $\mathrm{Be}$, which was collected in cleaned original beakers. The columns were then cleaned using $5 \mathrm{ml}+5 \mathrm{ml} 0.3 \mathrm{M} \mathrm{HCl}$. Samples were dried down overnight on a hotplate. Once dry, $20 \mathrm{ml}$ of oxalic acid was added to the beakers that were then warmed on a hotplate $\left(60^{\circ} \mathrm{C}\right)$ for $2 \mathrm{hrs}$ to redissolve samples. Samples were cooled for 30 minutes before being transferred into 50 centrifuge tubes and centrifuged for 5 minutes at $3500 \mathrm{rpm}$.

Beryllium was extracted using $25 \mathrm{ml}$ Eichrom columns containing $5 \mathrm{ml}$ of Biorad AG50-X8 200-400 mesh (cation) resin. Five $\mathrm{ml}+10 \mathrm{ml}$ of $5 \mathrm{M} \mathrm{HNO}_{3}$ then $5 \mathrm{ml}+$ $5 \mathrm{ml}$ of milliQ $\mathrm{H}_{2} \mathrm{O}$ was added to clean the resin. Columns were then conditioned using $5 \mathrm{ml}+10 \mathrm{ml} 0.4 \mathrm{M}$ oxalic acid. Samples in $20 \mathrm{ml}$ of $0.4 \mathrm{M}$ oxalic acid were then added and washed down using $5 \mathrm{ml}+5 \mathrm{ml}$ of oxalic acid. Fifty $\mathrm{ml}$ of oxalic acid was used to elute $\mathrm{Fe}, \mathrm{Al}$, and $\mathrm{Ti}$ waste. Fifteen $\mathrm{ml}+25 \mathrm{ml}$ of $0.5 \mathrm{M} \mathrm{HNO}_{3}$ was used to elute $\mathrm{Na}$ waste. Be was eluted into cleaned beakers using $20 \mathrm{ml}+20 \mathrm{ml}+$ 
$20 \mathrm{ml} 1 \mathrm{M} \mathrm{HNO}_{3}$. Columns were cleaned using $40 \mathrm{ml}$ of $5 \mathrm{M} \mathrm{HNO}$. Samples were then dried down on a hotplate overnight.

Samples were redissolved in $5 \mathrm{ml}$ of $1 \mathrm{M} \mathrm{HNO}_{3}$ and transferred into $15 \mathrm{ml}$ centrifuge tubes. $\mathrm{Be}(\mathrm{OH})_{2}$ was precipitated by changing the $\mathrm{pH}$ to $\sim 9$ using $0.55 \mathrm{ml}$ of $25 \%$ $\mathrm{NH}_{4} \mathrm{OH}$ (Ochs \& Ivy-Ochs, 1997). Samples were vortexed for 1 minute and left to rest until $\mathrm{Be}(\mathrm{OH})_{2}$ precipitate formed $(\sim 1 \mathrm{hr})$. Samples were then centrifuged, forming a $\mathrm{Be}(\mathrm{OH})_{2}$ gel at the bottom of each centrifuge tube. The supernate was then decanted and gels were rinsed twice using $\sim 5 \mathrm{ml}$ of milliQ $\mathrm{H}_{2} \mathrm{O}$ (vortexed and centrifuged).

Gels were then transferred into quartz crucibles and dried down on a hotplate overnight. Dried samples were then calcined by holding each crucible over an open flame for $\sim 1$ minute converting $\mathrm{Be}(\mathrm{OH})_{2}$ into a $\mathrm{BeO}$. $\mathrm{BeO}$ was then powdered using a metal spatula and mixed with $\mathrm{Nb}$ (2:3 ratio). The mixture was then transferred and pressed into steel AMS cathodes using a drill stem and hammer.

\subsection{3 ${ }^{10} \mathrm{Be}$ measurement and exposure age calculation}

${ }^{10} \mathrm{Be} /{ }^{9} \mathrm{Be}$ ratios were measured using the HVEC $10 \mathrm{MV}$ Model FN Tandem Van de Graaff Accelerator at the Center for Accelerator Mass Spectrometry (CAMS) Lawrence Livermore National Laboratory (LLNL). Ratios were normalised using the 07KNSTD3110 standard (Nishiizumi et al., 2007) and corrected for background ${ }^{10} \mathrm{Be} /{ }^{9} \mathrm{Be}$ using process blanks. ${ }^{10} \mathrm{Be} /{ }^{9} \mathrm{Be}$ ratio measurements from the AMS were reduced to ${ }^{10} \mathrm{Be}$ concentrations using the reduction protocol outlined by Balco (2006). ${ }^{10} \mathrm{Be}$ concentration uncertainties were also calculated using standard errorpropagation methods, which incorporate analytical, blank, and carrier uncertainties (Balco, 2006). Surface exposure ages were calculated using version 3 of "the online exposure age calculator formerly known as the CRONUS-Earth online exposure age calculator" (https://hess.ess.washington.edu/). Like other online exposure age calculators, such as those described by Balco et al. (2008) and Marrero et al. (2016), version 3 calculates exposure ages using measured ${ }^{10} \mathrm{Be}$ concentrations, ${ }^{10} \mathrm{Be}$ production rates (referenced to SLHL), and established scaling methods including St (Stone, 2000), Lm (Balco et al., 2008), and LSD (Lifton et al., 2014) scaling models (see Section 2.3.6). However, version 3 includes several improvements to 
previous calculators by increasing calculation speed and allowing for easy input of code from online databases containing production rate datasets, such as the ICE-D production rate calibration database (http://calibration.ice-d.org/) (Balco, 2017a). Surface exposure ages were calculated using the 'Macaulay' calibration dataset from the central Southern Alps established by Putnam et al. (2010b). This production rate was favoured for several reasons: (i) the close proximity of the calibration site to the Dart valley; (ii) the direct, independent radiocarbon ages for the Macaulay debris flow provide precise age constraint of the regional production rate; and (iii) the calibration site integrates cosmogenic ${ }^{10} \mathrm{Be}$ production over the Holocene, which is useful to the application of surface exposure dating at Dart Glacier. For comparison, exposure ages were also calculated using the global production rate calibrated by Borchers et al. (2016).

No corrections were made for boulder surface erosion in our surface exposure age calculations. This is justified as precise bedrock erosion rates are poorly constrained in New Zealand (Portenga \& Bierman, 2011). Furthermore, in the extreme case that the erosion rate is $5 \mathrm{~mm} / \mathrm{kyr}$ (equivalent to $0.0005 \mathrm{~cm} / \mathrm{yr}$ ) (Portenga \& Bierman, 2011) the calculated exposure ages increase by 5-9\%, with the influence of erosion being more significant for moraine boulders than have been exposed for longer durations. However, such an increase in surface exposure ages does not have a significant impact on the broad conclusions drawn in this study. During field work we also targeted quartz veins that were elevated above the rock surface, indicating that the sampled surfaces have be subject to minimal erosion since exposure.

\section{3 ${ }^{10}$ Be sensitivity experiment}

Based on the previous attribution of the age 'AD1850' to the prominent moraines (U8 and L8) at Dart Glacier, I anticipated that the samples would contain low ${ }^{10} \mathrm{Be}$ concentrations. As discussed in Section 2.3.8, low ${ }^{10} \mathrm{Be}$ concentration measurements require the following: (i) ${ }^{10} \mathrm{Be}$ concentrations need to be detectable above background levels by the AMS and (ii) process blanks are sufficiently low to minimise background ${ }^{10} \mathrm{Be}$.

In order to measure samples with exposure ages on centennial timescales, a low AMS detection limit such as that at LLNL was required as well as large sample 
masses ( $60-80 \mathrm{~g})$ with high purity. To better understand potential contamination sources in the VUW Cosmogenic Laboratory, a ${ }^{10} \mathrm{Be}$ sensitivity experiment was designed with the ultimate aim of enabling future reduction or elimination of these sources of contamination. The experiment was conducted through the preparation and analysis of a systematic series of partial-blanks and comprises three main experiment components that are discussed below.

\subsubsection{Airborne contamination}

Background levels of airborne ${ }^{10} \mathrm{Be}$ in both the laboratory and fume hood bench spaces were measured. Airborne contamination was assessed using two controlled beaker experiments; one in the HF dissolution fume hood and the other in the bench space used for general laboratory work. Each $350 \mathrm{ml}$ Savillex beaker was spiked with $\sim 0.89 \mu \mathrm{g}$ of ${ }^{9} \mathrm{Be}$ carrier mixed with $100 \mathrm{ml}$ of milliQ and left open on the respective bench spaces for seven days. During this week use of these spaces was not restricted and lab-users were asked to log their lab activity during the experiment (Appendix 1). Note that the beakers used in this experiment were not from the 'new' labware set (see Section 3.3.3). After seven days, the 'contaminated' solution in the beakers was evaporated on a hotplate overnight. As for all experimental samples, Be was precipitated, calcined, and packed into targets using standard procedures described in Section 3.2.2.2 (steps 22 to 26 in Figure 3.2).

\subsubsection{Contamination from reagents and the ${ }^{9} \mathrm{Be}$ carrier}

Samples are exposed to a number of reagents during routine Be extraction (Section 3.2.2.2), each of which may contribute unwanted ${ }^{10} \mathrm{Be}$ to the sample. To quantify these potential contamination sources, I tested: hydrofluoric acid (HF), hydrochloric acid $(\mathrm{HCl})$, nitric acid $\left(\mathrm{HNO}_{3}\right)$, and oxalic acid (grades specified in Table 3.2). Savillex beakers of $1 \mathrm{~L}$ volume from the 'new' labware (see Section 3.3.3) were used for testing the reagents. To measure the ${ }^{10} \mathrm{Be}$ in concentrated $\mathrm{HF}(28 \mathrm{M}), \mathrm{HCl}(12 \mathrm{M})$ and $\mathrm{HNO}_{3}$ (16M), $1 \mathrm{~L}$ of each acid mixed with $\sim 0.89 \mu \mathrm{g}$ of ${ }^{9} \mathrm{Be}$ carrier was evaporated on a hotplate. Be was precipitated, calcined, and packed into targets using standard procedures described in Section 3.2.2.2. 
${ }^{10} \mathrm{Be}$ in oxalic acid was tested using a different method as oxalic acid returns to its solid oxalate state when evaporated. ${ }^{10} \mathrm{Be}$ was extracted from $500 \mathrm{ml}$ of $0.4 \mathrm{M}$ oxalic acid (spiked with $\sim 0.89 \mu \mathrm{g}$ of ${ }^{9} \mathrm{Be}$ carrier) using two $25 \mathrm{ml}$ Eichrom columns containing 20 $\mathrm{ml}$ of Biorad AG50-X8 200-400 mesh (cation) resin (see Section 3.2.2.2). Be was collected in two 'new' $350 \mathrm{ml}$ Savillex beakers. The solutions in each beaker were combined in a $1 \mathrm{~L}$ beaker. The solution was evaporated and processed as outlined for the other acids in this component of the ${ }^{10} \mathrm{Be}$ sensitivity experiment.

Samples are exposed to large quantities of HF during chemical processing, predominantly during quartz digestion. If HF contributes significant quantities of ${ }^{10} \mathrm{Be}$ to the samples, then it should scale with sample sizes. The experiment aimed to verify the linearity of this ${ }^{10} \mathrm{Be}$ measurement by simulating the amounts of HF used to digest different quartz masses. Generally, the HF volume required for digestion equates to four to five times the given quartz mass. For example, $80 \mathrm{~g}$ of quartz requires $320-400 \mathrm{ml}$ of $\mathrm{HF}$ (28M) for digestion. To simulate the quartz digestion process, different volumes $(0,100,200,400$ and $500 \mathrm{ml})$ of $\mathrm{HF}(28 \mathrm{M})$ were added in $100 \mathrm{ml}$ increments to five $350 \mathrm{ml}$ Savillex beakers that had been spiked with ${ }^{9} \mathrm{Be}$ carrier. The beakers used were from the 'new' labware set (see Section 3.3.3). Once the HF was completely evaporated (i.e. simulating digested quartz) the samples in the experiment were precipitated, calcined, and packed into targets using standard procedures. In addition to the acid reagents, I also tested the ${ }^{10} \mathrm{Be} /{ }^{9} \mathrm{Be}$ ratio of our ${ }^{9} \mathrm{Be}$ carrier by adding $\sim 0.89 \mu \mathrm{g}$ of carrier to a $15 \mathrm{ml}$ centrifuge tube, precipitating Be and packing targets for AMS analysis as per Section 3.2.2.2 (steps 22 to 26 in Figure 3.2). 
Table 3.2 Acid grades and concentrations used in the reagent contamination component of the ${ }^{10}$ Be sensitivity experiment.

\begin{tabular}{lll}
\hline Acid & Concentration & Grade \\
\hline $\mathrm{HF}$ & $28 \mathrm{M}$ & Analytical grade \\
$\mathrm{HCl}$ & $12 \mathrm{M}$ & Trace analysis grade \\
$\mathrm{HNO}_{3}$ & $16 \mathrm{M}$ & Trace metal grade \\
Oxalic acid & $0.4 \mathrm{M}$ & Reagent grade \\
\hline
\end{tabular}

\subsubsection{Labware contamination}

The potential for ${ }^{10} \mathrm{Be}$ contamination from the reusing of labware during the ${ }^{10} \mathrm{Be}$ extraction process was also tested. ${ }^{10} \mathrm{Be}$ introduced through the reusing of beakers in the VUW laboratory was assessed by comparing 'new' (unused) and 'used' labware. In the VUW laboratory, 'used' beakers are currently utilised for in situ applications where ${ }^{10} \mathrm{Be}$ concentrations are no greater than $10^{7}$ at $\mathrm{g}^{-1}$. Although the beakers are referred to as 'used', in our lab beakers are cleaned between samples using a four-day heated acid cleaning process (24 hrs each of $6 \mathrm{M} \mathrm{HCl}, 5 \mathrm{M} \mathrm{HNO}_{3}, 7 \mathrm{M} \mathrm{HF}$, and milliQ). ${ }^{10} \mathrm{Be}$ in the beakers was tested using two process blanks that were run alongside the first batch of Dart Glacier samples; a 'new' beaker blank and a 'used' beaker blank.

Similarly, the potential for ${ }^{10} \mathrm{Be}$ to be introduced to samples via 'used' $\mathrm{Fe}$ (anion) and $\mathrm{Be}$ (cation) columns was also tested. ${ }^{10}$ Be contamination in 'new' and 'used' columns was tested using the Fe and Be column procedures outlined in Section 3.2.2.2, with samples containing $10 \mathrm{ml}$ of $6 \mathrm{M} \mathrm{HCl}$ and $\sim 0.89 \mu \mathrm{g}$ of ${ }^{9} \mathrm{Be}$ carrier. To ensure that the 'used' Fe and Be columns represented the worst-case scenario for potential ${ }^{10} \mathrm{Be}$ contamination, a 250 kyr old sample from central Patagonia (sample ID: MI-T13, ${ }^{10} \mathrm{Be}$ concentration: $1.509 \times$ $10^{6}$ at $\mathrm{g}^{-1}$ ), supplied from a previous study by Hein et al. (2017), was processed in the columns prior to conducting the experiment.

To test the potential for cross-contamination between samples during the ${ }^{10} \mathrm{Be}$ extraction procedures, two process blanks, placed at the start and end of the third sample batch, were processed. The rationale for this test is that if there is cross-talk between samples, the blank processed at the beginning of the batch, would contain less ${ }^{10} \mathrm{Be}$ compared to the 
blank processed at the end of the batch that has been exposed to all reused labware (e.g. pipettes and target packing tools). 


\section{CHAPTER 4: RESULTS}

\subsection{Glacial geomorphology of the upper Dart valley}

The final geomorphological map for the upper Dart valley is displayed in Appendix 2 at 1:25,000 scale. The map legend includes all unique symbols, colours, and/or textures attributed to the different landform types identified in the Dart valley. Descriptions of the landform types mapped are summarised in Table 3.1 (see Section 3.1.1) and are referred to in the geomorphological interpretations. These interpretations are organised under two broad headings: upper study site geomorphology, and lower study site and Dart Hut site geomorphology.

\subsubsection{Upper study site geomorphology}

Directly outboard of the present-day ice surface, we identified bedrock that has previously been eroded by the glacier ('ice-sculpted bedrock' in Table 3.1). This area comprises multiple features that have glacially-polished and striated (oriented parallel to the current ice flow direction) upstream faces, and steep jagged downstream slopes. The bedrock surface contains irregular rises that are accentuated by weathering, striations, and stream incision. Sommerville et al. (1982) previously identified moraines U1 and U2 (Figure 2.17) within this bedrock region, however, patches of unconsolidated sediment in this region did not exhibit clear discrete ridges and therefore have not been classified as moraine ridges in this study. Much smoother ice-sculpted bedrock extends up the eastern valley wall towards the present-day ice cover (Figure 4.1 and Appendix 2).

Inboard of the ice-sculpted bedrock, we distinguished three well-defined moraine ridges (Table 3.1) on the eastern valley wall between the present-day ice surface and Cascade Saddle (Figure $4.1 \& 4.2$ ). The moraine ridges identified at the upper study site have distinctive crests and ice-contact slopes that descend towards the current ice surface. The three moraine ridges at the upper study site are surrounded by till (Table 3.1) that is more irregular and varied in shape compared to the morphology of the moraine ridges. The innermost moraine ridge is located $\sim 100 \mathrm{~m}$ above the present-day ice surface at $\sim 1370 \mathrm{~m}$ elevation above sea level (asl) (Figure 4.2). This feature was also identified by Sommerville et al. (1982), which they labelled 'U4' (Figure 2.17), and has a relatively diffuse crest comprising of till. The $\mathrm{U} 4$ feature is restricted to the northern section of the 
upper study site and is dissected by streams (Figure 4.2). Outboard and $\sim 40 \mathrm{~m}$ upslope of this feature is a lateral moraine previously labelled U5 (Figure 2.17; Sommerville et al., 1982). Although the feature comprises till, it does not fit our definition of a moraine ridge because its apex is a flat surface opposed to a well-defined crest. For this reason, the U5 feature has been delineated in Figures 4.1 and 4.2 by its ice-contact slope within the till that covers the valley wall at the upper study site. Outboard of this landform, approximately $\sim 140 \mathrm{~m}$ above the present-day ice surface at $\sim 1410 \mathrm{~m}$ asl, we identified the moraine ridge referred to as 'U6' by Sommerville et al. (1982). The moraine ridge has a sharp crest that extends slightly further down valley relative to the U4 moraine. No suitable boulders for cosmogenic ${ }^{10} \mathrm{Be}$ surface exposure dating (see Section 4.2) were identified on the crests of the lateral moraines described (U4 and U6).

We also recognised the outermost prominent moraine ridge that Sommerville et al. (1982) refer to as ' $U 8$ ', which is located at $\sim 1440 \mathrm{~m}$ asl, approximately $170 \mathrm{~m}$ above the present ice surface. This moraine is the most distinctive of the three moraine ridges in the upper study site with large boulders (length up to $6 \mathrm{~m}$, width up to $5 \mathrm{~m}$ ) well embedded in the crest (Figure 4.3A-B). Several of these boulders were sampled for cosmogenic ${ }^{10} \mathrm{Be}$ surface exposure dating (samples DU-28-01 to DU-28-06 in Section 4.2). The ice-contact slope descends into the valley transporting till downslope. The ice-distal side of the moraine ridge is steep and rises $\sim 1 \mathrm{~m}$ above the valley wall. This moraine ridge is the most continuous of the three moraine ridges in the upper study site, extending $\sim 1.2 \mathrm{~km}$ down valley to where it is dissected by a stream and large landslide deposit (Figure 4.1 \& 4.2; Appendix 2).

Sommerville et al. (1982) also identified three moraines (U9, U10 and U11) outboard of the described moraine sequence (Figure 2.17). In this study, we have reclassified these features as bedrock benches. In aerial photographs and on the ground these linear features have moraine-like morphologies. During field-mapping, we inspected the composition of these features where they have been incised by streams and found that these ridges comprise a bedrock core, with a soil mantle. The crests of these bedrock benches are mostly devoid of clasts, except for the occasional boulder in some locations. Given that the composition of these benches is bedrock, it is unclear whether these rare, isolated boulders observed were deposited by ice, or were derived from the fracturing of the underlying bedrock. Furthermore, the bedrock in this area dips approximately $42^{\circ}$ toward the north-west. The bedrock benches expressed at the surface are thus oriented along- 
strike, which consequently, is parallel to the direction of ice flow and lateral moraines below. The bedrock benches on eastern valley wall at the upper study site can be traced near-continuously across the drainage divide to the eastern slopes of Cascade Creek (Figure $4.1 \& 4.3 \mathrm{C}$ ). The near-vertical structure of their up-hill facing slopes has resulted in ponding behind several of these bench features. Vegetation and soil are well developed on these surfaces, suggesting that these slopes are not presently active and have not recently been exposed to glacial erosion. 


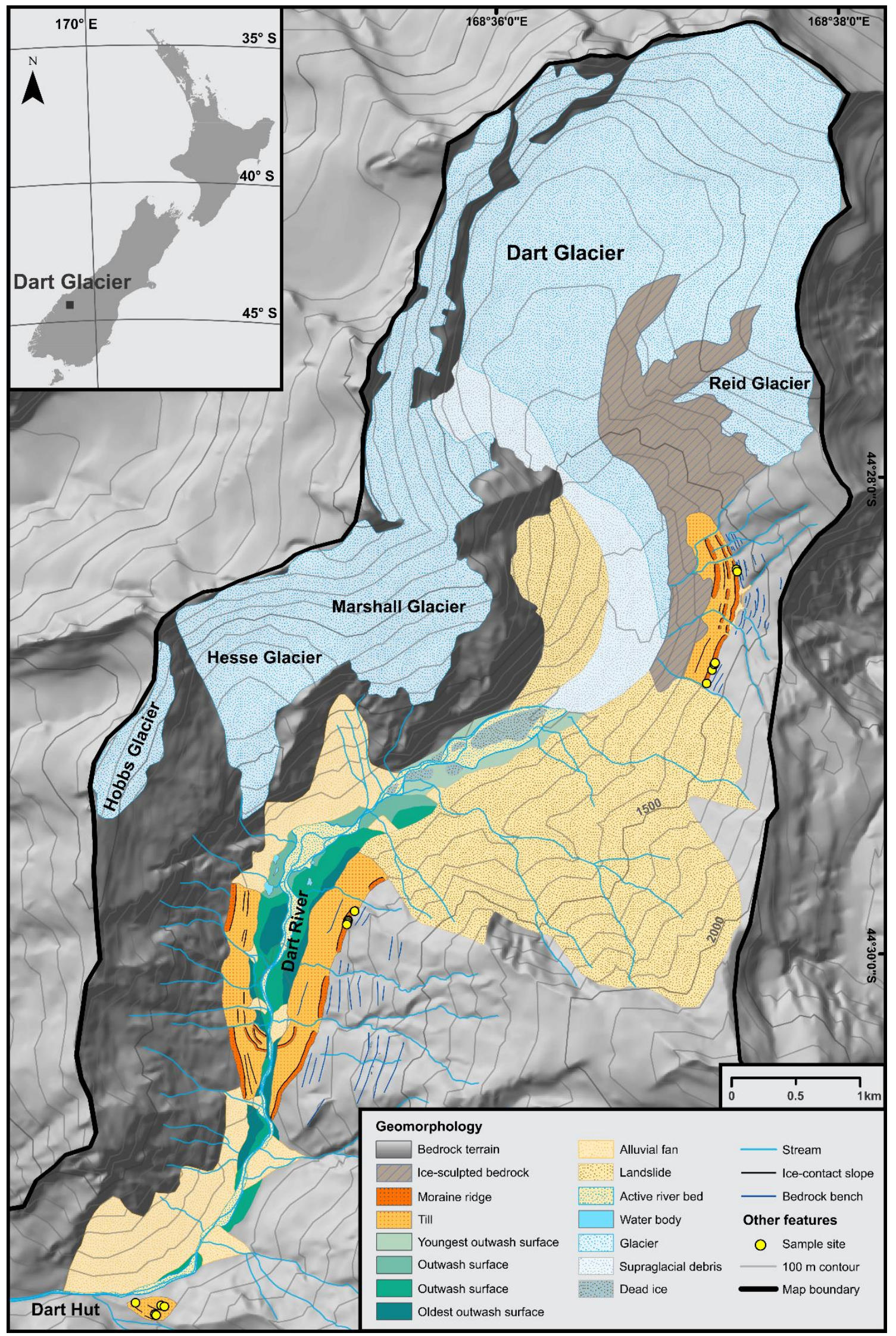

Figure 4.1 Geomorphological map of the upper Dart valley (1:25,000 scale). An enlarged version of this map is presented in Appendix 2. 


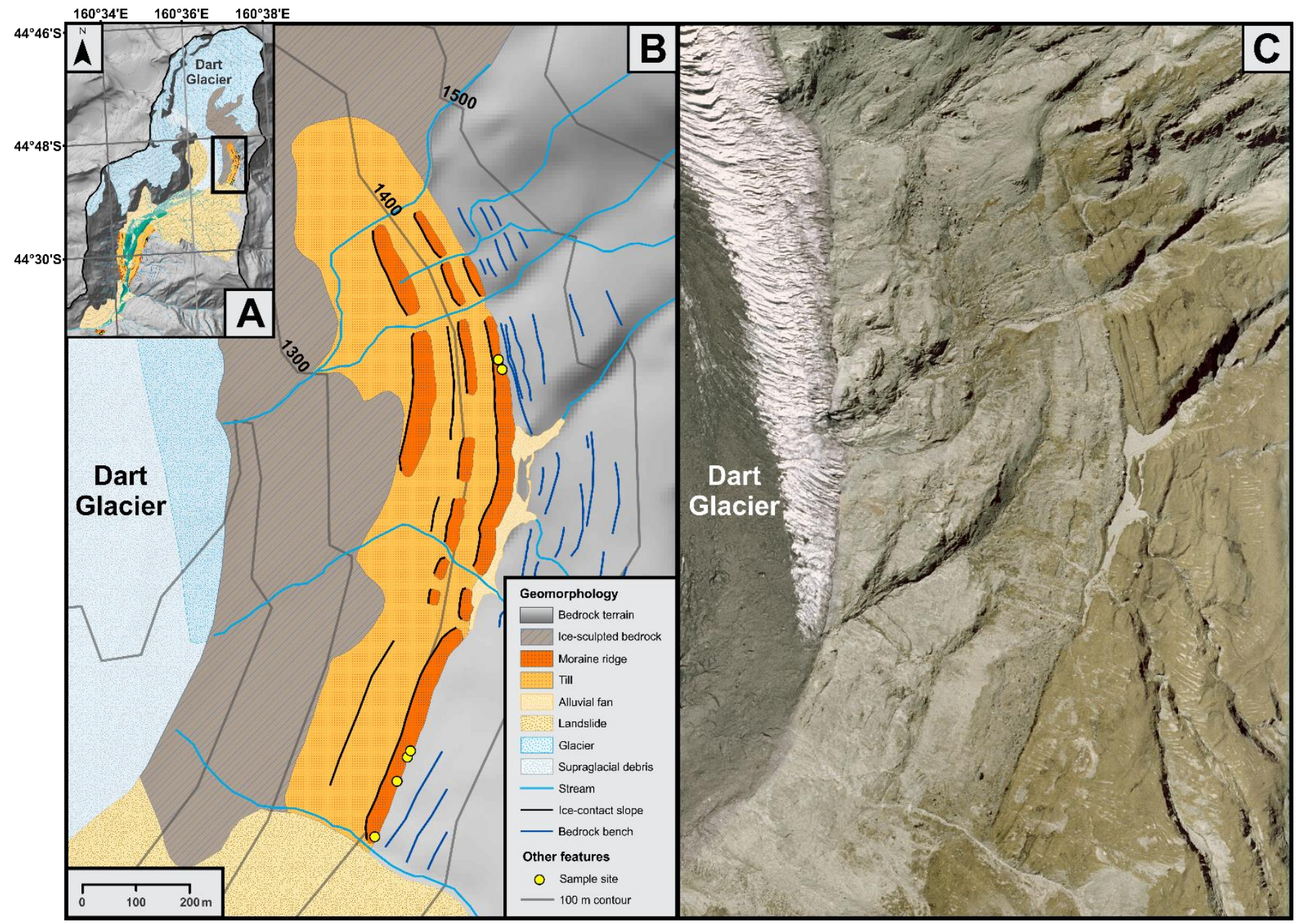

Figure 4.2 Upper study site geomorphology. (A) Full geomorphological map of the upper Dart valley denoting the location of the upper study site area. (B) Detailed view of the geomorphology mapped at the upper study site including contour line elevations $(m$ asl). (C) Aerial photograph of the same view shown in panel $(B)$ 


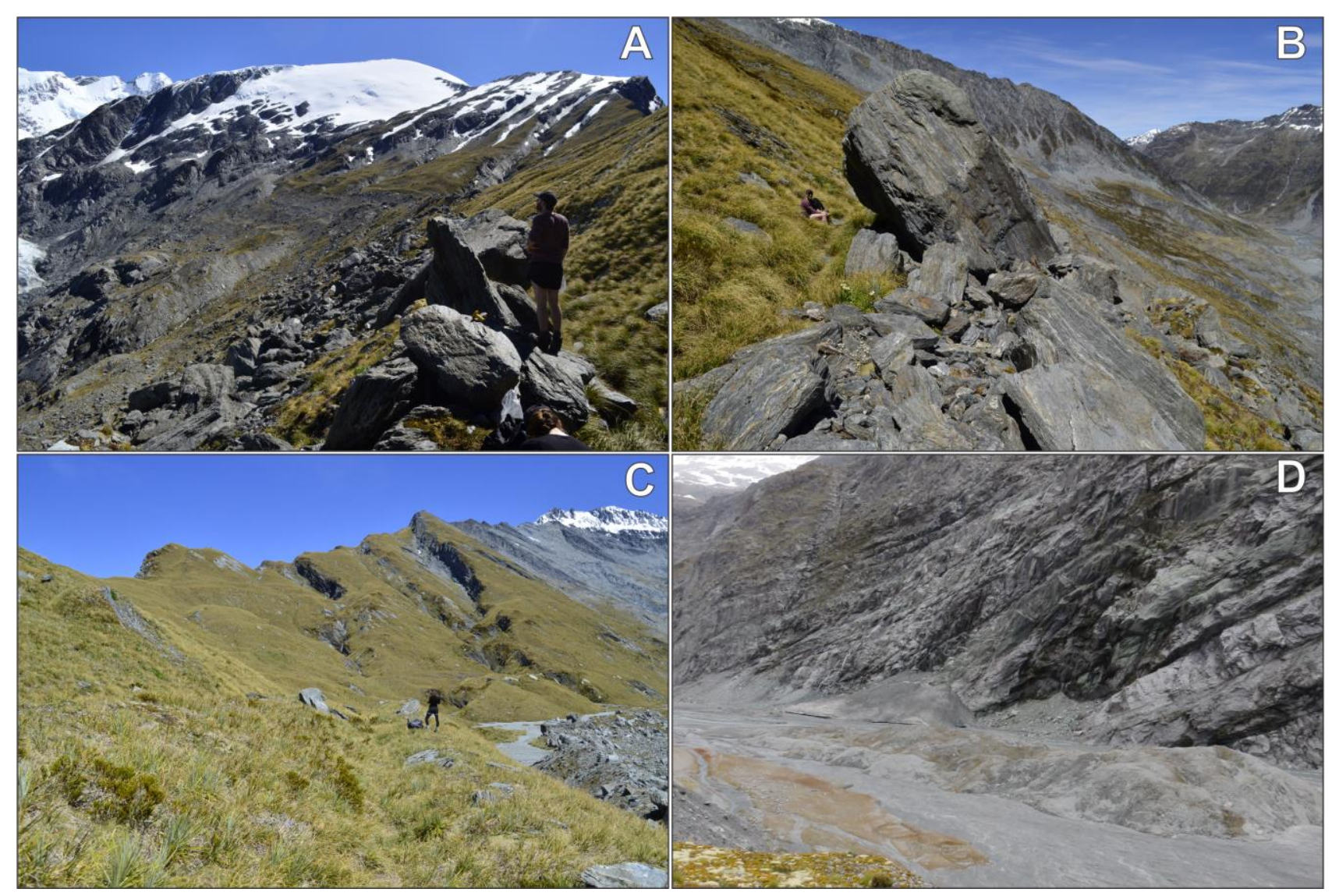

Figure 4.3 Images of geomorphic features at or near the upper study site. (A) View of moraines mapped at the upper study site looking up valley from the outermost (U8) moraine. (B) Outermost (U8) moraine continuing down valley; large boulder embedded in the crest; large landslide that bisects U8 and L8 moraines in the background (left). (C) Bedrock foliations continuing down valley (background, centre); vegetated bedrock bench (centre) contrasting unvegetated U8 moraine (left) comprising till. (D) Dead ice on the valley floor located near the present-day glacier terminus. 
No glacial features are preserved on the opposite western valley wall in the upper Dart valley due to the presence of a landslide deposit that is slumping onto the present-day glacier terminus (Figure $4.1 \&$ Appendix 2). Further down valley (middle valley region), the steep western wall is frequently covered in alluvial fan deposits associated with tributary streams entering the Dart valley, which may have affected the preservation of glacial landforms (Figure $4.1 \& 4.4$ ). Immediately down-valley from the present glacier terminus, there is a $\sim 3 \mathrm{~km}$ wide landslide deposit that completely dominates the middle region of the eastern valley wall (Figure $4.1 \&$ Figure 4.3B). The slope is active and shows evidence of slumping at the base that likely coincides with past glacier retreat and thinning.

Downstream of the present glacier there are no moraines on the valley floor to infer former ice marginal positions. However, 'dead ice' (Table 3.1) is found on the valley floor directly downstream of the present glacier terminus where glacier ice has been preserved as the former terminus was insulated from melting under a thick layer of debris (Figure 4.3D \& Figure 4.4). The valley floor is also covered in outwash surfaces that have formed as the floodplain of the current and previous glacial meltwater system in association with the deposition of glaciofluvial material (Figure 4.5D). These outwash surfaces are distinguished by their relative ages in the final geomorphological map (Figure $4.1 \&$ Appendix 2) where the glacier terminus position has varied over time. The relative ages of outwash surfaces were largely inferred from the former terminus positions captured in historical photographs and maps. Age distinctions are also based on vegetation development on the surfaces, inferred from field observations and aerial photographs.

\subsubsection{Lower study site and Dart Hut site geomorphology}

At the lower study site on the eastern valley wall, we identified similar glacial geomorphology to that described for the upper study site (Figure 4.4). Approximately $200 \mathrm{~m}$ above the valley floor at $\sim 1200 \mathrm{~m}$ asl, we recognised a similar outermost prominent moraine ridge (Figure $4.4 \&$ Figure 4.5A) which Sommerville et al. (1982) named the 'L8' moraine (Figure 2.17). The well-defined ridge can be traced for $\sim 2 \mathrm{~km}$ despite minor dissection by stream incision and is cut at the northern end by the same landslide deposit that cuts the southern section of the upper study site moraine sequence. Large boulders (length up to $3.4 \mathrm{~m}$, width up to $1.7 \mathrm{~m}$ ) were found embedded in the crest of the moraine, 
several of which were sampled for cosmogenic ${ }^{10} \mathrm{Be}$ surface exposure dating (samples DL-23-05 to DL-23-10 in Section 4.2). A similar feature is mirrored on the western valley wall (Figure 4.4 \& Figure 4.5C-D), although this moraine ridge is less well preserved, possibly as a result of fluvial erosion and steeper topography. These two prominent, outermost moraine ridges continue down valley gradually converging towards the valley floor, clearly delineating the former shape of Dart Glacier when the terminus was situated at approximately $\sim 1000 \mathrm{~m}$ asl and $\sim 4.3 \mathrm{~km}$ down valley from the present-day glacier terminus. Several smaller moraine ridges were identified inside the described former glacier terminus (Figure 4.4). These features are likely small recessional features (i.e. formed during standstills that occurred during glacier retreat) and may potentially correlate with the U4-U6 moraines described in Section 4.1.1.

The remaining area on the valley walls, inboard of the outermost moraine ridges, has been classified as till (Figure 4.4). Similar to that described at the upper study site, this area is covered in till that is irregular and varied in shape. On the eastern valley wall, there is evidence for outcropping bedrock inboard of the outer moraine ridge that was confirmed through ground-truthing (see Figure 4.5B). These features are classified as bedrock benches that are mantled and surrounded by till. On the western valley wall at the lower study site, we identified several ice-contact slopes inboard of the outermost moraine within the larger feature that comprises till. Note that these geomorphological interpretations made on the western valley wall are largely based on observations made in the field from the opposite valley wall (Figure 4.5C), and later field and aerial photographs.

Similar to the upper study site, outboard of the outer moraine ridge (L8) on the eastern valley wall there are several discontinuous bedrock benches. Sommerville et al. (1982) previously identified these features as moraines (L9, L10 and L11).

Further down valley, the walls (both east and west) are covered in heavily vegetated general bedrock terrain and alluvial fan deposits. At the bottom of the valley, within the vicinity of the Dart Hut, we identified several discontinuous linear features that had not been previously described. This feature has been classified as a series of ice-contact slopes within general moraine. The landform was distinguished from other landform types that consist of irregular, debris-covered surfaces such as landslides. The moraine remnants are perched up above the valley floor on the valley side in an area distant from 
any streams that could incise the landform and where there is no evidence for a landslide source from the upper surrounding topography. There is also no evidence of scarps either side of the feature that are generally more characteristic of landslides. The landform clearly comprises of unlithified sediment, rather than bedrock and is arranged in ridges oriented parallel to subparallel with the valley axis, which is consistent with other moraines identified further upstream in the Dart valley. Large boulders (length up to $7 \mathrm{~m}$, width up to $4 \mathrm{~m}$ ) embedded in the crests of these linear features were sampled for cosmogenic ${ }^{10} \mathrm{Be}$ surface exposure dating (samples DH-24-01 to DH-24-01) (see Section $4.2)$. 


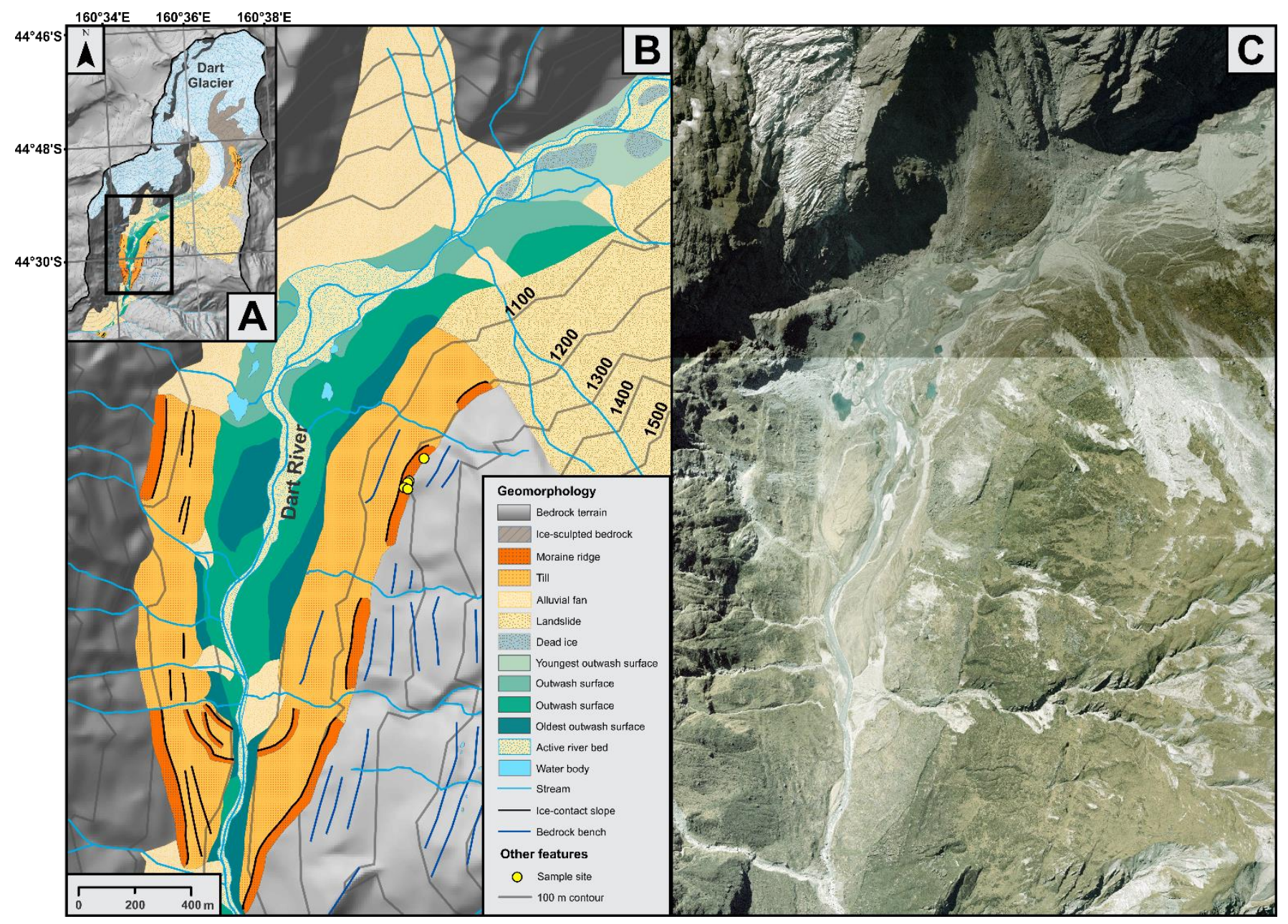

Figure 4.4 Lower study site geomorphology. (A) Full geomorphological map of the Dart valley showing the location of the lower study site area. $(B)$ Detailed view of the geomorphology mapped at the lower study site including contour line elevations $(m$ asl). (C) Aerial photograph of the same view shown in panel $(B)$ 


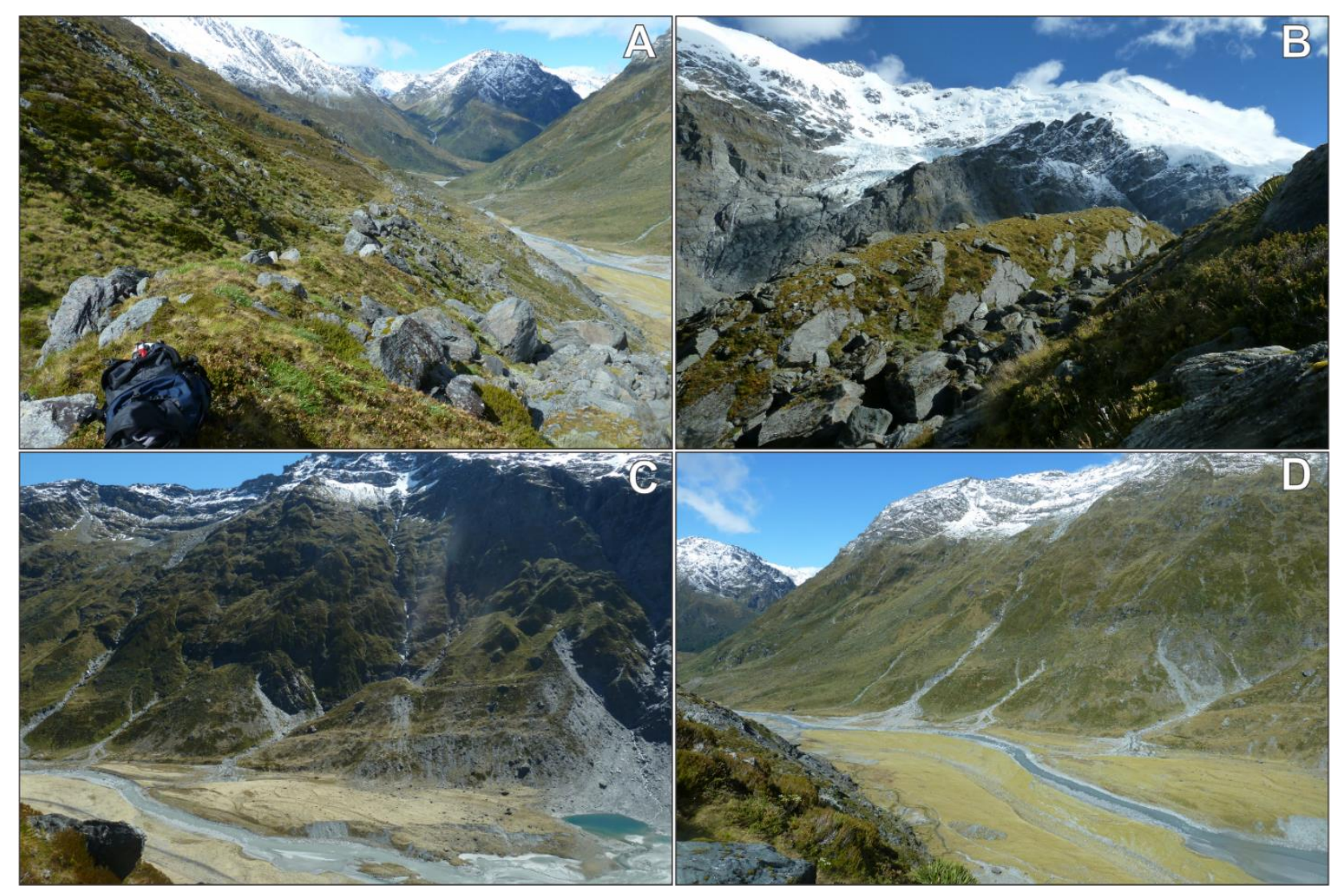

Figure 4.5 Images of geomorphic features at the lower study site. (A) Outermost (L8) moraine on the eastern valley wall; image looking down valley. (B) Outcropping bedrock bench mantled by soil and till; located inboard of the L8 moraine. (C) View of outermost moraine and ice-contact slopes mapped on the western valley wall at the lower study site; image taken from the opposite eastern valley wall. (D) Outwash plains on the valley floor; trimline on the western valley wall (shown in image) grading towards the valley floor - trimline correlates with outermost (L8) moraine on the eastern valley wall that was sampled for ${ }^{10}$ Be surface exposure dating. 


\section{2 ${ }^{10}$ Be surface exposure ages}

The results from cosmogenic ${ }^{10} \mathrm{Be}$ sample analysis and the associated process blank ${ }^{10} \mathrm{Be}$ data are presented in Tables 4.2 and 4.3, respectively. The process blanks indicate that the amount of background ${ }^{10} \mathrm{Be}$ introduced during sample preparation ranges between $1.157 \times 10^{5}$ and $1.533 \times 10^{5}{ }^{10} \mathrm{Be}$ atoms (see Table 4.2). The specific process blank number used for blank correction is reported for each sample in Table 4.1. Sample analytical uncertainties range from $\sim 2-4 \%$, whereas blank analytical uncertainties are around $\sim 6-7 \%$. ${ }^{10} \mathrm{Be}$ concentrations for each sample and process blank are reported with their $1-\sigma$ uncertainties (includes analytical, blank and carrier uncertainties).

From the upper study site, six exposure ages from the outermost (U8) moraine are plotted on a normal kernel density plot or 'camel plot' in Figure 4.8A. This plot shows that individual exposure ages range from $271 \pm 18$ yrs to $397 \pm 19$ yrs (also see Table $4.3 \&$ Figure 4.6). The ages are clustered around an exposure age of $327 \pm 48 \mathrm{yrs}$, based on the arithmetic mean and standard deviation of the six exposure ages. From the lower study site, five exposure ages from the outermost (L8) moraine, range from $267 \pm 24$ yrs to 372 \pm 21 yrs (Table $4.3 \&$ Figure 4.6). These five ages yield an arithmetic mean age of $315 \pm$ 45 yrs (Figure 4.8B). Because the mean ages of the outmost moraines at the upper and lower sites are within error of each other, I interpret this feature as one continuous feature that formed $321 \pm 44$ yrs ago $(n=11$; Figure $4.8 C \&$ Table 4.3$)$ and has since been bisected by the large landslide described in Section 4.1. The mean exposure age of the U8/L8 moraine equates to a calendar age of $\sim \mathrm{AD} 1696 \pm 44$. Five ages from the moraine remnants at the bottom of the valley at the Dart Hut site have boulder ages that range from $7466 \pm$ 208 to $8356 \pm 231$ (Table $4.3 \&$ Figure 4.6). This landform has a mean exposure age of $7846 \pm 336$ yrs (Figure 4.8D).

Comparison of exposure ages from the same sample (see Table 4.3) shows that ages agree within their $1 \sigma$ uncertainties, regardless of the calibration data or scaling scheme used. Therefore, the choice of scaling scheme or production rate (i.e. local vs. global) does not influence the conclusions that are drawn from the calculated ages. Hereafter, surface exposure ages are discussed using the 'Lm' scaling scheme and 'Macauley' production rate calibration (Putnam et al., 2010b). The Lm scaling scheme was chosen for two reasons: (i) because Dart Glacier is located at mid-latitude, a scaling scheme is required that accounts for variation in ${ }^{10} \mathrm{Be}$ production through time due to changes in the 
geomagnetic field (Gosse \& Phillips, 2001; Dunai \& Lifton, 2014) and (ii) to be consistent with other studies (e.g. Schaefer et al., 2009; Putnam et al., 2012) which previously presented ${ }^{10} \mathrm{Be}$ Holocene moraine chronologies from New Zealand using this scheme, thus making for easy direct comparison with our new data.

A chi-squared outlier detection routine in the version 3 exposure age calculator (Balco, 2017a, 2017b) was used to assess whether the spread in the ${ }^{10} \mathrm{Be}$ exposure ages for each moraine is consistent with the assumptions outlined in Section 3.2.1 and to test whether the spread in a single landform exposure age dataset can be explained by analytical uncertainties alone. If the dataset has a p-value greater than 0.05 , this means that the hypothesis that the ages in the dataset belong to a single landform cannot be excluded, therefore no outliers are removed, and the moraine age is reported as the error-weighted mean age (and standard error for age uncertainty) (Table 4.4). If the dataset p-value is greater than 0.01 but not 0.05 , the hypothesis that the ages in the dataset belong to a single landform can be excluded. In this case, the calculator removes or "prunes" sample exposure ages until all ages in the dataset belong to a single landform and the moraine age is reported as the "pruned" arithmetic mean age (and standard deviation for age uncertainty) (Table 4.4). The "pruned" arithmetic mean ages and error-weighted mean ages for the Dart valley moraines are very similar to the arithmetic mean ages (within their uncertainties) where no outliers have been removed from the datasets (Table $4.3 \&$ 4.4). Therefore, the process of removing outliers is unlikely to affect the conclusions made in this study. Hereafter to describe the exposure age of each moraine I take a conservative approach and refer to the arithmetic mean ages and their standard deviation values for the whole dataset where no outliers have been removed. 
Table $4.1^{10} \mathrm{Be} P \mathrm{~B}$ B ratios and ${ }^{10} \mathrm{Be}$ concentrations and all associated information with analysis and exposure age calculations for samples from the upper (U8), lower (L8) and Dart Hut study sites. Exposure ages were also calculated with a sample density of $2.7 \mathrm{~g} \mathrm{~cm}^{-3}$, erosion rate of $0 \mathrm{~cm}$ $y r^{-1}$, elevation flag 'std' and AMS standard 07KNSTD (Nishiizumi et al., 2007).

\begin{tabular}{|c|c|c|c|c|c|c|c|c|c|c|c|c|}
\hline $\begin{array}{l}\text { Sample } \\
\text { ID }\end{array}$ & $\begin{array}{l}\text { Latitude } \\
\text { (DD) }\end{array}$ & $\begin{array}{l}\text { Longitude } \\
\text { (DD) }\end{array}$ & $\begin{array}{c}\text { Elevation } \\
(\mathrm{m} \text { asl) }\end{array}$ & $\begin{array}{c}\text { Sample } \\
\text { thickness } \\
(\mathrm{cm})\end{array}$ & $\begin{array}{l}\text { Topographic } \\
\text { shielding } \\
\text { correction }\end{array}$ & $\begin{array}{l}\text { Quartz } \\
\text { mass (g) }\end{array}$ & $\begin{array}{c}{ }^{9} \text { Be mass } \\
(\mu \mathrm{g})\end{array}$ & $\begin{array}{c}{ }^{10} \mathrm{Be}^{9}{ }^{9} \mathrm{Be} \\
\left(10^{-14}\right)\end{array}$ & $\begin{array}{c}{ }^{10} \mathrm{Be} /{ }^{9} \mathrm{Be} \\
(1 \sigma)\left(10^{-14}\right)\end{array}$ & $\begin{array}{l}{ }^{10} \text { Be conc. } \\
\left(10^{3} \text { at } \mathrm{g}^{-1}\right)\end{array}$ & $\begin{array}{c}{ }^{10} \text { Be conc. } \\
(1 \sigma) \\
\left(10^{3} \text { at } \mathrm{g}^{-1}\right)\end{array}$ & $\begin{array}{c}\text { Blank } \\
\text { Correction }\end{array}$ \\
\hline \multicolumn{13}{|c|}{ U8 Moraine } \\
\hline DU-28-01 & -44.48045 & 168.61706 & 1431 & 3 & 0.9748 & 74.2451 & 272.884 & 2.467 & 0.077 & 4.501 & 0.246 & Blank 3 \\
\hline DU-28-02 & -44.47954 & 168.61768 & 1426 & 2 & 0.9789 & 73.1789 & 272.975 & 2.128 & 0.078 & 3.723 & 0.243 & Blank 3 \\
\hline DU-28-03 & -44.47915 & 168.61793 & 1427 & 2 & 0.9670 & 69.2093 & 271.999 & 2.452 & 0.092 & 4.767 & 0.293 & Blank 3 \\
\hline DU-28-04 & -44.47904 & 168.61802 & 1427 & 3 & 0.9764 & 77.2822 & 272.060 & 2.438 & 0.088 & 3.750 & 0.264 & Blank 1 \\
\hline DU-28-06 & -44.47259 & 168.62057 & 1447 & 3 & 0.9817 & 78.0012 & 272.853 & 2.987 & 0.084 & 5.498 & 0.258 & Blank 3 \\
\hline DU-28-07 & -44.47273 & 168.62064 & 1450 & 4 & 0.9794 & 71.7793 & 273.128 & 2.434 & 0.011 & 4.576 & 0.314 & Blank 3 \\
\hline \multicolumn{13}{|c|}{ L8 Moraine } \\
\hline DL-23-06 & -44.49569 & 168.58084 & 1215 & 2 & 0.9523 & 74.2860 & 273.097 & 1.884 & 0.081 & 3.071 & 0.243 & Blank 3 \\
\hline DL-23-07 & -44.49575 & 168.58081 & 1219 & 2 & 0.9510 & 71.6424 & 272.975 & 2.103 & 0.070 & 3.740 & 0.233 & Blank 3 \\
\hline DL-23-08 & -44.49580 & 168.58076 & 1213 & 1.5 & 0.9286 & 73.4435 & 272.975 & 2.287 & 0.073 & 4.106 & 0.236 & Blank 3 \\
\hline DL-23-09 & -44.49582 & 168.58081 & 1215 & 2.5 & 0.9624 & 75.0164 & 272.365 & 2.094 & 0.092 & 3.036 & 0.274 & Blank 1 \\
\hline DL-23-10 & -44.49489 & 168.58125 & 1213 & 2 & 0.9701 & 70.2485 & 272.884 & 2.109 & 0.076 & 3.828 & 0.250 & Blank 3 \\
\hline \multicolumn{13}{|c|}{ Dart Hut Moraines } \\
\hline DH-24-01 & -44.52188 & 168.56055 & 995 & 2 & 0.9513 & 61.7795 & 272.762 & 2.453 & 0.066 & 70.143 & 2.398 & Blank 5 \\
\hline DH-24-02 & -44.52197 & 168.56087 & 996 & 2.5 & 0.9619 & 73.8690 & 271.755 & 2.887 & 0.053 & 68.883 & 1.883 & Blank 1 \\
\hline DH-24-03 & -44.52247 & 168.55989 & 998 & 2.5 & 0.9647 & 66.0162 & 272.060 & 2.791 & 0.052 & 74.526 & 2.058 & Blank 1 \\
\hline DH-24-04 & -44.52254 & 168.55997 & 998 & 3 & 0.9589 & 74.7486 & 272.060 & 2.869 & 0.053 & 67.731 & 1.868 & Blank 1 \\
\hline DH-24-05 & -44.52160 & 168.55806 & 974 & 1.5 & 0.9581 & 61.6865 & 272.396 & 2.287 & 0.043 & 65.253 & 1.811 & Blank 5 \\
\hline
\end{tabular}


Table 4.2 Process blank ${ }^{10} \mathrm{Be} / \mathrm{Be}$ ratios and ${ }^{10} \mathrm{Be}$ atoms

\begin{tabular}{|c|c|c|c|c|c|}
\hline Sample ID & $\begin{array}{l}{ }^{9} \text { Be mass } \\
(\mu \mathrm{g})\end{array}$ & $\begin{array}{l}{ }^{10} \mathrm{Be} /{ }^{9} \mathrm{Be} \\
\left(10^{-15}\right)\end{array}$ & $\begin{array}{l}{ }^{10} \mathrm{Be} /{ }^{9} \mathrm{Be} \\
(1 \sigma)\left(10^{-15}\right)\end{array}$ & $\begin{array}{l}{ }^{10} \mathrm{Be} \\
\left(10^{5} \text { at }\right)\end{array}$ & $\begin{array}{l}{ }^{10} \mathrm{Be}(1 \sigma) \\
\left(10^{5} \text { at }\right)\end{array}$ \\
\hline \multicolumn{6}{|c|}{ Process Blanks } \\
\hline Blank 1 & 271.755 & 8.444 & 0.492 & 1.533 & 0.094 \\
\hline Blank 2 & 272.670 & 6.586 & 0.422 & 1.200 & 0.080 \\
\hline Blank 3 & 272.609 & 6.350 & 0.409 & 1.157 & 0.078 \\
\hline Blank 4 & 271.938 & 6.678 & 0.481 & 1.213 & 0.090 \\
\hline Blank 5 & 272.457 & 7.554 & 0.503 & 1.375 & 0.095 \\
\hline
\end{tabular}


Table 4.3 Cosmogenic ${ }^{10}$ Be exposure ages for the moraines in the Dart valley calculated using the version 3 exposure age calculator (Balco, 2017b). Ages are reported in 'yrs' before AD2017 with their internal uncertainty which accounts for all propagated uncertainties within the reported ${ }^{10}$ Be concentration $1 \sigma$ uncertainties (Table 4.1). Reported exposure ages were calculated using three scaling schemes: St (Stone, 2000), Lm (Balco et al., 2008), and LSD (Lifton et al., 2014) and using the 'Macaulay' production rate established by Putnam et al. (2010b). Ages calculated using a global production calibrated by Borchers et al. (2016) are also reported for comparison. Arithmetic mean ages for each of the three landforms are reported, as well as the "pruned" arithmetic means or error-weighted means calculated using a chi-squared outlier detection routine (Balco, 2017a, 2017b). Underlined ages indicate the outliers removed through the chi-squared test. *Note that the internal uncertainty is reported for the global production rate Lm ages; the external uncertainties that are not reported are much higher due to the large uncertainties in the global ${ }^{10} \mathrm{Be}$ production rate calibration dataset.

\begin{tabular}{|c|c|c|c|c|}
\hline Sample ID & St age (yrs) & Lm age (yrs) & $\begin{array}{c}\text { LSD age } \\
(\mathrm{yrs})\end{array}$ & $\begin{array}{c}\text { Lm age (yrs) } \\
\text { (global prod. } \\
\text { rate*) }\end{array}$ \\
\hline \multicolumn{5}{|l|}{ U8 Moraine } \\
\hline DU-28-01 & $362 \pm 20$ & $331 \pm 18$ & $312 \pm 17$ & $315 \pm 17$ \\
\hline DU-28-02 & $297 \pm 19$ & $271 \pm 18$ & $260 \pm 17$ & $258 \pm 17$ \\
\hline DU-28-03 & $384 \pm 24$ & $\underline{352} \pm 22$ & $330 \pm 20$ & $335 \pm 21$ \\
\hline DU-28-04 & $302 \pm 21$ & $276 \pm 19$ & $264 \pm 19$ & $263 \pm 18$ \\
\hline DU-28-06 & $434 \pm 20$ & $\underline{397 \pm 19}$ & $372 \pm 17$ & $378 \pm 18$ \\
\hline DU-28-07 & $364 \pm 25$ & $333 \pm 23$ & $313 \pm 21$ & $317 \pm 22$ \\
\hline Arith. Mean $(n=6)$ & & $327 \pm 48$ & & \\
\hline Pruned Arith. Mean $(n=4)$ & & $323 \pm 33$ & & \\
\hline \multicolumn{5}{|l|}{ L8 Moraine } \\
\hline DL-23-06 & $296 \pm 23$ & $271 \pm 21$ & $262 \pm 21$ & $258 \pm 20$ \\
\hline DL-23-07 & $360 \pm 22$ & $330 \pm 21$ & $314 \pm 20$ & $314 \pm 20$ \\
\hline DL-23-08 & $405 \pm 23$ & $372 \pm 21$ & $352 \pm 20$ & $354 \pm 20$ \\
\hline DL-23-09 & $291 \pm 26$ & $267 \pm 24$ & $258 \pm 23$ & $254 \pm 23$ \\
\hline DL-23-10 & $363 \pm 24$ & $333 \pm 22$ & $316 \pm 21$ & $317 \pm 21$ \\
\hline Arith. Mean $(n=5)$ & & $315 \pm 45$ & & \\
\hline Pruned Arith. Mean $(n=4)$ & & $300 \pm 36$ & & \\
\hline \multicolumn{5}{|l|}{ Dart Hut Moraines } \\
\hline DH-24-01 & $8073 \pm 277$ & $7959 \pm 273$ & $7854 \pm 269$ & $7594 \pm 260$ \\
\hline DH-24-02 & $7868 \pm 216$ & $7766 \pm 213$ & $7670 \pm 210$ & $7410 \pm 203$ \\
\hline DH-24-03 & $8475 \pm 235$ & $8356 \pm 231$ & $8224 \pm 228$ & $7957 \pm 220$ \\
\hline DH-24-04 & $7779 \pm 215$ & $7681 \pm 212$ & $7590 \pm 210$ & $7327 \pm 203$ \\
\hline DH-24-05 & $7552 \pm 210$ & $7466 \pm 208$ & $7402 \pm 206$ & $7107 \pm 198$ \\
\hline Arith. Mean (n=5) & & $7846 \pm 336$ & & \\
\hline Err. Weighted mean $(n=5)$ & & $7814 \pm 100$ & & \\
\hline
\end{tabular}




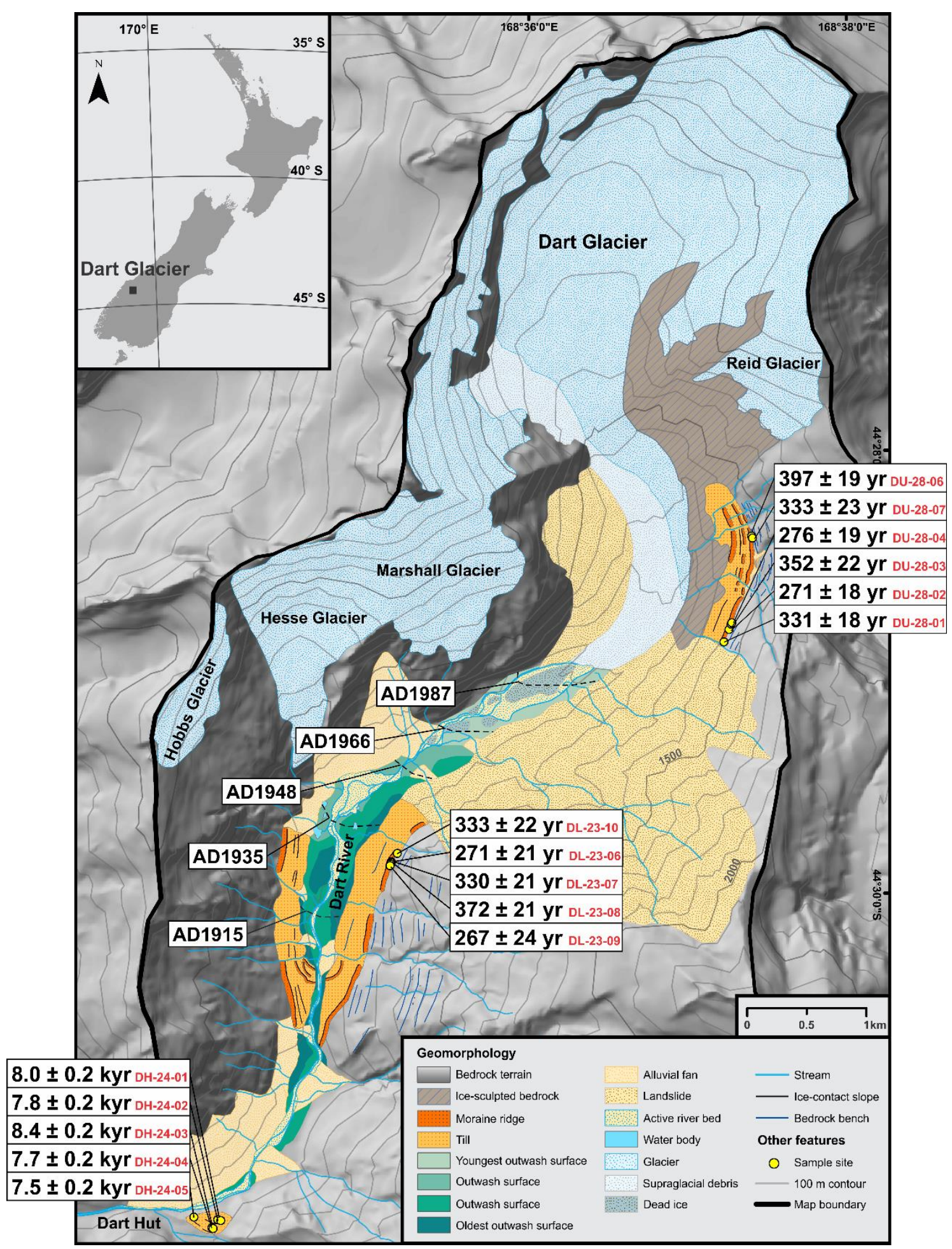

Figure 4.6 Sample exposure ages overlaid on the geomorphological map of the upper Dart valley. 


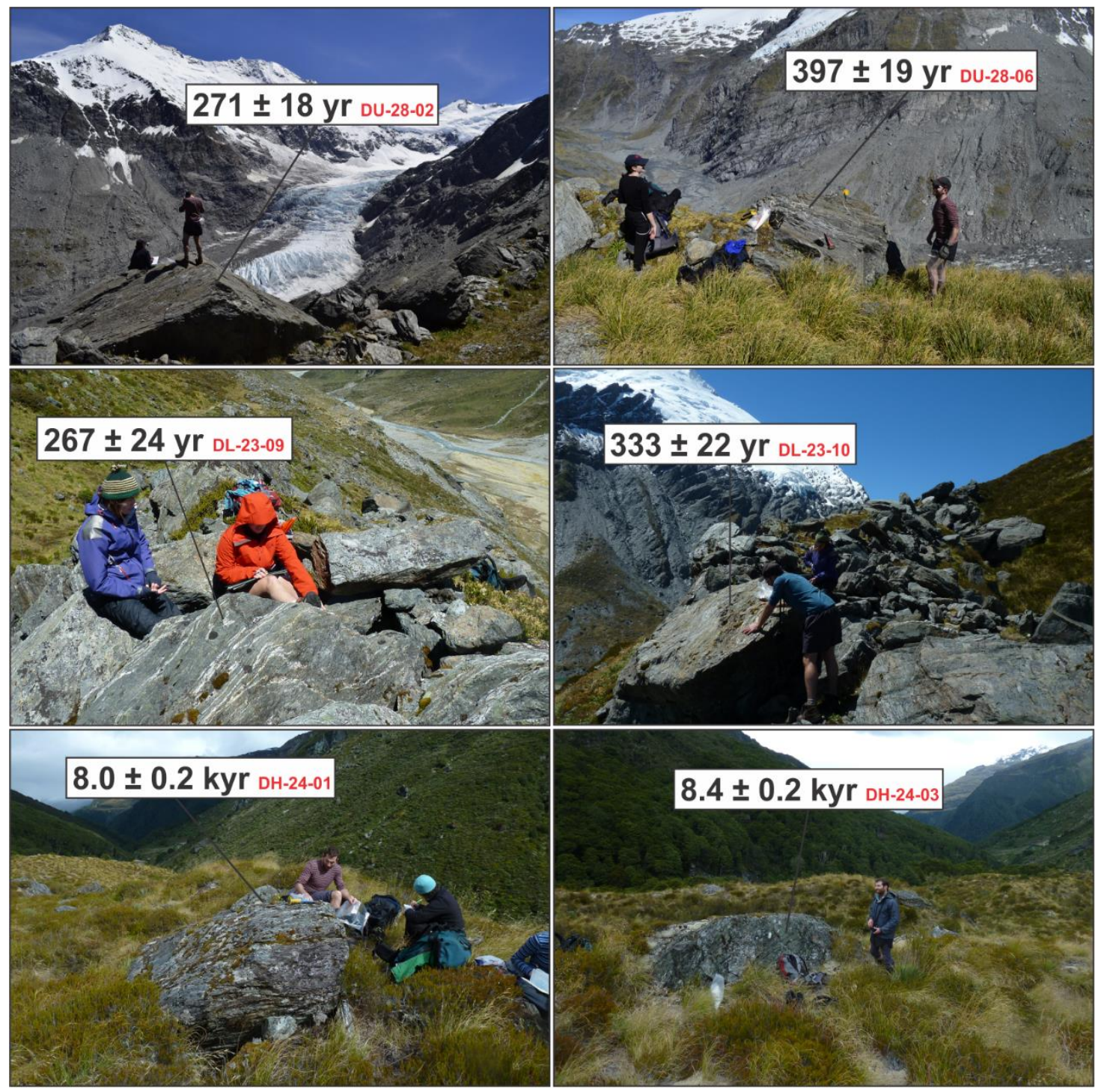

Figure 4.7 Images of sampled boulders and their associated exposure ages. 

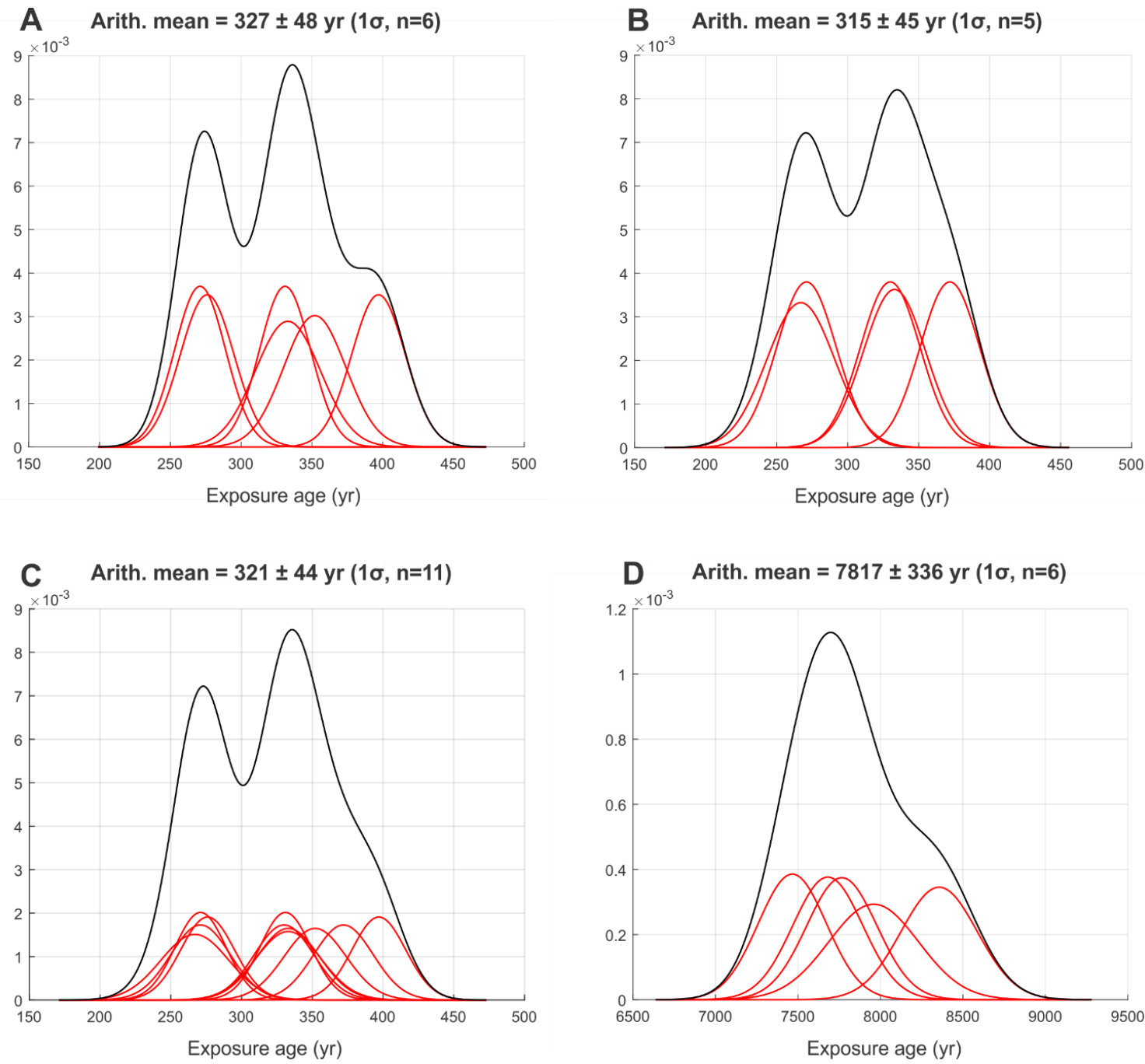

Figure 4.8 Camel plots and arithmetic mean ages $( \pm 1 \sigma)$ for individual moraines including: (A) U8 moraine, (B) L8 moraine, (C) combined U8 and L8 moraine (U8/L8), and $(D)$ Dart Hut moraines. The red lines represent the individual age probabilities for each sample. The black lines represent the cumulative age probabilities for the sampled moraines. 
Table 4.4 Summary statistics for each moraine age dataset from a chi-squared outlier detection routine used in the version 3 online exposure age

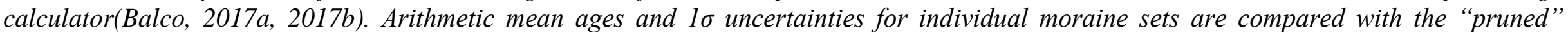
arithmetic mean and standard deviation (std) or error-weighted mean and standard error (SE). This comparison shows that the "unpruned" and "pruned" ages are within their uncertainties.

\begin{tabular}{|c|c|c|c|c|c|c|c|}
\hline Landform & $\begin{array}{c}\text { No. of } \\
\text { samples } \\
\text { in } \\
\text { unpruned } \\
\text { dataset } \\
\end{array}$ & $\begin{array}{c}\text { Arithmetic } \\
\text { mean }( \pm \\
1 \sigma)\end{array}$ & $\begin{array}{c}\text { No. of } \\
\text { samples } \\
\text { pruned }\end{array}$ & $\begin{array}{c}\text { No. of } \\
\text { samples } \\
\text { in pruned } \\
\text { dataset }\end{array}$ & $\begin{array}{l}\text { p-value for } \\
\text { pruned } \\
\text { dataset }\end{array}$ & $\begin{array}{l}\text { Method for reported } \\
\text { pruned age }\end{array}$ & $\begin{array}{c}\text { Pruned ages } \\
( \pm \\
\text { uncertainty })\end{array}$ \\
\hline U8 Moraine & 6 & $327 \pm 48$ & 2 & 4 & $0.05>p>0.01$ & Arithmetic mean ( \pm std) & $323 \pm 33$ \\
\hline L8 Moraine & 5 & $315 \pm 45$ & 1 & 4 & $0.05>p>0.01$ & Arithmetic mean $( \pm$ std $)$ & $300 \pm 36$ \\
\hline U8/L8 Moraine & 11 & $321 \pm 44$ & 3 & 8 & $0.05>p>0.01$ & Arithmetic mean $( \pm \mathrm{std})$ & $301 \pm 32$ \\
\hline Dart Hut Moraines & 5 & $7846 \pm 336$ & 0 & 5 & $\mathrm{p}>0.05$ & Error-weighted mean $( \pm \mathrm{SE})$ & $7814 \pm 100$ \\
\hline
\end{tabular}




\section{3 ${ }^{10}$ Be sensitivity experiment results}

Results from the ${ }^{10} \mathrm{Be}$ sensitivity experiment are reported in Table 4.5 , including ${ }^{10} \mathrm{Be} /{ }^{9} \mathrm{Be}$ ratios and ${ }^{10} \mathrm{Be}$ atoms for each of the experimental samples within the three experiment components: airborne contamination, acid and carrier contamination, and labware contamination. Refer to Section 3.3 for the methods used in each component of the experiment. The reported ${ }^{10} \mathrm{Be}$ atoms for each experimental sample have also been corrected for measured ${ }^{10} \mathrm{Be}$ in the ${ }^{9} \mathrm{Be}$ carrier (see Table 4.5). ${ }^{10} \mathrm{Be}$ measurements for each experimental sample have been scaled in order to estimate the relative contribution of each contamination source (e.g. acid, carrier, airborne or labware) to the total ${ }^{10} \mathrm{Be}$ atoms in an average full-process blank (Table 4.6). The total amount of ${ }^{10} \mathrm{Be}$ in an average full-process blank is estimated to be $\sim 1.32 \times 10^{5}$ atoms based on blanks 1,3 and 5 (Table 4.2).

\subsubsection{Airborne contamination results}

Results from the seven-day open beaker lab-exposure experiment which tested for airborne ${ }^{10} \mathrm{Be}$ contamination in the VUW Cosmogenic Laboratory (see Section 3.3.1) showed that there were indistinguishable amounts of airborne ${ }^{10} \mathrm{Be}$ contamination in the fume hood bench space compared to the bench space outside of the fume hood (within $1 \sigma$ uncertainties) (see Table 4.5). During ${ }^{10} \mathrm{Be}$ preparation procedures, real samples are mostly exposed to airborne contamination in the fume hood and, for this reason, the bench space ${ }^{10} \mathrm{Be}$ measurements are not included in our estimation of contamination sources in the full-process blanks (Table 4.6). The airborne contamination in the fume hood is estimated to be the third largest source $(\sim 14 \%)$ of the total ${ }^{10} \mathrm{Be}$ in an average full-process blank. However, the airborne contamination samples are testing the worst-case scenario where beakers were open in these spaces for seven days under non-restricted lab-user conditions. In reality, airborne contamination likely contributes less ${ }^{10} \mathrm{Be}$ to the fullprocess blanks than indicated in Tables 4.5 and 4.6.

\subsubsection{Reagent contamination results}

The contribution of ${ }^{10} \mathrm{Be}$ contamination in the acids and ${ }^{9} \mathrm{Be}$ carrier used in the $\mathrm{Be}$ extraction procedures in the VUW Cosmogenic Laboratory (Section 3.2.2.2 and steps 12 to 20 in Figure 3.2) was also measured. In order to achieve this, ${ }^{10} \mathrm{Be}$ was measured in 1 
L of $\mathrm{HF}, \mathrm{HNO}_{3}$ and $\mathrm{HCl}, 500 \mathrm{ml}$ of oxalic acid and $\sim 0.89 \mu \mathrm{g}$ of our in-house ${ }^{9} \mathrm{Be}$ solution (305 ppm) (see Section 3.3.2). Table 4.6 summarises the total volumes of each acid that a typical ( $75 \mathrm{~g})$ quartz sample in this study encounters during the stages of ${ }^{10} \mathrm{Be}$ extraction (i.e. digestion to calcining). These volumes are used to scale the ${ }^{10} \mathrm{Be}$ measurements for each acid (corrected for ${ }^{10} \mathrm{Be}$ atoms in ${ }^{9} \mathrm{Be}$ carrier) in order to assess their individual contributions to the total amount of ${ }^{10} \mathrm{Be}$ in an average full-process blank. This comparison suggests that $\mathrm{HF}$ is one of the largest contributors of ${ }^{10} \mathrm{Be}$ contamination, accounting for $\sim 24 \%$ of the total ${ }^{10} \mathrm{Be}$ in an average process blank (Table 4.6). Oxalic acid makes up $\sim 8 \%$ of the total ${ }^{10} \mathrm{Be}$ (Table 4.6). Although $\mathrm{HNO}_{3}$ and $\mathrm{HCl}$ exhibit similar, or higher, concentrations of ${ }^{10} \mathrm{Be}$ to $\mathrm{HF}$, their contribution to full-process blanks is negligible $(\sim 1 \%)$ as these acids are used in much smaller quantities (Table 4.6).

Because HF is the largest source of ${ }^{10} \mathrm{Be}$ contamination, I assessed whether ${ }^{10} \mathrm{Be}$ concentration increased linearly with HF volume (see Section 3.3.2). Results from the HF linearity test are presented in Figure 4.9. Increasing HF volumes shows a broadly linear trend with an $\mathrm{R}^{2}$ value of 0.6323 . The control sample (HF volume of $0 \mathrm{ml}$ ) appears to have more ${ }^{10} \mathrm{Be}$ atoms than samples with 100 and $200 \mathrm{ml}$ of $\mathrm{HF}$, however, these differences are within their $1 \sigma$ uncertainties.

\subsubsection{Labware contamination results}

Labware contamination was the third component of the ${ }^{10} \mathrm{Be}$ sensitivity experiment (see Section 3.3.3). Two full-process blanks (blanks 1 and 2) were used to assess whether the reusing of beakers introduces additional ${ }^{10} \mathrm{Be}$ contamination to full-process blanks in the VUW Cosmogenic Laboratory. Blank 1 was processed in a 'used' beaker, whereas blank 2 was processed in a 'new' beaker. This component of the experiment showed that used beakers contribute more ${ }^{10} \mathrm{Be}$ atoms than new beakers, suggesting that ${ }^{10} \mathrm{Be}$ may be passed on or inherited with the reusing of beakers (Table 4.5). All quartz samples in this study were processed in used beakers, which is estimated to contribute approximately $\sim 25 \%$ of the total ${ }^{10} \mathrm{Be}$ in an average process blank (Table 4.6). Thus, reused beakers are the largest contributor of ${ }^{10} \mathrm{Be}$ contamination. In contrast, the column test yielded high ${ }^{10} \mathrm{Be}$ totals from a brand-new column (resin and plastic), compared to a well-used column that has previously processed a $250 \mathrm{kyr}$ old sample (see Section 3.3.3) (Table 4.5). Based on just two columns, this result suggests that there is no legacy effect from re-using columns. 
Therefore, it is assumed that columns contribute negligible amounts of ${ }^{10} \mathrm{Be}$ to the total ${ }^{10} \mathrm{Be}$ in a process blank (Table 4.6). Two full-process blanks (blanks 4 and 5) were also used to test for cross-contamination between samples. Blank 4 (blank processed at the beginning of the batch) contained less ${ }^{10} \mathrm{Be}$ atoms than blank 5 (blank processed at the end of the batch) (Table 4.5) which suggests that cross-talk between samples contributes $\sim 12 \%$ of the ${ }^{10} \mathrm{Be}$ in an average process blank (Table 4.6). However, blanks 4 and 5 are nearly within their $1 \sigma$ uncertainties (Table 4.5 ), meaning that the true contribution of ${ }^{10} \mathrm{Be}$ from cross-talk may be lower. 
Table $4.5^{10} \mathrm{Be} P \mathrm{~B}$ e ratios and ${ }^{10} \mathrm{Be}$ contents for ${ }^{10} \mathrm{Be}$ sensitivity experiment. ${ }^{10} \mathrm{Be}$ contents that have been corrected for measured ${ }^{10} \mathrm{Be}$ in the ${ }^{9} \mathrm{Be}$ carrier.

\begin{tabular}{|c|c|c|c|c|c|c|c|c|}
\hline Sample ID & Source & $\begin{array}{c}\text { Volume } \\
\text { (ml) }\end{array}$ & $\begin{array}{c}{ }^{9} \text { Be mass } \\
(\mu \mathrm{g})\end{array}$ & $\begin{array}{c}{ }^{10} \mathrm{Be} /{ }^{9} \mathrm{Be} \\
\left(10^{-15}\right)\end{array}$ & $\begin{array}{c}{ }^{10} \mathrm{Be} /{ }^{9} \mathrm{Be}(1 \sigma) \\
\left(10^{-15}\right)\end{array}$ & $\begin{array}{c}{ }^{10} \mathrm{Be} \\
\left(10^{4} \text { at }\right)\end{array}$ & $\begin{array}{c}{ }^{10} \mathrm{Be}(1 \sigma) \\
\left(10^{4} \mathrm{at}\right)\end{array}$ & $\begin{array}{c}{ }^{10} \mathrm{Be} \\
\left(10^{4} \text { at }\right) \\
\text { corrected* }\end{array}$ \\
\hline \multicolumn{9}{|c|}{${ }^{10}$ Be sensitivity experiment } \\
\hline LD1 & $15 \mathrm{M} \mathrm{HNO}_{3}$ & 1000 & 273.646 & 7.887 & 0.509 & 14.423 & 0.971 & 13.907 \\
\hline LD2 & $28 \mathrm{M} \mathrm{HF}$ & 1000 & 273.158 & 4.903 & 0.459 & 8.949 & 0.855 & 8.433 \\
\hline LD3 & $12 \mathrm{M} \mathrm{HCl}$ & 1000 & 273.890 & 3.036 & 0.322 & 5.556 & 0.598 & 5.041 \\
\hline Ox3 & Oxalic acid & 500 & 274.866 & 3.710 & 0.436 & 6.814 & 0.811 & 6.299 \\
\hline LD4 & Airborne (bench) & N/A & 273.463 & 2.014 & 0.230 & 3.681 & 0.426 & 3.166 \\
\hline LD5 & Airborne (fume hood) & N/A & 273.463 & 2.239 & 0.225 & 4.091 & 0.418 & 3.576 \\
\hline LD6 & ${ }^{9} \mathrm{Be}$ carrier & N/A & 273.006 & 0.282 & 0.085 & 0.515 & 0.156 & 0 \\
\hline LD7 & $28 \mathrm{M} \mathrm{HF}$ & 0 & 272.579 & 3.543 & 0.483 & 6.454 & 0.889 & 5.938 \\
\hline LD8 & $28 \mathrm{M} \mathrm{HF}$ & 100 & 272.609 & 2.928 & 0.367 & 5.334 & 0.677 & 4.819 \\
\hline LD9 & $28 \mathrm{M} \mathrm{HF}$ & 200 & 273.036 & 3.065 & 0.453 & 5.591 & 0.833 & 5.076 \\
\hline LD10 & $28 \mathrm{M} \mathrm{HF}$ & 300 & 273.341 & 4.007 & 0.445 & 7.320 & 0.825 & 6.804 \\
\hline LD11 & $28 \mathrm{M} \mathrm{HF}$ & 400 & 273.341 & 4.406 & 0.483 & 8.048 & 0.896 & 7.533 \\
\hline LD12 & $28 \mathrm{M} \mathrm{HF}$ & 500 & 273.311 & 4.379 & 0.464 & 7.998 & 0.862 & 7.482 \\
\hline C1-New & New columns & N/A & 272.457 & 1.356 & 0.236 & 2.469 & 0.433 & 1.954 \\
\hline C2-Old & Old columns & N/A & 271.847 & 0.791 & 0.171 & 1.438 & 0.312 & 0.922 \\
\hline
\end{tabular}


Table 4.6 Percentage contribution of sources of ${ }^{10}$ Be contamination to an average process blank which typically contains $1.32 \times 10^{5}$ atoms of ${ }^{10} \mathrm{Be} .{ }^{* 10} \mathrm{Be}$ measurements for each experimental sample (corrected for ${ }^{10} \mathrm{Be}$ atoms in ${ }^{9} \mathrm{Be}$ carrier) are multiplied by the scaling factor in order to scale $10 B$ e values to the amounts of acid and airborne contamination that the average process blank was exposed to. **Fe and Be columns (plastic and resin) contribute negligible amounts of ${ }^{10} \mathrm{Be}$ to the average process blank when old and new column samples are corrected for the ${ }^{10} \mathrm{Be}$ introduced via acids $\left(\mathrm{HNO}_{3}, \mathrm{HCl}\right.$ and oxalic acid) used in column experiment.

\begin{tabular}{|c|c|c|c|c|c|}
\hline Source of ${ }^{10} \mathrm{Be}$ contamination & $\begin{array}{l}\text { Scaled acid } \\
\text { volume }\end{array}$ & $\begin{array}{c}\text { Duration of } \\
\text { exposure to } \\
\text { airborne }{ }^{10} \mathrm{Be}\end{array}$ & $\begin{array}{l}\text { Scaling } \\
\text { factor* }\end{array}$ & $\begin{array}{c}\text { Scaled }{ }^{10} \mathrm{Be} \\
\left(10^{4} \text { at }\right)\end{array}$ & $\begin{array}{l}\% \text { of total }{ }^{10} \mathrm{Be} \\
\text { (at) in average } \\
\text { process blank }\end{array}$ \\
\hline $\mathrm{HNO}_{3}(15 \mathrm{M})$ & $5.5 \mathrm{ml}$ & N/A & 0.0055 & 0.076 & 1 \\
\hline $\mathrm{HF}(28 \mathrm{M})$ & $375 \mathrm{ml}$ & N/A & 0.375 & 3.163 & 24 \\
\hline $\mathrm{HCl}(12 \mathrm{M})$ & $8 \mathrm{ml}$ & N/A & 0.008 & 0.040 & 0 \\
\hline Oxalic acid $(0.4 \mathrm{M})$ & $80 \mathrm{ml}$ & N/A & 0.16 & 1.008 & 8 \\
\hline${ }^{9} \mathrm{Be}$ carrier & N/A & N/A & N/A & 0.515 & 4 \\
\hline Fume hood bench space & N/A & $\sim 3.5$ days & 0.5 & 1.788 & 14 \\
\hline Beakers (used minus new) & N/A & N/A & N/A & 3.333 & 25 \\
\hline Fe and Be columns & N/A & N/A & N/A & $0 * *$ & 0 \\
\hline Cross-talk (blank 5 minus blank 4) & N/A & N/A & N/A & 1.618 & 12 \\
\hline Other sources & N/A & N/A & N/A & 1.656 & 13 \\
\hline
\end{tabular}


Chapter 4: Results

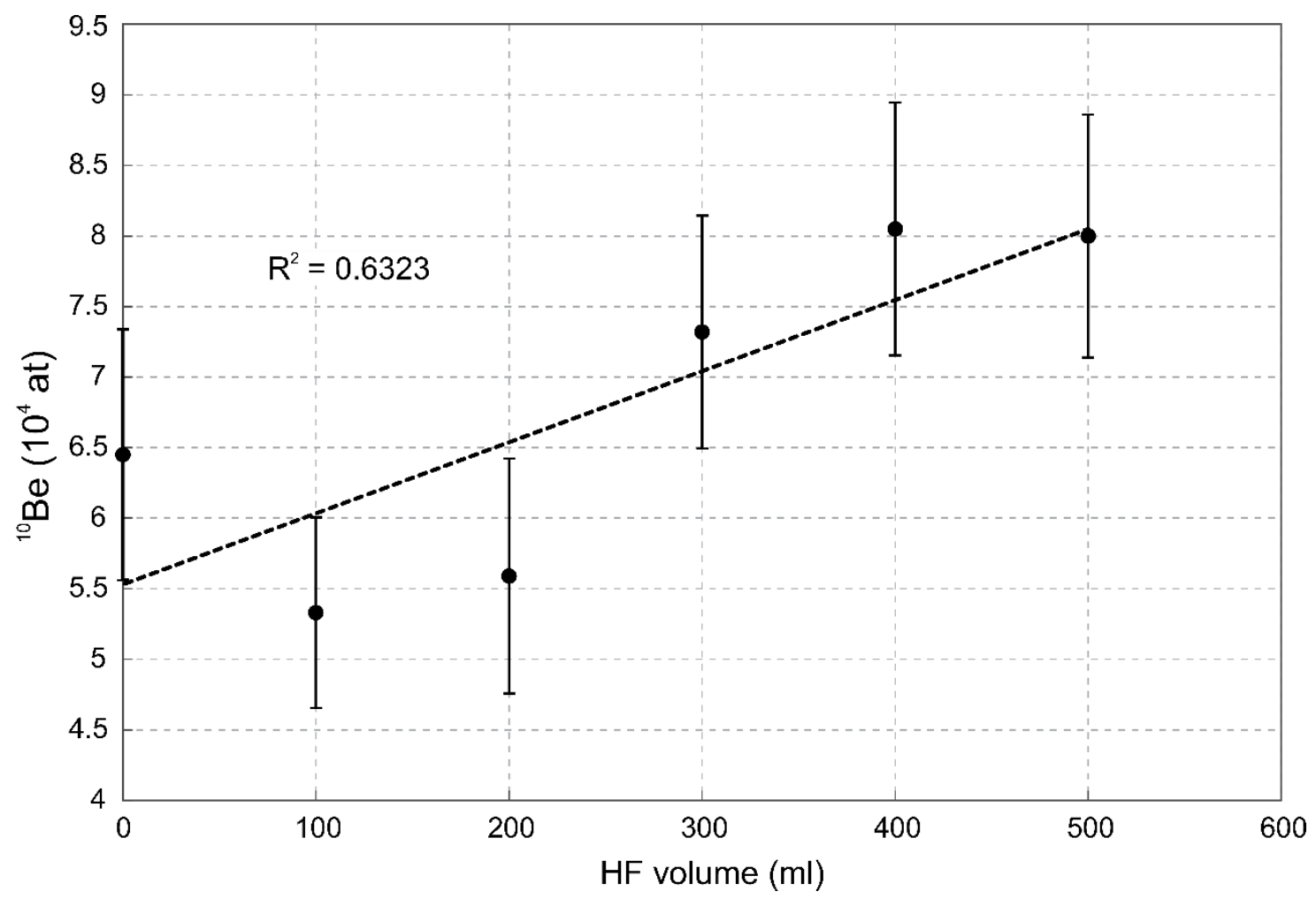

Figure 4.9 Results from the HF linearity test showing the relationship between ${ }^{10} \mathrm{Be}$ content and HF volume used. 


\section{CHAPTER 5: DISCUSSION}

This discussion is structured around my two central aims which are: i) to better constrain the magnitude, timing, and climatic drivers of Holocene glacier length changes in New Zealand; and ii) to facilitate routine application of low concentration cosmogenic surface exposure dating to near-historic landforms in the VUW Cosmogenic Laboratory.

Geomorphological mapping and cosmogenic ${ }^{10} \mathrm{Be}$ surface exposure dating of glacial landforms are combined in Section 5.1 to constrain the timing and magnitude of past glacier advances in the Dart valley. The ${ }^{10} \mathrm{Be}$ moraine record from Dart Glacier is then situated in the context of the Southern Alps to assess whether glacier length changes occurred simultaneously in adjacent glaciated valleys. Possible drivers of Holocene glacier length changes at Dart Glacier, and in the Southern Alps more generally, are hypothesised in Section 5.3 through the reconsideration of previously proposed drivers and comparison with other palaeoclimate proxy records. Section 5.4 addresses my second aim by considering the implications of the ${ }^{10} \mathrm{Be}$ sensitivity experiment for reducing process blank ratios in the VUW Cosmogenic Laboratory, which is required for future near-historic landform applications.

\subsection{Magnitude and timing of glacier length changes at Dart Glacier}

Geomorphological mapping of the glacial landforms in the Dart valley including moraine ridges, general moraine, and ice-contact slopes, reveals the extent of former glacier advances (Figures $4.1 \&$ Appendix 2) and allowed for suitable surfaces for ${ }^{10} \mathrm{Be}$ sampling to be identified (Figure 4.6). Through detailed mapping, we were also able to critically assess the geomorphological interpretations that were previously made by Sommerville et al. (1982). In this study, only three of the eleven features (U1-U11) identified at the upper site by Sommerville et al. (1982) have been classified as moraine ridges including U4, U6, and U8 (Figure 2.17). The remaining eight landforms have been reclassified as bedrock benches, ice-sculpted bedrock, or till (see Section 4.1). Similarly, at the lower study site, only one prominent lateral moraine ridge (L8 moraine) was recognised compared to the twelve features that were identified by Sommerville et al. (1982). However, near the valley floor, on both the eastern and western valley sides, several smaller recessional moraines inboard of the L8 moraine were identified (Figures 4.1 \& 4.4; Appendix 2). ${ }^{10} \mathrm{Be}$ surface exposure dating indicates that the U8 and L8 moraines 
were once one continuous feature that has been bisected by a landslide deposit since deposition, confirming the interpretation made by Sommerville et al. (1982) that these features were deposited during the same glacier advance event. We also found moraine remnants within the vicinity of the Dart Hut that had not been previously identified which delineate more extensive glacier advance in the Dart valley.

Cosmogenic ${ }^{10} \mathrm{Be}$ surface exposure dating constrains the timing of former glacier advance and the subsequent formation of the outermost lateral moraine (combined U8/L8 moraine) on the eastern valley side at $\sim 321 \pm 44(\mathrm{n}=11)$ yrs. The timing of the moraine formation near the Dart Hut site was also constrained at $\sim 7817 \pm 336$ yrs $(n=5)$. The mean moraine ages of $321 \pm 44$ and $7817 \pm 336$ yrs are based on sample populations that exhibit small amounts of scatter, particularly in the U8 and L8 sample datasets (see Figure 4.8 \& Table 4.4 in Section 4.2). The scatter observed in these datasets is likely caused by geological processes that led to incomplete or prior exposure (see Figure 2.8 in Section 2.3.6; Balco, 2011; Heyman et al., 2011; Ivy-Ochs \& Briner, 2014). Geomorphological mapping also provided key information about the post-depositional modification of glacial landforms that have occurred in the Dart valley such as fluvial activity and mass wasting (Figure $4.1 \&$ Appendix 2). These insights further allowed for ${ }^{10} \mathrm{Be}$ sampling of well-preserved moraines that are positioned distant from active geomorphic features. The boulders sampled for cosmogenic ${ }^{10} \mathrm{Be}$ surface exposure dating (see Figure 4.7) showed minimal evidence for post-depositional processes such as erosion, burial or exhumation which can cause incomplete exposure and younger than expected moraine ages (Figure 2.8 and Section 3.2.1). Furthermore, the degree to which post-depositional processes could have affected these surfaces is reduced by the short exposure duration of the boulder samples collected from the U8 and L8 moraines.

Boulder movement or rotation can cause incomplete exposure and geological scatter (Figure 2.8 and Section 2.2.7). McColl and Davies (2013) proposed that the area that we defined as till inboard of the outermost (U8) moraine on the eastern wall at the upper study site (Figure 4.1 \& Appendix 2) is moving due to deep-seated gravitational slope deformation (DSGSD). Upon ground truthing we found that the moraine ridges in this area were well-preserved, suggesting that the eastern valley wall is relatively stable compared to the Mueller Rockslide which McColl and Davies (2013) describe as being analogous to the movement of this slope (see Section 2.5.4). Furthermore, the agreement between the U8 and L8 moraine age datasets also suggests that this area on the eastern 
valley wall has not moved significantly due to DSGSD during the last $\sim 300$ years. Based on this assessment, it is unlikely that DSGSD has contributed to the scatter in the U8 moraine age dataset. The process origins of the bedrock benches identified at both the upper and lower sites are still unknown. These features may have formed due to differential erosion, or due to minor (m-scale) slope deformation via glacio-isostatic adjustment as the morphological features of some of the bedrock benches (e.g. the uphill facing scarp shown in Figure 4.5B in Section 4.1.2) are similar to the gravitational and postglacial rebound or reactivation features identified in the Swiss Alps described by Ustaszewski and Pfiffner (2008) and Ustaszewski et al. (2008). Regardless of the process origins of these features, the mechanism is unlikely to have caused significant boulder movement on the U8 or L8 moraines as slope deformation would be occurring over long (greater than multi-decadal) timescales. In alpine regions, snow cover and small amounts of weathering are likely to have affected these surfaces at some point since deposition, therefore these factors are more likely to have caused the minor scatter exhibited in the sample age datasets (Balco, 2011).

No striae were found on the sampled boulders; therefore, it is more uncertain whether these boulders contained inherited ${ }^{10} \mathrm{Be}$ from previous exposure (Figure 2.8 and Section 3.2.1). The sample DU-28-06 (age $397 \pm 18$ yrs) from the U8 moraine is older than the $1 \sigma$ range of the combined U8/L8 sample population mean $(321 \pm 44)$, which suggests that this boulder may contain small amounts of inherited ${ }^{10} \mathrm{Be}$ (corresponding to less than 100 years of previous exposure). Similar evidence for minor (multi-decadal) inheritance is also observed in the moraine datasets obtained from Mueller Glacier (Schaefer et al., 2009). Schaefer et al. (2009) attribute the small influence of inheritance to the exposure of supraglacial material to cosmic rays during transportation on the ice surface in the ablation zone. They also acknowledge that the small amount of inherited ${ }^{10} \mathrm{Be}$ may be a result of the reworking of moraine boulders that had previously been exposed to cosmic rays. The latter suggestion seems an unlikely reason for the one 'old' outlier in the U8 dataset due to the consistency between the other ages. The removal of outliers had little impact on the mean ages suggesting that any scatter in the U8 and L8 datasets does not have a significant influence on the conclusions drawn from these ages (see Table 4.4 and Section 4.2). Therefore, with the exception of a minor potential influence of inheritance on the sampled moraine boulders, the consistent boulder ages obtained in this study 
provide robust age constraints for the timing of moraine formation that coincided with Holocene glacier length changes in the Dart valley.

The mean age of $321 \pm 44$ yrs for the U8/L8 moraine is equivalent to the calendar age of $\sim$ AD1696 \pm 44 which differs from the $\sim$ AD1850 age attributed to the landform by Sommerville et al. (1982) using lichenometry, thus indicating that the lichenometry curve underestimated the ages of the glacial landforms in the Dart valley. Based on a historical photograph of Dart Glacier (see Figure 2.14) we know that the innermost moraine at the upper site (Figure 4.1 \& Appendix 2) was deposited in $\sim$ AD1914. The recessional moraine (U6) located inboard of the outermost moraine (U8) and outboard of the AD1914 moraine (U4) (Figures $2.17 \& 4.1$; Appendix 2) were not dated using surface exposure dating as there were no suitable boulders embedded in the crest of the moraine. The ${ }^{10} \mathrm{Be}$ age of $321 \pm 44$ yrs and historical age of AD1914 provide direct age constraints that I have used to recalibrate the lichenometry curve established by Burrows and Maunder (1975) and previously applied at Dart Glacier by Sommerville et al. (1982) (Figure 5.1). This recalibrated lichenometry curve equation (Figure 5.1) was used to calculate the age of the recessional U6 moraine, giving an age of $\sim \mathrm{AD} 1760$. 


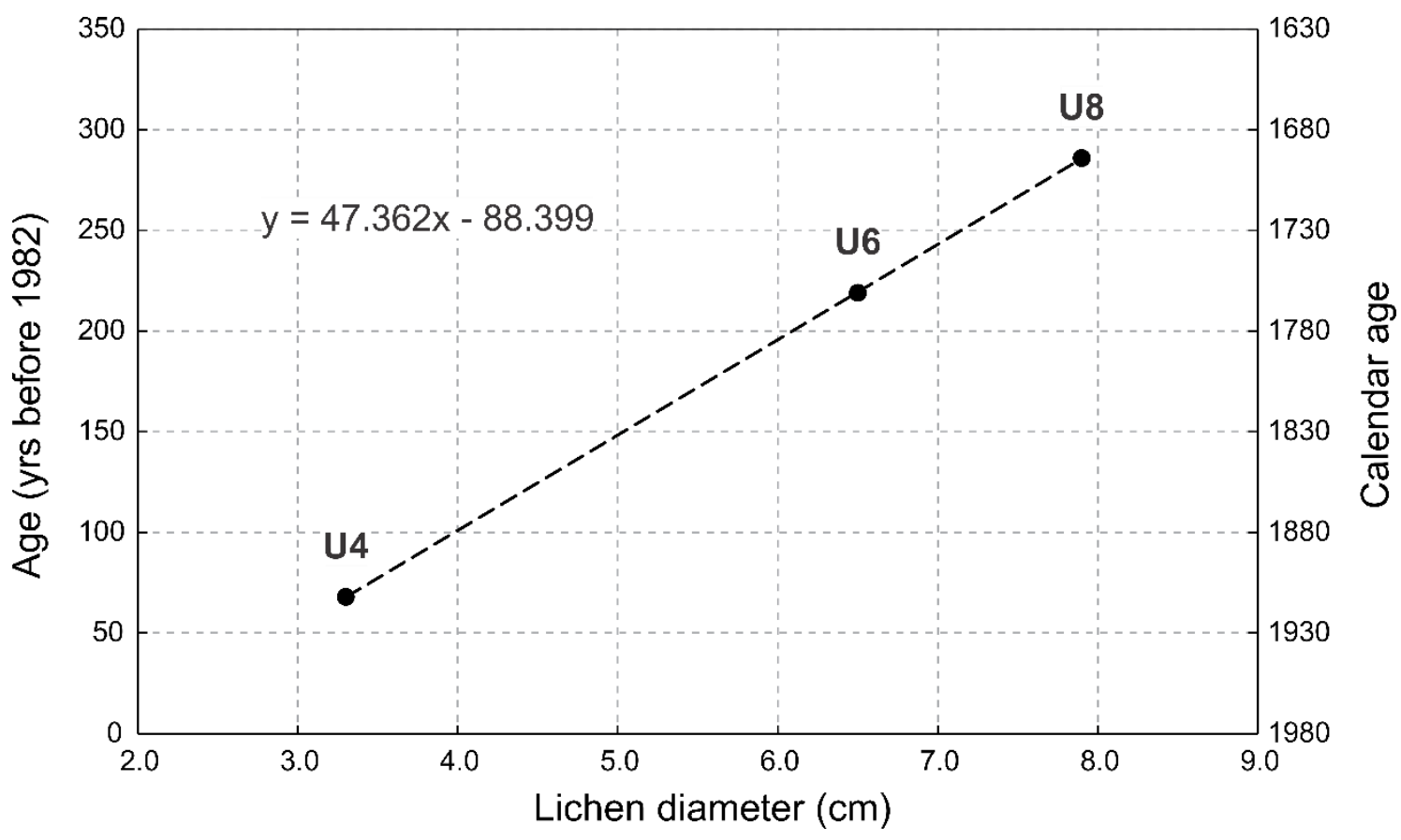

Figure 5.1 Recalibrated moraine ages using lichen diameters measured by Sommerville et al. (1982) at Dart Glacier, and moraine ages (yrs) based on the ${ }^{10}$ Be surface exposure age for the U8 moraine of 286 yrs (equivalent to $\sim$ AD1696) and the historical age for the U4 moraine of $\sim 68$ yrs ( AD1914). The equation derived from the recalibrated lichen growth curve has been used to calculate the U6 moraine age of 219 yrs ( AD1760). Note that the predicted ages used in the lichen growth curve are relative to AD1982 when the lichen thalli were measured by Sommerville et al. (1982).

The pre-historic ${ }^{10} \mathrm{Be}$ moraine chronology developed in this study shows that Dart Glacier has responded to at least two cooling and/or high precipitation events during the Holocene, resulting in periods of glacier advance and moraine formation. The early Holocene position is more extensive than the late Holocene advance position, thus suggesting that Dart Glacier has overall retreated since $7817 \pm 336$ yrs. The individual exposure ages of the outermost lateral moraines (U8 and L8) at the upper and lower sites indicate that glacier readvance, or alternatively standstill, took place during the late Holocene around $321 \pm 44 \mathrm{yrs}$ ago. It is possible that other smaller readvances occurred between the late and early Holocene events; however, if so, the records have been erased by the subsequent 321 yrs event. The revised moraine chronology combined with existing historical observations of Dart Glacier also suggest that minor readvances or standstills took place at $\sim$ AD1760 and $\sim$ AD1914. Historical observations of the Dart Glacier further capture the progressive $\sim 3.5 \mathrm{~km}$ retreat of the glacier up the valley to its present-day terminus since AD1914 (Figure 2.16; Bishop \& Forsyth, 1988; Ruddell, 1995). Overall, the combination of geomorphological mapping and ${ }^{10} \mathrm{Be}$ surface exposure dating of 
glacial landforms tightly constrains the timing and magnitude of Holocene glacier length changes in the Dart valley.

\subsection{Holocene glacier length changes in the Southern Alps}

In order to determine whether the described glacier length changes at Dart Glacier were driven by a regional climate signal, the ${ }^{10} \mathrm{Be}$ moraine ages must first be situated within the context of the other Holocene ${ }^{10} \mathrm{Be}$ moraine chronologies in the Southern Alps. Combining the moraine record from Dart Glacier with those records from the central Southern Alps (Schaefer et al., 2009; Putnam et al., 2012; Kaplan et al., 2013; Winkler, 2014; Koffman et al., 2017) provides a composite chronology of Southern Alps glacier fluctuations ( $\mathrm{n}=165{ }^{10} \mathrm{Be}$ ages) that can be used to assess whether glacier length changes in different mountain valley glaciers followed a broadly similar trend (Figure 5.2).

Comparison between early Holocene ${ }^{10} \mathrm{Be}$ moraine records suggests that moraine formation occurred coevally at Dart Glacier (7817 \pm 336; $n=5)$, Whale Stream in Ben Ohau Range (8060 \pm 100 n=4; Figure 2.9; Kaplan et al., 2013), and Cameron Glacier $(8190 \pm 230 ; n=5 ;$ Figure 2.9; Putnam et al., 2012). However, the timing of moraine formation at Dart Glacier also overlaps with other periods of moraine formation at Whale Stream (e.g. $8670 \pm 290 \mathrm{yrs}, \mathrm{n}=1 ; 7190 \pm 120 \mathrm{yrs}, \mathrm{n}=4$ ) when considering the $1 \sigma$ uncertainties of the ${ }^{10} \mathrm{Be}$ exposure ages (Kaplan et al., 2013). Moraines also formed in the central Southern Alps prior to 7.8 ka (Figure 5.2; Putnam et al., 2012; Kaplan et al., 2013; Koffman et al., 2017), yet no moraines deposited during this time were observed in the Dart valley. It is possible that moraines were deposited in the Dart valley prior to $7.8 \mathrm{ka}$, though they may have been destroyed by post-depositional processes (see Section 2.2.2) or obscured by the dense vegetation cover downstream of the Dart Hut site. 


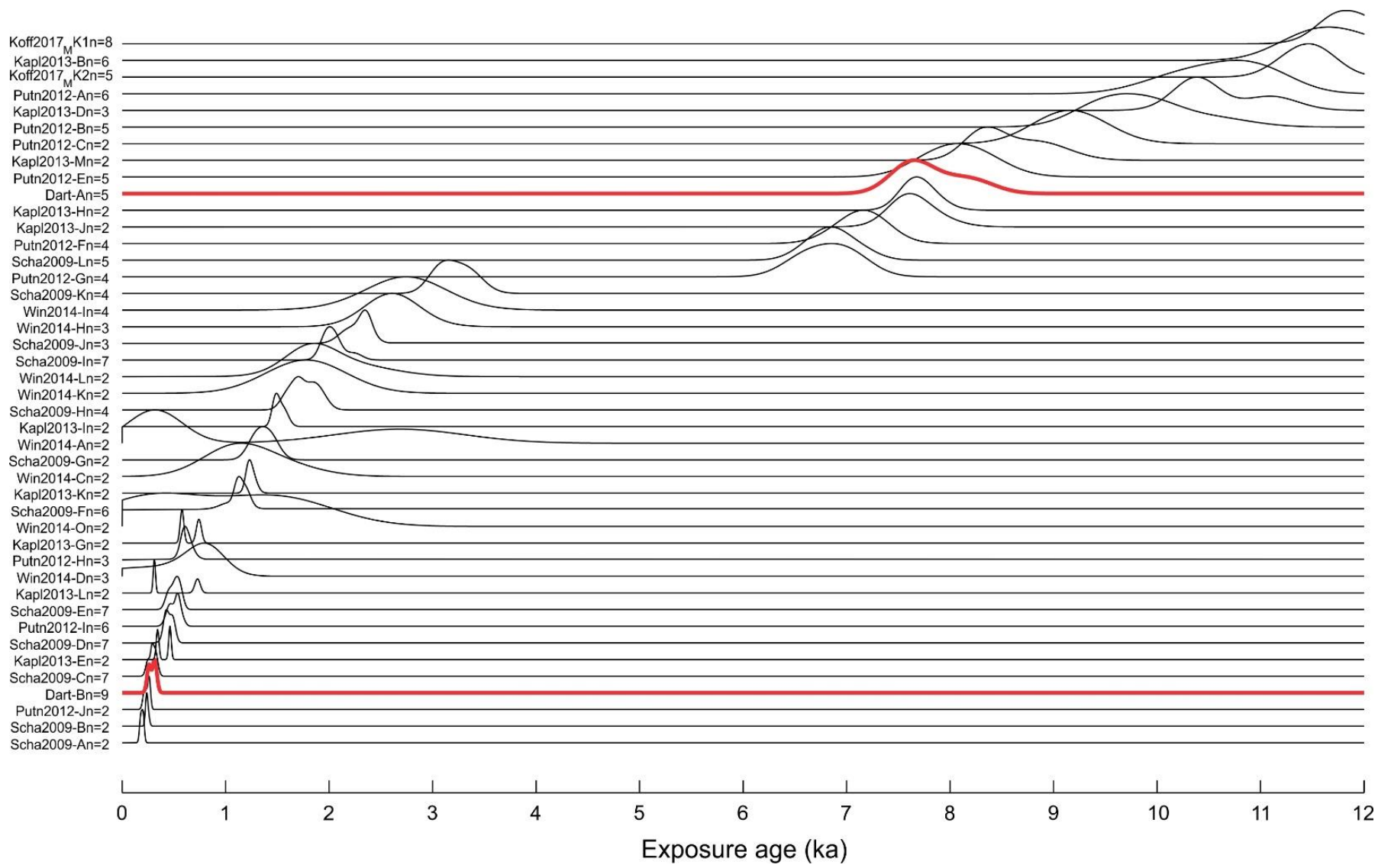

Figure 5.2 Compilation of Holocene moraine records in the Southern Alps that have been dated using cosmogenic ${ }^{10}$ Be surface exposure dating. The horizontal lines are stacked kernel density estimates (commonly known as camel plots) denoting individual moraine exposure ages from different mountain valleys in the Southern Alps. Moraine codes given on y-axis correspond to identifiers in the Alpine-ICE-D database of cosmogenic nuclide measurements from mountain glaciers (http://alpine.ice-d.org/). The two Dart moraines are highlighted (red lines) at approximately $7817 \pm 336$ yrs and $321 \pm 44$ yrs. All ${ }^{10}$ Be surface exposure ages were calculated using the same parameters as described in Section 3.2.3. Figure provided by $S$. Eaves, produced using code originally constructed by G. Balco. 
The composite moraine chronology for the Southern Alps (Figure 5.2) reveals that there is robust evidence from multiple glaciated valleys that suggests that a culmination of ice advance occurred in New Zealand between $\sim 8-7 \mathrm{ka}$. This culmination immediately precedes a hiatus in the moraine record between $\sim 7-3 \mathrm{ka}$. The absence of moraines could be an artefact of sampling; that is, these moraines exist but have not been identified in the field and therefore have not been sampled yet. Alternatively, this gap may indicate a prolonged period of glacier retreat, during which time glaciers were at least shorter than during the late Holocene (post $\sim 3 \mathrm{ka}$ ). More moraine records from New Zealand should help to elucidate the meaning of the absence of moraines in the composite moraine chronology for the Southern Alps (Figure 5.2). Furthermore, the sampling of bedrock surfaces inside the early Holocene (12-7 ka) ice limits for cosmogenic ${ }^{10} \mathrm{Be}$ surface exposure dating may also provide a way to test the possibility of past retreat during $\sim 7-3$ ka (Goehring et al., 2011; Ivy-Ochs \& Briner, 2014).

The $321 \pm 44$ yr old moraine at Dart Glacier formed at a similar time to other moraines in the Southern Alps. The closest moraine ages are reported at Mueller Glacier by Schaefer et al. (2009) at $400 \pm 70(n=9)$ and $270 \pm 50(n=10)$, although these moraines have been interpreted as a minor standstill or readvance that occurred after a larger advance denoted by the $570 \pm 70$ yrs $(n=12)$ moraine. Putnam et al. (2012) also suggest that the most significant glacier advance at Cameron Glacier during the last millennium occurred during the early $15^{\text {th }}$ century ( $\left.580 \pm 60 \mathrm{yrs} ; \mathrm{n}=9\right)$, which coincides with the onset of the Northern Hemisphere Little Ice Age (AD1450 to AD1850). These ages contrast with the findings from Dart Glacier which indicate that the most significant late Holocene glacier advance occurred during the late $17^{\text {th }}$ century. Moraine chronologies from Cameron and Mueller glaciers show that glacier advance during the early $15^{\text {th }}$ century ( $\sim 600$ yrs ago) was followed by glacier retreat and several standstills or minor readvances at approximately AD1605, AD1735, AD1770, AD1785, AD1850, and AD1930 (Schaefer et al., 2009; Putnam et al., 2012). Moraines formed during standstills or minor advances are also found at Dart Glacier inboard of the $321 \pm 44 \mathrm{yr}$ old moraine; recalculation of the lichenometry ages presented by Sommerville et al. (1982) (see Section 5.1) and historical records suggest that these occurred at $\sim$ AD1750 and $\sim$ AD1914.

Evidently, there is some overlap between the timing of moraine formation at Dart Glacier and other mountain glaciers in the central Southern Alps; particularly at Whale Stream, Cameron Glacier, and Mueller Glacier. However, there are slight discrepancies between 
the exact timing of moraine formation. These discrepancies likely reflect variations between individual glacier response times and length sensitivities which influence both moraine formation and preservation in different mountain valleys (see Section 2.2.2). As outlined in Section 2.5.2, the geometry and climatic setting of Dart Glacier promotes a relatively fast response time that causes the glacier to fluctuate regularly in response to both high-frequency (interannual to decadal) and low-frequency (multi-decadal to centennial) climate changes (see Section 2.2.1; Anderson et al., 2008; Purdie et al., 2014; Mackintosh et al., 2017a; Mackintosh et al., 2017b). Dart Glacier also has a large length sensitivity meaning moraine sequences are spread out across the Dart valley (Figure 4.1 \& Appendix 2). Several glaciers in other adjacent mountain valleys, such as Mueller Glacier, have comparatively slower response times and lower length sensitivities because of their gentle bed slopes, large debris covers, and geometries which consist of small confined accumulation zones and widening ablation zones (Schaefer et al., 2009; Reznichenko et al., 2016; Mackintosh et al., 2017b). While the Southern Alps glaciers were likely forced by the same climate signals in the past, several of these glaciers fluctuate less frequently in response to climate perturbations and therefore exhibit more compound moraine sequences (e.g. Mueller and Cameron glaciers) (Mackintosh et al., 2017b). In contrast, Dart Glacier likely experienced more frequent fluctuations compared to adjacent valley glaciers. Furthermore, in the Dart valley, meltwater systems, aggrading outwash surfaces, mass movement, and steep terrain have all likely had a significant impact on moraine preservation (see Section 2.2.2). These factors combined may have contributed to a more incomplete moraine record in the Dart valley compared to other mountain valleys in the Southern Alps.

Due to the discontinuous nature of moraines as palaeoclimate proxies, broad trends in past glacier length changes in the Southern Alps in response to climate perturbations are best assessed by comparing all ${ }^{10} \mathrm{Be}$ moraine records across different mountain valleys (Figure 5.2). In general, the composite glacier-climate record presented in Figure 5.2 suggests that the moraine record from the Dart Glacier fits well with the emerging pattern of Holocene glacier length changes in the Southern Alps, despite the discussed variations in the timing of moraine formation in different mountain valleys. 


\subsection{Drivers of the Holocene glacier length changes}

\subsubsection{Potential non-climatic drivers of glacier length changes}

The ablation zone of Dart Glacier is covered in supraglacial debris. Based on historical records (e.g. Figure 2.15), this sediment cover has been present for at least the past 100 years and is likely derived from the steep and active valley walls (Bishop \& Forsyth, 1988; Ruddell, 1995). Therefore, we must consider whether a large rockfall event during the Holocene has had the ability to cause non-climatically driven advances at Dart Glacier. Furthermore, the coincidence of the 300 yr old moraine at Dart Glacier with the last known rupture of the Alpine Fault ( $\mathrm{AD} 1717)$ warrants that the possibility of a rockfall driver of glacier advance event is addressed (Wells et al., 1999; Larsen et al., 2005).

There is limited observational evidence to suggest that a rock fall event could have any significant impact on glacier dynamics (Post, 1967; Schaefer et al., 2009). For example, Schaefer et al. (2009) notes that the $\sim$ AD1717 earthquake unlikely had a significant impact on moraine formation recorded at Mueller Glacier as a very large rock avalanche (12 million cubic meters) onto Tasman Glacier in 1991 had no discernible effect on the behaviour of the glacier (Kirkbride \& Warren, 1999). Like at Mueller Glacier, there is no direct evidence that large earthquakes on the Alpine Fault have caused widespread rock falls in the Dart Glacier catchment. Additionally, most of our understanding surrounding the feasibility of rock fall-induced glacier advance is largely conceptual and is inferred from sedimentology and geological interpretation (e.g. Tovar et al., 2008; Shulmeister et al., 2009; Reznichenko et al., 2010; Reznichenko et al., 2011; Reznichenko et al., 2012) as opposed to direct observation or physics-based reasoning. Vacco et al. (2010) used a numerical glacier model, with superimposed rock debris, to simulate the effect of rock fall derived supraglacial debris on glacier behaviour. Their results show that deposition of debris from a rock fall could induce glacier to advance, however, rockfall-induced glacier length changes would more likely be recorded as widespread hummocky, glacial stagnation features, as opposed to discrete moraine ridges. The U8 and L8 moraines at Dart Glacier were both well defined, single moraine ridges as opposed to being widespread and hummocky, suggesting that the $\sim$ AD1717 Alpine fault earthquake was unlikely responsible for the formation of these moraines. Based on the limited viable 
observational and physics-based evidence for rock fall-induced glacier advance, I argue that moraine formation in the Dart valley was associated with climatic drivers.

\subsubsection{The role of temperature and precipitation in glacier length changes}

In order to constrain the drivers of glacier length changes, it is important to determine whether these changes are primarily controlled by either temperature or precipitation. However, this type of attribution cannot be determined directly from a moraine chronology alone. The relative importance of both temperature and precipitation forcing in determining glacier length fluctuations in New Zealand has been extensively investigated (Oerlemans \& Fortuin, 1992; Oerlemans, 1997; Anderson \& Mackintosh, 2006; Anderson et al., 2010; Mackintosh et al., 2017a). There is strong evidence to suggest that temperature is the dominant driver of glacier length changes in the Southern Alps (Hessell, 1983; Salinger et al., 1983; Anderson \& Mackintosh, 2006; Anderson et al., 2010; Mackintosh et al., 2017a). For example, numerical modelling of Franz Josef Glacier by Anderson and Mackintosh (2006) suggests that a $\sim 1{ }^{\circ} \mathrm{C}$ cooling would be required to drive the glacier to its Little Ice Age extent; whereas an unlikely increase in precipitation $(\sim 37-57 \%)$ would have been required to generate the same advance. Furthermore, Mackintosh et al. (2017a) use a regional-scale energy balance model to show that reduced air temperatures, as a result of reduced SSTs in the Tasman Sea, were likely the dominant driver of the discrete periods of glacier advance observed in the Southern Alps between 1983 and 2005. Despite robust evidence for temperature as the dominant control on glacier length changes throughout the Southern Alps, similar diagnostic numerical modelling is required to determine whether this argument holds true for the glacier length changes recorded at Dart Glacier during the Holocene. Because Dart Glacier is similar to Franz Josef Glacier in terms of its geometry and climatic setting (see Section 2.5.2), it is likely that the glacier length changes recorded in the Dart valley were primarily controlled by temperature. 


\subsubsection{Drivers of early Holocene glacier advance and Holocene net glacier}

retreat

The composite moraine record presented in Figure 5.2, including the $\sim 7.8 \mathrm{ka}{ }^{10} \mathrm{Be}$ moraine age at Dart Glacier, shows that moraine formation took place between $\sim 12$ and $7 \mathrm{ka}$. Preservation of these features indicates that glaciers the Southern Alps were larger during the early Holocene than at any other time in the Holocene epoch (Figure 5.2). The early Holocene glacier advance signal in the Southern Alps conflicts with marine paleoclimate marine records of SSTs (e.g. Vimeux et al., 2001; Barrows et al., 2007a; Prebble et al., 2017), Antarctic ice core temperature proxies (e.g. Masson et al., 2000), some ecological proxies (e.g. McGlone et al., 2004; Wilmshurst et al., 2007), and regional (and global) temperature reconstructions (e.g. Marcott et al., 2013) that suggest peak warming in the Southern Hemisphere took place during the early Holocene between 129 ka. However, early Holocene moraine formation at Dart Glacier, and elsewhere in the Southern Alps, is consistent with New Zealand ecological proxy evidence that indicates low seasonality and cooler summer temperatures relative to present-day (e.g. McGlone et al., 2010a; Putnam et al., 2012; Kaplan et al., 2013; Jara et al., 2015; van den Bos et al., 2018). Low seasonality during the early Holocene is also consistent with environmental changes recorded in the subantarctic islands (44-54 ${ }^{\circ} \mathrm{S}$ ) (McGlone, 2002; McGlone et al., 2010b). The discrepancies between proxies are likely a reflection of marine and ice-core records being better recorders of annual mean temperatures, compared to glaciers (e.g. Schaefer et al., 2009; Putnam et al., 2012), and certain ecological proxies (e.g. van den Bos et al., 2018) which are more sensitive to changes in summer temperatures (McGlone et al., 2010b).

Cooler summer temperatures during the early Holocene would have reduced glacier melt during the ablation seasons and increased the duration of the accumulation season, resulting in an extended period of positive mass balance and glacier advance (Oerlemans, 2001). An increase in precipitation may have also contributed to the positive mass balance trend (Putnam et al., 2012; Kaplan et al., 2013; van den Bos et al., 2018), depending on whether glaciers were more responsive to temperature or precipitation (see Section 5.3.2). Overall, low seasonality and cool summer temperatures are most likely responsible for the large glacier extents and moraine formation during the early Holocene at Dart Glacier and other glaciers in the Southern Alps. 
Geomorphological mapping in the Southern Alps (e.g. Figure 4.1 \& Appendix 2), shows that glacier advances were less extensive during the late Holocene. This observation, combined with the gap in the composite moraine record between $7 \mathrm{ka}$ and $3 \mathrm{ka}$ (Figure 5.2), suggests that New Zealand glaciers overall retreated throughout the Holocene. Net glacier retreat is supported by other palaeoclimate proxies in New Zealand which indicate that summer temperatures increased from $\sim 7$ ka onwards (Putnam et al., 2012; van den Bos et al., 2018). This summer warming and net glacier retreat trend in the Southern Alps (Figure 5.2) also correlates well with the summer insolation curve for $45^{\circ} \mathrm{S}$ (Figure $5.3 \mathrm{~d}$ \& e) (Berger \& Loutre, 1991; Putnam et al., 2012; Kaplan et al., 2013; van den Bos et al., 2018). In contrast, glacier records from the Northern Hemisphere suggest that summer temperatures during the early Holocene were warmer and glaciers in the European Alps were smaller than present day (Figure 5.3a) (e.g. Holzhauser et al., 2005; Joerin et al., 2006; Joerin et al., 2008; Ivy-Ochs et al., 2009; Goehring et al., 2011). These records also suggest that summer temperatures cooled through the mid-to-late Holocene $(\sim 7 \mathrm{ka}$ onwards), coinciding with snowline depression and net glacier advance (Figure 5.3b). This Northern Hemisphere trend is opposite to that observed in the Southern Alps and summer cooling and glacier advance is consistent with the summer insolation curve for $45^{\circ} \mathrm{N}$ (Figure 5.3a, b \& c).

Correlation between summer insolation and glacier length changes in both hemispheres suggests that insolation may play an important role in determining the multi-millennial pattern of climatic change throughout the Holocene. However, insolation likely indirectly played a role in the long-term trend of glacier retreat during the mid-to-late Holocene in New Zealand as glaciers in the Southern Alps are more responsive to turbulent heat fluxes and longwave radiation than direct solar (shortwave) radiation (Oerlemans, 2001; Anderson \& Mackintosh, 2006; Anderson et al., 2010; Mackintosh et al., 2017a). That is, increasing summer insolation at the southern mid-latitudes throughout the Holocene may have induced gradual warming of the sea surface temperatures (SSTs) upwind of the Southern Alps. Because there is a strong connection between SSTs and air temperature in New Zealand, this would have increased the frequency of warm and humid air masses across the Southern Alps, thus increasing longwave radiation, turbulent heat fluxes and the elevation of the snow/rain threshold over the glaciers, possibly driving glacier melt and retreat (Anderson et al., 2010; Mackintosh et al., 2017a). 
Overall, the long-term net glacier retreat trend in the Southern Alps supports previous paleoclimate proxy-based evidence that increasing summer insolation, coinciding with a gradual southward migration of the ITCZ (Haug et al., 2001), could explain cool summer temperatures and glacier advance during the early Holocene, that was followed by an increase in seasonality and net glacier recession over the remainder of the interglacial (McGlone et al., 2010b; Putnam et al., 2012; Kaplan et al., 2013; van den Bos et al., 2018). Superimposed on this broad multi-millennial-scale trend, individual moraine forming events such as the $7.8 \mathrm{ka}$ and $0.3 \mathrm{ka}$ events at Dart Glacier (see Figure 5.2), likely reflect shorter duration (decadal-centennial) climate variability. 


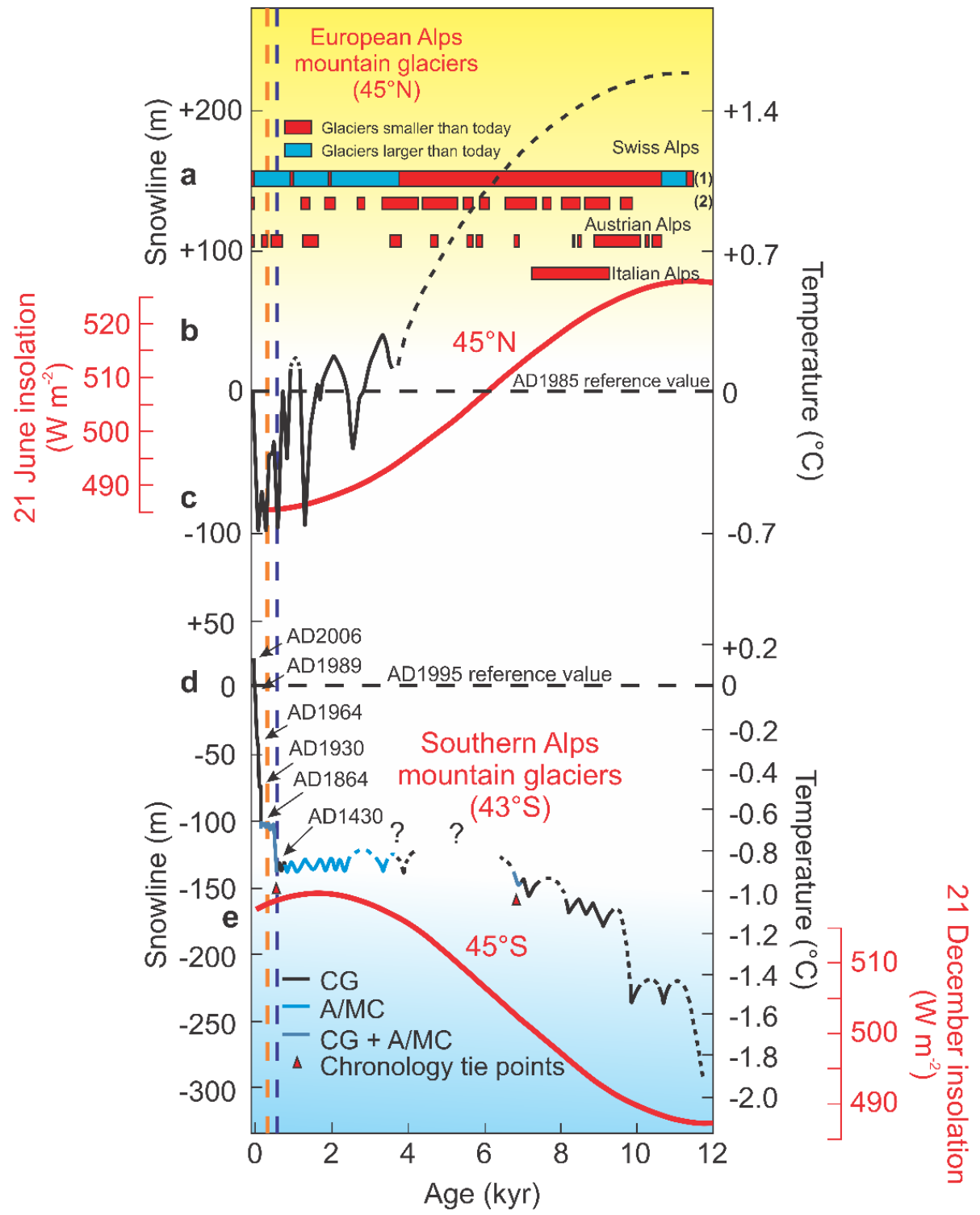

Figure 5.3 Comparison of snowline derived temperature records with summer insolation curves. (a) Glacier extents of mountain glaciers in the European Alps $\left(45^{\circ} \mathrm{N}\right)$ relative to present-day: Swiss Alps (1) (Goehring et al., 2011) and (2) (Hormes et al., 2006; Joerin et al., 2006; Joerin et al., 2008); Austrian Alps (Porter \& Orombelli, 1985); Italian Alps (Nicolussi \& Patzelt, 2000). (b) European Alps snowline-based temperature reconstruction based on Holzhauser et al. (2005) and Joerin et al. (2008). c) Summer insolation curve for $45^{\circ} \mathrm{N}$. (d) Southern Alps snowline-based temperature reconstruction based on moraine records at Cameron Glacier (CG) and Aoraki/Mt Cook (A/MC) (Schaefer et al., 2009; Putnam et al., 2012). (e) Summer insolation curve for $45^{\circ} \mathrm{S}$. Dark blue dashed line denotes the onset of the Little Ice Age at $\sim$ AD1430. Orange dashed line denotes the formation of the U8/L8 moraine at Dart Glacier at $\sim A D 1696$. Figure adapted from Putnam et al. (2012). 


\subsubsection{Drivers of Little Ice Age glacier length changes}

The composite ${ }^{10} \mathrm{Be}$ moraine record for the Southern Alps reveals that moraine formation took place numerous times during the period that is known as the Little Ice Age ( AD1450-1850) (Figure 5.2). However, unlike in the Northern Hemisphere, glacier extents delineated by moraines during the Little Ice Age in the Southern Hemisphere, are relatively small compared to other glacier advances that took place earlier in the Holocene (e.g. this study; Schaefer et al., 2009; Putnam et al., 2012). Contrasting glacier behaviour in both hemispheres indicates clear differences in the climate drivers during the Holocene at multi-millennial timescales (see Section 5.3.3). However, synchronous moraine formation in both hemispheres during the Little Ice Age is consistent with a globally common driver. Therefore, our new moraine chronology from Dart Glacier warrants revisiting the question as to whether the Little Ice Age cooling was a global phenomenon. That is, whether glaciers responded to a common global driver of glacier advance during this time, or whether two independent drivers were operating in both hemispheres. These questions cannot be answered using the moraine chronologies alone. However, testable hypotheses can be generated through consideration of existing proposed drivers and comparison of the Little Ice Age moraine record from Dart Glacier with other palaeoclimate records.

In the Northern Hemisphere, glacier expansion during the Little Ice Age is thought to be linked to one or a combination of radiative forcings that resulted in reduced atmospheric temperatures. Reduced atmospheric temperatures during the Little Ice Age have been linked to solar forcing (total solar irradiation), volcanic eruptions, and reduction in atmospheric $\mathrm{CO}_{2}$ which could be linked to land use changes (Mann et al., 2009; Neukom et al., 2014). Attributing these proposed forcings to the Northern Hemisphere (or global) Little Ice Age cooling period is difficult as each would promote a globally-coherent climate response, whereas feedback mechanisms in the climate system can either amplify or diminish the climatic effects produced by external forcings (e.g. Miller et al., 2012), thus resulting in regional differences in climatic conditions on Earth. For this reason, global climate model simulations are typically used to assess the relative contributions of external forcings to climatic changes (Taylor et al., 2012; Neukom et al., 2014; Atwood et al., 2015). 
In terms of solar forcing, the Spörer Minimum (AD1416-1537) and the Maunder Minimum (AD1645-1715) are commonly suggested to explain the cold conditions that were observed in Europe during the Little Ice Age (Schurer et al., 2013; Owens et al., 2017). The impact of aerosols from large volcanic eruptions on solar radiation is also thought to have caused a reduction in atmospheric temperatures (Crowley et al., 2008; Miller et al., 2012). Globally, of the 40 largest eruptions in the past 2500 years, 9 occurred during the same time frame as the Little Ice Age (Sigl et al., 2015). However, a global climate reconstruction by Neukom et al. (2014) (see Figure 5.4) suggests that Southern Hemisphere temperatures tend to show a weaker cooling response to strong volcanic eruptions relative to the Northern Hemisphere (e.g. Tambora AD1815 \& Kuwae AD1450).

Ice core records from Law Dome and the West Antarctic Ice Sheet show a decline in atmospheric $\mathrm{CO}_{2}$ from $\sim \mathrm{AD} 1530$, which reached a minimum between $\sim \mathrm{AD} 1650$ and $\sim \mathrm{AD} 1700$, after which $\mathrm{CO}_{2}$ concentrations began to increase again around the same time as the beginning of the industrial revolution (MacFarling-Meure et al., 2006; Ahn et al., 2012). The reduction in $\mathrm{CO}_{2}$ is thought to be linked to an increase in terrestrial carbon uptake that occurred between $\sim$ AD1530 and AD1700 (Bauska et al., 2015) which has been attributed to anthropogenic land use changes and decreased human populations in the Americas, Europe, Africa, and Asia (Ruddiman, 2003; Koch et al., 2019). The lower atmospheric $\mathrm{CO}_{2}$ coincides with lower surface air temperatures during this time. Indeed, global synthesis of over 500 palaeoclimate records shows that AD1594-1677 was a period of significant global cooling relative to other times during the past millennium and this is the only part of the Little Ice Age time frame that is thought to be global in extent (Figure 5.4; Neukom et al., 2014). During the rest of the millennium, warm and cold episodes in both hemispheres are more asynchronous with the exception of the present-day warm period (Figure 5.4; Neukom et al., 2014). 


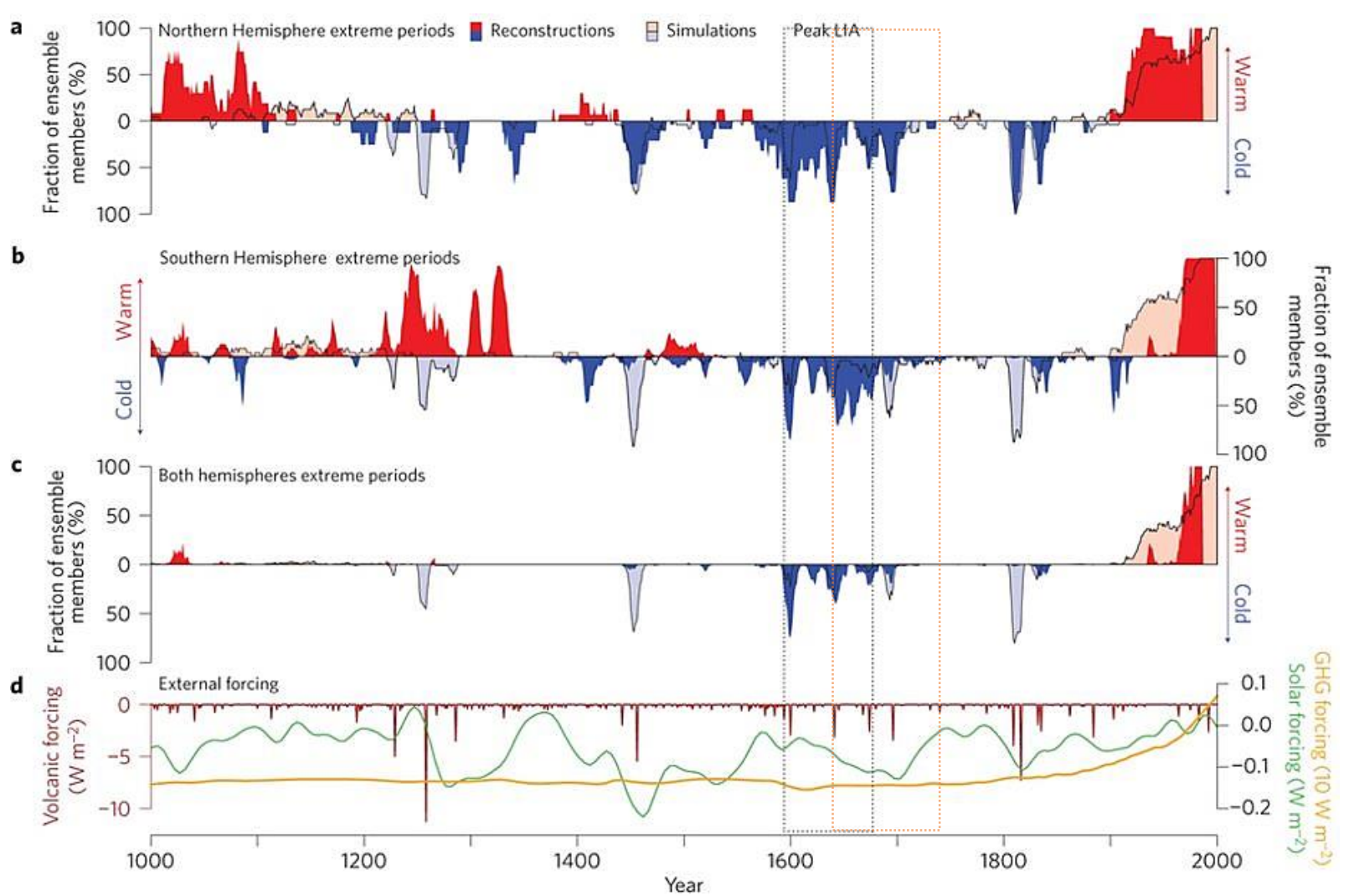

Figure 5.4 Interhemispheric variability in temperature extremes over the past millennium. The fraction of ensemble members (refer to Neukom et al., 2014) in the global climate reconstruction that present extreme warm (red) or cold (blue) temperatures are shown for the (a) Southern Hemisphere and (b) Northern Hemisphere. Darker colouring represents reconstruction from palaeoclimate records, whereas lighter colouring shows global climate model simulations. (c) Probabilities for synchronous warming or cooling in both hemispheres. (d) Shows volcanic (brown), solar (green), and greenhouse gas forcing (yellow) over the past millennium (MacFarling-Meure et al., 2006; Crowley et al., 2008; Steinhilber et al., 2009). The dotted line area shows the peak globally expressed Little Ice Age cooling signal between AD1594 and AD1677. Orange dotted area denotes the formation of the U8/L8 moraine at Dart Glacier at $\sim A D 1696 \pm 44$. Figure adapted from Neukom et al. (2014) 
Moraine formation at Dart Glacier and elsewhere in the Southern Alps fits well with the proposed global cooling interval from AD1594-1677. Warming after AD1677 is consistent with the abandonment of the U8/L8 moraine $\sim$ AD1696 \pm 44 yrs ago (Figure 5.4). However, if Little Ice Age glacier advances in New Zealand were connected to the Northern Hemisphere (or global) cooling event, then the signal was small in the context of the Holocene based on more extensive previous glacier advances in the early Holocene. This discrepancy may reflect differences in summer insolation between the two hemispheres. That is, the Little Ice Age advances in the Southern Hemisphere were small in comparison to the early Holocene as insolation may have caused summer temperatures to warm throughout the interglacial, whereas in the Northern Hemisphere the advances were larger as insolation caused summer temperatures to cool (Figure 5.3). Evidence for cooling during this period followed by gradual warming is recorded in tree ring records from Oroko Swamp produced by Cook et al. (2002) which shows a clear reduction in temperatures (below the $20^{\text {th }}$ century average) during the period AD1500-1700 followed by a more general trend of increasing temperatures during the AD1800s. Lorrey et al. (2008) present speleothem records from Fiordland and other palaeohydrological proxies that also indicate cool and wet conditions in the South Island from AD1500 to 1650. Although there is prominent climate variability within these records, Lorrey et al. (2014) suggest that mean summer temperatures were on average $0.6{ }^{\circ} \mathrm{C}$ lower than present across the Southern Alps. Evidence for minor glacier readvances during the Little Ice Age has also been recorded in the ${ }^{10} \mathrm{Be}$ moraine chronologies from southern Patagonia (Kaplan et al., 2016), suggesting that the cooling phase was widespread throughout the Southern Hemisphere mid-latitudes. Based on the close agreement between climate proxy records during the period $\sim$ AD1500-1700, it is likely that a regional (and possibly global) reduction in air temperatures during this time frame was responsible for the formation of the $\sim 321 \pm 44$ yr old moraine at Dart Glacier and other moraines recorded elsewhere in the Southern Alps (Figure 5.2).

Cold climatic conditions are thought to reflect interannual to decadal-scale changes in atmospheric conditions during this time including an increase in the circumpolar westerly and southerly circulation that gradually lessened after the $16^{\text {th }}$ century (Lorrey et al., 2008; Lorrey et al., 2014; Lorrey \& Bostock, 2017). These changes in atmospheric circulation combined with possible cooling of the Tasman Sea west of the South Island (Mann et al., 2009) may have caused regional temperature anomaly during the Little Ice Age. Lorrey 
and Bostock (2017) suggest that these changes in atmospheric circulation may be related to large-scale regional climate phenomena including changes in the SAM (Villalba et al., 2012; Abram et al., 2014) along with increased ENSO activity (Fowler et al., 2012) (Section 2.5.1). However, the agreement between the moraine record from Dart Glacier and the cooling trend observed in palaeoclimate records from both hemispheres (e.g. Neukom et al., 2014 \& Figure 5.4) may suggest that New Zealand glacier length changes were driven by a globally coherent climate signal associated with external forcings.

\subsection{Implications of ${ }^{10} \mathrm{Be}$ sensitivity experiment for future low concentration applications}

The results from the ${ }^{10} \mathrm{Be}$ sensitivity experiment have important implications for improving our ability to develop precise moraine chronologies in studies aimed at reconstructing glacier length changes during the last millennium. Application of cosmogenic ${ }^{10} \mathrm{Be}$ surface exposure dating on surfaces with very low ${ }^{10} \mathrm{Be}$ content requires:

(i) low detection limits and highly precise AMS to provide low analytical uncertainties,

(ii) clean samples that are sufficiently large to increase the number of ${ }^{10} \mathrm{Be}$ counts and, (iii) low process blanks in order to maximise signal-to-noise ratios. The AMS facilities at LLNL CAMS have provided ${ }^{10} \mathrm{Be}$ measurements with low analytical uncertainties. Additionally, large quartz masses ( 60-80 g; Table 4.1) with high purity were also obtained. The main limitation to the preparation of samples with low ${ }^{10} \mathrm{Be}$ content in the VUW Cosmogenic Laboratory is the need for lower process blanks. The process blank

${ }^{10} \mathrm{Be} /{ }^{9} \mathrm{Be}$ ratios reported in this study are in the order of $10^{-15}\left(\sim 10^{4}-10^{5}{ }^{10} \mathrm{Be}\right.$ atoms $)$, which are higher than the process blanks reported in other low ${ }^{10} \mathrm{Be}$ studies (e.g. Schaefer et al., 2009; Shakun et al., 2018) that report ratios on the order of $10^{-16}\left(\sim 10^{3}-10^{4}{ }^{10} \mathrm{Be}\right.$ atoms $)$. Although our blank ratios are sufficient for dating the $>300 \mathrm{yr}$ old landforms at Dart Glacier, surface exposure dating of younger surfaces, at similar elevations ( 1400 m asl), would require lower process blank ratios. Therefore, the results of the ${ }^{10} \mathrm{Be}$ sensitivity experiment provide valuable insights into how low process blank ratios may be achieved in the future.

The results from the ${ }^{10} \mathrm{Be}$ sensitivity experiment showed that $\mathrm{HF}$ and reused beakers were the largest sources of ${ }^{10} \mathrm{Be}$ contamination, each accounting for $\sim 25 \%$ of the total number of ${ }^{10} \mathrm{Be}$ atoms in an average process blank. This is followed by airborne contamination 
and potential cross-talk between samples which account for $\sim 14 \%$ and $\sim 12 \%$ of the total ${ }^{10} \mathrm{Be}$, respectively (see Table 4.6 in Section 4.3). These results highlight that a trade-off is required between using large quartz masses to increase ${ }^{10} \mathrm{Be}$ counts and the use of large quantities of $\mathrm{HF}$ in quartz digestion, which in turn introduces more ${ }^{10} \mathrm{Be}$ to process blanks. Furthermore, these results suggest that ${ }^{10} \mathrm{Be}$ atoms may be inherited from former beaker use in high concentration applications, thus suggesting that there is a need to dedicate a set of beakers to low concentration applications (e.g. Corbett et al., 2016). Processing of further blanks in 'new' and 'used' beakers is required to confirm the legacy effect of reused beakers, which may vary significantly between beakers depending on the usage history.

The labware component of this experiment also showed that the use of new columns (plastic and resin) does not reduce the number of ${ }^{10} \mathrm{Be}$ atoms added to the process blanks. Therefore, the existing column-cleaning procedures used in the VUW Cosmogenic Laboratory are effective at removing ${ }^{10} \mathrm{Be}$ contamination between uses. The low ${ }^{10} \mathrm{Be}$ measurements in both the old and new columns samples also suggest minimal amounts $(<10 \%)$ of ${ }^{10} \mathrm{Be}$ contamination (Table 4.6) is introduced during ${ }^{10} \mathrm{Be}$ preparation stages from anion columns through to sample packing (see steps 17 to 26 in Figure 3.2). Therefore, the stages of quartz dissolution (see steps 13 to 16 in Figure 3.2) contribute the most significant amounts of ${ }^{10} \mathrm{Be}$ contamination to the process blanks ( 25-50\%). The experiment results also indicate that cross-talk between samples may also contribute ${ }^{10} \mathrm{Be}$ atoms to the total amount of ${ }^{10} \mathrm{Be}$ in a process blank. However, blanks 4 and 5, used for testing for cross-contamination between samples, are also within their $1 \sigma$ uncertainties. Nevertheless, because the percentage contribution could be up to $12 \%$ (Table 2.6), consideration should be given to ways in which laboratory procedures could minimise the effect of cross-talk on process blanks.

Although this experiment has allowed for the primary sources of contamination to be identified, there are limitations with the experimental design that prevent individual sources of contamination from being isolated and accurately quantified. This is because individual samples were treated slightly differently during the experiment. Exposure to different labware, acid volumes, and airborne contamination may have resulted in varying amounts of exposure to confounding sources of ${ }^{10} \mathrm{Be}$ contamination. For example, when testing for acid contamination, oxalic acid was processed through columns whereas the other acids were not. Furthermore, several experimental samples were processed in old 
beakers. If old beakers contain non-uniform amounts of ${ }^{10} \mathrm{Be}$, this may cause ${ }^{10} \mathrm{Be}$ measurements to diverge. For example, the weak relationship between HF volume and the number of ${ }^{10} \mathrm{Be}$ atoms in the low HF tests (e.g. 0-200 ml; Figure 4.9) could suggest that there is an inconsistent external source of ${ }^{10} \mathrm{Be}$ contamination that was introduced through 'used' beakers. Additionally, because the blanks used for testing cross-talk (blanks 4 and 5) were processed in used beakers, it is possible that the difference in ${ }^{10} \mathrm{Be}$ amounts in blank 4 and blank 5 could be explained by the inconsistencies in the legacy effect of reused beakers.

Regardless of these limitations, the results from the ${ }^{10} \mathrm{Be}$ sensitivity experiment suggest that small methodological changes in the preparation of low concentration samples could be made in to order lower process blanks in the VUW Cosmogenic Laboratory. Future recommendations include:

- Use beakers dedicated to low ${ }^{10} \mathrm{Be}$ concentration applications, for example where total ${ }^{10} \mathrm{Be}$ is anticipated to be $<3$ times the average process blank $\left(\sim 10^{5}\right.$ atoms).

- To reduce excess ${ }^{10} \mathrm{Be}$ contamination, experiment with distilled HF during quartz digestion stages to assess whether it offers a cleaner alternative to analytical grade $\mathrm{HF}$

- Avoid open beaker quartz digestion, thus reducing airborne contamination

- Use smaller quartz masses (40-50 g) to reduce the amount of HF and evaporation time required during quartz digestion stages; although reduction of quartz masses should not compromise ${ }^{10} \mathrm{Be}$ counts

- Minimise all sources of cross-talk by processing low concentration ${ }^{10} \mathrm{Be}$ samples separately to high concentration ${ }^{10} \mathrm{Be}$ samples 


\section{CHAPTER 6: CONCLUSION}

In summary, this study further constrains the timing, magnitude, and climatic drivers of Holocene glacier length changes in New Zealand. This was achieved through geomorphological mapping which documents the distribution of glacial landforms in the upper Dart valley and through developing a new moraine chronology using ${ }^{10} \mathrm{Be}$ surface exposure dating. This study also aimed to explore ways in which process blank ratios could be lowered in order to facilitate routine application of low concentration cosmogenic ${ }^{10} \mathrm{Be}$ surface exposure dating to near-historic landforms in the VUW Cosmogenic Laboratory. I have achieved this aim by quantifying the contributions of ${ }^{10} \mathrm{Be}$ to full-process blanks using a series of systematic partial-process blank experiments.

Geomorphological mapping of the glacial landforms preserved in the upper regions of the Dart valley allowed for reclassification of several geomorphic features that had been identified as glacial landforms in previous studies. The distribution of moraines clearly delineates former ice geometries that constrain the magnitude of former glaciers advance at Dart Glacier. Cosmogenic ${ }^{10} \mathrm{Be}$ surface exposure dating in the Dart valley yielded consistent boulder age distributions, which exhibit only minimal amounts of scatter. These moraine ages show that late Holocene glacier advance formed the outermost lateral moraine (U8/L8 moraine) on the eastern valley side at $321 \pm 44(n=11)$. This moraine clearly delineates that the glacier was $\sim 10 \mathrm{~km}$ long during this time, which is $\sim 4 \mathrm{~km}$ greater than present. The moraine remnants near the Dart Hut site yielded a mean age of $7817 \pm 336$ yrs ago $(n=5)$, constraining the timing of a more extensive early Holocene glacier advance event that took place in the upper regions of the Dart valley. The position of these moraine remnants shows that the glacier was $\sim 12 \mathrm{~km}$ long during the early Holocene.

The ${ }^{10} \mathrm{Be}$ process blank ratios presented in this study are sufficient for dating the $>300 \mathrm{yr}$ old landforms at Dart Glacier, however, surface exposure dating of younger surfaces, at similar elevations, would require lower process blanks. Using a ${ }^{10} \mathrm{Be}$ sensitivity experiment, which involved a systematic series of partial-process blank tests, I have successfully quantified the relative contributions of different contamination sources ${ }^{10} \mathrm{Be}$ to full-process blanks in the VUW Cosmogenic Laboratory. The results from this experiment showed that concentrated analytical grade HF and 'used' beakers are the largest contributors $(\sim 25 \%)$ of ${ }^{10} \mathrm{Be}$ to the average process blank. Airborne contamination 
in the HF dissolution fume hood and cross-talk between samples may also contribute $\sim 14 \%$ and $\sim 12 \%$ of the total ${ }^{10} \mathrm{Be}$ contamination, respectively. Based on these findings I recommend small methodological improvements that could be implemented in the future in order to lower process blank ratios in the VUW Cosmogenic Laboratory. These recommendations include: (i) using beakers dedicated to low ${ }^{10} \mathrm{Be}$ concentration applications, (ii) experimenting with distilled HF which may lower excess ${ }^{10} \mathrm{Be}$ contamination, (iii) avoiding open beaker quartz digestion, (iv) using smaller quartz masses, and (v) processing low concentration ${ }^{10} \mathrm{Be}$ samples separately to high concentration ${ }^{10} \mathrm{Be}$ samples to minimise sources of cross-talk between samples.

When situated within the context of a composite moraine chronology for the Southern Alps, the pre-historic moraine record at Dart glacier is consistent with the emerging pattern seen in other Holocene glacial records in New Zealand, which shows that early Holocene glacier advance was followed by net glacier retreat over the remainder of the interglacial. This pattern also shows individual moraine forming events are superimposed on the long-term multi-millennial trend, including moraine formation during the same time frame as the Little Ice Age ( AD1450-1850).

Consistent trends of glacier length changes observed across multiple glaciated valleys in the Southern Alps allow for climatic drivers to be reconsidered and better constrained. More extensive early Holocene glacier advance followed by net glacier retreat in the Southern Alps, is consistent with recent hypotheses that suggest increasing summer insolation intensity, and therefore seasonality, was the dominant driver of regional climate during the Holocene. Individual moraine forming events superimposed on this long-term trend, including those at Dart Glacier at $7.8 \mathrm{ka}$ and $0.3 \mathrm{ka}$, may reflect shorter duration (decadal-centennial) climatic changes. For example, moraine formation in the Southern Alps during the Little Ice Age may reflect a regionally-felt cold temperature anomaly, perhaps due to changes in regional-scale climate phenomena (e.g. ENSO and SAM) (Lorrey et al., 2008; Lorrey et al., 2014; Lorrey \& Bostock, 2017). However, the agreement between the timing of moraine formation and the cooling signal recorded in palaeoclimate proxies globally is also consistent with forced climate variability as the driver of the climate change in New Zealand at this time (e.g. Neukom et al., 2014).

In the future, global climate and glacier models could be used in conjunction with the high-resolution moraine chronology from Dart Glacier to further test these hypothesised 
climatic drivers of Holocene glacier length changes. Numerical modelling can be used to inform whether temperature or precipitation primarily controlled the glacier length changes observed at Dart Glacier (Oerlemans, 1997; Anderson \& Mackintosh, 2006; Mackintosh et al., 2017a). Through quantifying the temperature and/or precipitation changes that would have been required to form the early and late Holocene moraines, the response of Dart Glacier to interannual variability could also be tested (e.g. Roe, 2011; Anderson et al., 2014; Doughty et al., 2017) to assess whether interannual climate variability alone could force the glacier to its former ice marginal positions. Global climate model simulations, such as those from the Coupled Model Intercomparison Project phase 5 (CMIP5) or Palaeoclimate Modelling Intercomparison Project phase 3 (PMIP3) could also be used in order to test the hypothesis that Holocene glacier length changes in the Southern Alps were driven by forced climate variability (e.g. orbital cycles, volcanism, solar irradiance, or greenhouse gases) (Taylor et al., 2011; Atwood et al., 2015). Outputs from these global climate model simulations can be used to assess whether the combined or individual effect of external climate forcings may produce the changes in temperature (and/or precipitation) required to drive the advance of Dart Glacier during the early and late Holocene (e.g. Marzeion et al., 2014; Mackintosh et al., 2017a). This approach offers a chance for utilisation of the moraine record from Dart Glacier to further constrain the drivers of glacier length changes in New Zealand during the Holocene.

Additional ${ }^{10} \mathrm{Be}$ moraine records will help to confirm the emerging pattern of Holocene glacier length changes in the Southern Alps, and possibly reconcile the gap in the existing moraine record between $~ 7-3 \mathrm{ka}$. More reconstructions of glacier length changes during the last millennium can especially help to augment the short instrumental climate record in New Zealand. Therefore, the methodological recommendations made in Section 5.4 should also be applied in future preparation of low ${ }^{10} \mathrm{Be}$ concentration samples in order to achieve lower process blanks and to successfully carry out surface exposure dating on near-historic landforms.

Overall, the glacier-climate reconstruction of the Dart Glacier presented in this study adds to the limited number of existing Southern Hemisphere palaeoclimate records, providing baseline constraints of pre-historic glacier and climate variability. Future research should continue to contribute toward Southern Hemisphere palaeoclimate records in order to help improve our understanding of natural climate variability during pre-industrial times, which is critical for determining the extent of anthropogenic climate change. 


\section{REFERENCES}

Abram, N. J., Mulvaney, R., Vimeux, F., Phipps, S. J., Turner, J., \& England, M. H. (2014). Evolution of the Southern Annular Mode during the past millennium. Nature Climate Change, 4(7), 564.

Ahn, J., Brook, E. J., Mitchell, L., Rosen, J., McConnell, J. R., Taylor, K., Etheridge, D., \& Rubino, M. (2012). Atmospheric CO2 over the last 1000 years: A highresolution record from the West Antarctic Ice Sheet (WAIS) Divide ice core. Global Biogeochemical Cycles, 26(2).

Anderson, B., Lawson, W., \& Owens, I. (2008). Response of Franz Josef Glacier Ka Roimata o Hine Hukatere to climate change. Global \& Planetary Change, 63(1), 23-30.

Anderson, B., Lawson, W., Owens, I., \& Goodsell, B. (2006). Past and future mass balance of 'Ka Roimata o Hine Hukatere' Franz Josef Glacier, New Zealand. Journal of Glaciology, 52(179), 597-607.

Anderson, B., \& Mackintosh, A. (2006). Temperature change is the major driver of lateglacial and Holocene glacier fluctuations in New Zealand. Geology, 34(2), 121124.

Anderson, B., \& Mackintosh, A. (2012). Controls on mass balance sensitivity of maritime glaciers in the Southern Alps, New Zealand: The role of debris cover. Journal of Geophysical Research: Earth Surface, 117(F1).

Anderson, B., Mackintosh, A., Stumm, D., George, L., Kerr, T., Winter-Billington, A., \& Fitzsimons, S. (2010). Climate sensitivity of a high-precipitation glacier in New Zealand. Journal of Glaciology, 56(195), 114-128.

Anderson, L. S., Anderson, R. S., \& Roe, G. H. (2014). The effects of interannual climate variability on the moraine record. Geology, 42(1), 55-58.

Applegate, P. J., Urban, N. M., Keller, K., Lowell, T. V., Laabs, B. J. C., Kelly, M. A., \& Alley, R. B. (2012). Improved moraine age interpretations through explicit matching of geomorphic process models to cosmogenic nuclide measurements from single landforms. Quaternary Research, 77(2), 293-304.

Atwood, A. R., Wu, E., Frierson, D. M. W., Battisti, D. S., \& Sachs, J. P. (2015). Quantifying Climate Forcings and Feedbacks over the Last Millennium in the CMIP5-PMIP3 Models. Journal of Climate, 29(3), 1161-1178.

Balco, G. (2006). Converting $\mathrm{Al}$ and Be isotope ratio measurements to nuclide concentrations in quartz. Retrieved from http://hess.ess.washington.edu/math/docs/common/ams_data_reduction/

Balco, G. (2009). The geographic footprint of glacier change. Science, 324(5927), 599600. 
Balco, G. (2011). Contributions and unrealized potential contributions of cosmogenicnuclide exposure dating to glacier chronology, 1990-2010. Quaternary Science Reviews, 30(1), 3-27.

Balco, G. (2017a). Documentation -- v3 exposure age calculator. Retrieved from https://sites.google.com/a/bgc.org/v3docs/home

Balco, G. (2017b). The online exposure age calculator formerly known as the CRONUS-Earth online exposure age calculator. Retrieved from https://hess.ess.washington.edu/math/v3/v3_age_in.html

Balco, G. (2017c). Production rate calculations for cosmic-ray-muon-produced 10Be and 26Al benchmarked against geological calibration data. Quaternary Geochronology, 39, 150-173.

Balco, G., Briner, J., Finkel, R. C., Rayburn, J. A., Ridge, J. C., \& Schaefer, J. M. (2009). Regional beryllium-10 production rate calibration for late-glacial northeastern North America. Quaternary Geochronology, 4(2), 93-107.

Balco, G., Stone, J. O., Lifton, N. A., \& Dunai, T. J. (2008). A complete and easily accessible means of calculating surface exposure ages or erosion rates from $10 \mathrm{Be}$ and 26Al measurements. Quaternary Geochronology, 3(3), 174-195.

Barclay, D. J., Wiles, G. C., \& Calkin, P. E. (2009). Holocene glacier fluctuations in Alaska. Quaternary Science Reviews, 28(21), 2034-2048.

Barrell, D. J., Andersen, B. G., \& Denton, G. H. (2011). Glacial geomorphology of the central South Island, New Zealand. GNS Science Monography, 27(81).

Barrell, D. J. A. (2014). The Balmoral moraines near Lake Pukaki, Southern Alps: a new reference area for the early Otira Glaciation in New Zealand. New Zealand Journal of Geology and Geophysics, 57(4), 442-452.

Barrows, T. T., Almond, P., Rose, R., Fifield, L. K., Mills, S. C., \& Tims, S. G. (2013). Late Pleistocene glacial stratigraphy of the Kumara-Moana region, west coast of South Island, New Zealand. Quaternary Science Reviews, 74, 139-159.

Barrows, T. T., Juggins, S., De Deckker, P., Calvo, E., \& Pelejero, C. (2007a). Longterm sea surface temperature and climate change in the Australian-New Zealand region. Paleoceanography, 22(2).

Barrows, T. T., Lehman, S. J., Fifield, L. K., \& De Deckker, P. (2007b). Absence of cooling in New Zealand and the adjacent ocean during the Younger Dryas chronozone. Science, 318(5847), 86-89.

Bauska, T. K., Joos, F., Mix, A. C., Roth, R., Ahn, J., \& Brook, E. J. (2015). Links between atmospheric carbon dioxide, the land carbon reservoir and climate over the past millennium. Nature Geoscience, 8(5), 383.

Benn, D. I., \& Evans, D. J. A. (2010). Glaciers and Glaciation (2nd ed.). New York: Routledge. 
Berger, A., \& Loutre, M. F. (1991). Insolation values for the climate of the last 10 million years. Quaternary Science Reviews, 10(4), 297-317.

Bierman, P. R., Marsella, K. A., Patterson, C., Davis, P. T., \& Caffee, M. (1999). MidPleistocene cosmogenic minimum-age limits for pre-Wisconsinan glacial surfaces in southwestern Minnesota and southern Baffin Island: a multiple nuclide approach. Geomorphology, 27(1-2), 25-39.

Birkeland, P. W. (1981). Soil data and the shape of the lichen growth-rate curve for the Mt Cook area (Note). New Zealand Journal of Geology and Geophysics, 24(3), 443-445.

Birkeland, P. W. (1982). Subdivision of Holocene glacial deposits, Ben Ohau Range, New Zealand, using relative-dating methods. GSA Bulletin, 93(5), 433-449.

Bishop, G., \& Forsyth, J. (1988). Vanishing ice: an introduction to glaciers based on a study of the Dart Glacier. Dunedin, New Zealand: John McIndoe and New Zealand Geological Survey, DSIR.

Borchers, B., Marrero, S., Balco, G., Caffee, M., Goehring, B., Lifton, N., Nishiizumi, K., Phillips, F., Schaefer, J., \& Stone, J. (2016). Geological calibration of spallation production rates in the CRONUS-Earth project. Quaternary Geochronology, 31, 188-198.

Bradley, R. S., \& Jonest, P. D. (1993). 'Little Ice Age'summer temperature variations: their nature and relevance to recent global warming trends. The Holocene, 3(4), 367-376.

Braithwaite, R. J., Zhang, Y., \& Raper, S. (2003). Temperature sensitivity of the mass balance of mountain glaciers and ice caps as a climatological characteristic. Zeitschrift fur Gletscherkunde und Glazialgeologie, 38(1), 35-61.

Briner, J. P., Kaufman, D. S., Manley, W. F., Finkel, R. C., \& Caffee, M. W. (2005). Cosmogenic exposure dating of late Pleistocene moraine stabilization in Alaska. GSA Bulletin, 117(7-8), 1108-1120.

Broecker, W. S. (2001). Was the medieval warm period global? Science, 291(5508), 1497-1499.

Burrows, C., \& Maunder, B. (1975). The recent moraines of the Lyell and Ramsay glaciers Rakaia valley, Canterbury. Journal of the Royal Society of New Zealand, 5(4), 479-491.

Burrows, C. J. (1973). STUDIES ON SOME GLACIAL MORAINES IN NEW ZEALAND-2. New Zealand Journal of Geology and Geophysics, 16(4), 831856.

Burrows, C. J. (1975). Late Pleistocene and Holocene Moraines of the Cameron Valley, Arrowsmith Range, Canterbury, New Zealand. Arctic and Alpine Research, 7(2), 125-140. 
Burrows, C. J. (1980). Radiocarbon dates for post-Otiran glacial activity in the Mount Cook region, New Zealand. New Zealand Journal of Geology and Geophysics, 23(2), 239-248.

Burrows, C. J. (1989). Aranuian radiocarbon dates from moraines in the Mount Cook region, New Zealand. New Zealand Journal of Geology and Geophysics, 32(2), 205-216.

Burrows, C. J., Duncan, K. W., \& Spence, J. R. (1990). Aranuian vegetation history of the Arrowsmith Range, Canterbury II. Revised chronology for moraines of the Cameron Glacier. New Zealand Journal of Botany, 28(4), 455-466.

Burrows, C. J., \& Orwin, J. (1971). Studies on some glacial moraines in New Zealand I - the establishment of lichen-growth in the Mount Cook area. New Zealand Journal of Science, 14, 327-335.

Cane, M. A. (2005). The evolution of El Niño, past and future. Earth \& Planetary Science Letters, 230(3-4), 227-240.

Chinn, T. (1981). Use of rock weathering-rind thickness for Holocene absolute agedating in New Zealand. Arctic alpine research, 13(1), 33-45.

Ciais, P., Sabine, C., Bala, G., Bopp, L., Brovkin, V., Canadell, J., Chhabra, A., DeFries, R., Galloway, J., Heimann, M., Jones, C., Le Quéré, C., Myneni, R. B., Piao, S., \& Thornton, P. (2013). Carbon and Other Biogeochemical Cycles. In T. F. Stocker, D. Qin, G.-K. Plattner, M. Tignor, S. K. Allen, J. Boschung, A. Nauels, Y. Xia, V. Bex, \& P. M. Midgley (Eds.), Climate Change 2013: The Physical Science Basis. Contribution of Working Group I to the Fifth Assessment Report of the Intergovernmental Panel on Climate Change (pp. 465570). Cambridge, United Kingdom and New York, NY, USA: Cambridge University Press.

Cook, E. R., Palmer, J. G., Cook, B. I., Hogg, A., \& D D'Arrigo, R. (2002). A multimillennial palaeoclimatic resource from Lagarostrobos colensoi tree-rings at Oroko Swamp, New Zealand. Global Planetary Change, 33(3-4), 209-220.

Corbett, L. B., Bierman, P. R., \& Rood, D. H. (2016). An approach for optimizing in situ cosmogenic 10Be sample preparation. Quaternary Geochronology, 33, 2434.

Craw, D. (1984). Lithologic variations in Otago Schist, Mt Aspiring area, northwest Otago, New Zealand. New Zealand Journal of Geology and Geophysics, 27(2), 151-166.

Crowley, T. J., Zielinski, G., Vinther, B., Udisti, R., Kreutz, K., Cole-Dai, J., \& Castellano, E. (2008). Volcanism and the little ice age. PAGES news, 16(2), 2223.

Cuffey, K. M., \& Clow, G. D. (1997). Temperature, accumulation, and ice sheet elevation in central Greenland through the last deglacial transition. Journal of Geophysical Research: Oceans, 102(C12), 26383-26396. 
Darvill, C. M. (2013). Cosmogenic nuclide analysis. In L. E. Clarke \& J. M. Nield (Eds.), Geomorphological Techniques (pp. 1-25). London: British Society for Geomorphology.

Denton, G. H., \& Hendy, C. H. (1994). Younger Dryas Age Advance of Franz Josef Glacier in the Southern Alps of New Zealand. Science, 264(5164), 1434-1437.

Desilets, D., \& Zreda, M. (2003). Spatial and temporal distribution of secondary cosmic-ray nucleon intensities and applications to in situ cosmogenic dating. Earth and Planetary Science Letters, 206(1-2), 21-42.

Desilets, D., Zreda, M., \& Prabu, T. (2006). Extended scaling factors for in situ cosmogenic nuclides: New measurements at low latitude. Earth and Planetary Science Letters, 246(3), 265-276.

Doughty, A. M., Anderson, B. M., Mackintosh, A. N., Kaplan, M. R., Vandergoes, M. J., Barrell, D. J., Denton, G. H., Schaefer, J. M., Chinn, T. J., \& Putnam, A. E. (2013). Evaluation of Lateglacial temperatures in the Southern Alps of New Zealand based on glacier modelling at Irishman Stream, Ben Ohau Range. Quaternary Science Reviews, 74, 160-169.

Doughty, A. M., Mackintosh, A. N., Anderson, B. M., Dadic, R., Putnam, A. E., Barrell, D. J. A., Denton, G. H., Chinn, T. J. H., \& Schaefer, J. M. (2017). An exercise in glacier length modeling: Interannual climatic variability alone cannot explain Holocene glacier fluctuations in New Zealand. Earth and Planetary Science Letters, 470, 48-53.

Dunai, T. J. (2001). Influence of secular variation of the geomagnetic field on production rates of in situ produced cosmogenic nuclides. Earth and Planetary Science Letters, 193(1), 197-212.

Dunai, T. J. (2010). Cosmogenic Nuclides: United Kingdom: Cambridge University Press.

Dunai, T. J., \& Lifton, N. A. (2014). The Nuts and Bolts of Cosmogenic Nuclide Production. Elements, 10(5), 347-350.

Dunne, J., Elmore, D., \& Muzikar, P. (1999). Scaling factors for the rates of production of cosmogenic nuclides for geometric shielding and attenuation at depth on sloped surfaces. Geomorphology, 27(1), 3-11.

Eaves, S. R., Anderson, B. M., \& Mackintosh, A. N. (2017). Glacier-based climate reconstructions for the last glacial-interglacial transition: Arthur's Pass, New Zealand (43 ${ }^{\circ}$ S). Journal of Quaternary Science, 32(6), 877-887.

Eaves, S. R., Mackintosh, A. N., \& Anderson, B. M. (2019). Climate amelioration during the Last Glacial Maximum recorded by a sensitive mountain glacier in New Zealand. Geology, 47(4), 299-302. 
Eaves, S. R., N. Mackintosh, A., Winckler, G., Schaefer, J. M., Alloway, B. V., \& Townsend, D. B. (2016). A cosmogenic 3He chronology of late Quaternary glacier fluctuations in North Island, New Zealand $\left(39^{\circ} \mathrm{S}\right)$. Quaternary Science Reviews, 132, 40-56.

Eaves, S. R., Winckler, G., Schaefer, J. M., Vandergoes, M. J., Alloway, B. V., Mackintosh, A. N., Townsend, D. B., Ryan, M. T., \& Li, X. (2015). A test of the cosmogenic 3 He production rate in the south-west Pacific $\left(39^{\circ} \mathrm{S}\right)$. Journal of Quaternary Science, 30(1), 79-87.

Fitzharris, B. B., Chinn, T. J., \& Lamont, G. N. (1997). Glacier balance fluctuations and atmospheric circulation patterns over the Southern Alps, New Zealand. International Journal of Climatology, 17(7), 745-763.

Fowler, A. M., Boswijk, G., Lorrey, A. M., Gergis, J., Pirie, M., McCloskey, S. P., Palmer, J. G., \& Wunder, J. (2012). Multi-centennial tree-ring record of ENSOrelated activity in New Zealand. Nature Climate Change, 2(3), 172.

Gellatly, A. F. (1982). Lichenometry as a relative-age dating method in Mount Cook National Park, New Zealand. New Zealand Journal of Botany, 20(4), 343-353.

Gellatly, A. F. (1984). The use of rock weathering-rind thickness to redate moraines in Mount Cook National Park, New Zealand. Arctic \& Alpine Research, 16(2), 225-232.

Gibbons, A. B., Megeath, J. D., \& Pierce, K. L. (1984). Probability of moraine survival in a succession of glacial advances. Geology, 12(6), 327-330.

Goehring, B. M., Schaefer, J. M., Schluechter, C., Lifton, N. A., Finkel, R. C., Jull, A. J. T., Akçar, N., \& Alley, R. B. (2011). The Rhone Glacier was smaller than today for most of the Holocene. Geology, 39(7), 679-682.

Golledge, N. R., Mackintosh, A. N., Anderson, B. M., Buckley, K. M., Doughty, A. M., Barrell, D. J. A., Denton, G. H., Vandergoes, M. J., Andersen, B. G., \& Schaefer, J. M. (2012). Last Glacial Maximum climate in New Zealand inferred from a modelled Southern Alps icefield. Quaternary Science Reviews, 46, 3045 .

Gong, D., \& Wang, S. (1999). Definition of Antarctic Oscillation index. Geophysical Research Letters, 26(4), 459-462.

Gosse, J. C., \& Phillips, F. M. (2001). Terrestrial in situ cosmogenic nuclides: theory and application. Quaternary Science Reviews, 20(14), 1475-1560.

Goudie, A. S. (2006). The Schmidt Hammer in geomorphological research. Progress in Physical Geography: Earth and Environment, 30(6), 703-718.

Grootes, P. M., Stuiver, M., White, J. W. C., Johnsen, S., \& Jouzel, J. (1993). Comparison of oxygen isotope records from the GISP2 and GRIP Greenland ice cores. Nature, 366(6455), 552-554. 
Grove, J. M. (2004). Little ice ages: Ancient and modern (2nd Ed.). London, New York: Routledge.

Hartmann, D. L. (2016). Global physical climatology (2nd ed.). Amsterdam: Elsevier.

Hartmann, D. L., Klein Tank, A. M. G., Rusticucci, M., Alexander, L. V., Brönnimann, S., Charabi, Y., Dentener, F. J., Dlugokencky, E. J., Easterling, D. R., Kaplan, A., Soden, B. J., Thorne, P. W., Wild, M., \& Zhai, P. M. (2013). Observations: Atmosphere and Surface. In T. F. Stocker, D. Qin, G.-K. Plattner, M. Tignor, S. K. Allen, J. Boschung, A. Nauels, Y. Xia, V. Bex, \& P. M. Midgley (Eds.), Climate Change 2013: The Physical Science Basis. Contribution of Working Group I to the Fifth Assessment Report of the Intergovernmental Panel on Climate Change (pp. 159-254). Cambridge, United Kingdom and New York, NY, USA: Cambridge University Press.

Haug, G. H., Hughen, K. A., Sigman, D. M., Peterson, L. C., \& Röhl, U. (2001). Southward migration of the intertropical convergence zone through the Holocene. Science, 293(5533), 1304-1308.

Hays, J. D., Imbrie, J., \& Shackleton, N. J. (1976). Variations in the Earth's Orbit: Pacemaker of the Ice Ages. Science, 194(4270), 1121-1132.

Hedding, D. W., Brook, M. S., \& Winkler, S. (2018). Old landscapes, new eyes: Revisiting geomorphological research in the Southern Alps of New Zealand. New Zealand Geographer, 74(2), 109-112.

Hein, A. S., Cogez, A., Darvill, C. M., Mendelova, M., Kaplan, M. R., Herman, F., Dunai, T. J., Norton, K., Xu, S., Christl, M., \& Rodés, Á. (2017). Regional midPleistocene glaciation in central Patagonia. Quaternary Science Reviews, 164, 77-94.

Henderson, R., \& Thompson, S. (1999). Extreme rainfalls in the Southern Alps of New Zealand. Journal of Hydrology, 309-330.

Herman, F., Beyssac, O., Brughelli, M., Lane, S. N., Leprince, S., Adatte, T., Lin, J. Y. Y., Avouac, J.-P., \& Cox, S. C. (2015). Erosion by an Alpine glacier. Science, 350(6257), 193-195.

Herman, F., \& Braun, J. (2008). Evolution of the glacial landscape of the Southern Alps of New Zealand: Insights from a glacial erosion model. Journal of Geophysical Research: Earth Surface, 113(F2).

Hessell, J. W. D. (1983). Climatic effects on the recession of the Franz Josef Glacier (New Zealand). New Zealand Journal of Science, 26, 315-320.

Hewitt, K. (1999). Quaternary Moraines vs Catastrophic Rock Avalanches in the Karakoram Himalaya, Northern Pakistan. Quaternary Research, 51(3), 220-237.

Heyman, J., Stroeven, A. P., Harbor, J. M., \& Caffee, M. W. (2011). Too young or too old: Evaluating cosmogenic exposure dating based on an analysis of compiled boulder exposure ages. Earth and Planetary Science Letters, 302(1), 71-80. 
Holzhauser, H., Magny, M., \& Zumbuühl, H. J. (2005). Glacier and lake-level variations in west-central Europe over the last 3500 years. The Holocene, 15(6), 789-801.

Hormes, A., Beer, J., \& Schlüchter, C. (2006). A geochronological approach to understanding the role of solar activity on Holocene glacier length variability in the Swiss Alps. Geografiska Annaler: Series A, Physical Geography, 88(4), 281-294.

Hormes, A., Müller, B. U., \& Schlüchter, C. (2001). The Alps with little ice: evidence for eight Holocene phases of reduced glacier extent in the Central Swiss Alps. The Holocene, 11(3), 255-265.

Hunt, A. L., Larsen, J., Bierman, P. R., \& Petrucci, G. A. (2008). Investigation of factors that affect the sensivity of accelerator mass spectrometry for cosmogenic $10 \mathrm{Be}$ and 26Al isotope analysis. Analytical chemistry, 80, 1656-1663.

IPCC. (2013). Climate Change 2013: The Physical Science Basis. Contribution of Working Group I to the Fifth Assessment Report of the Intergovernmental Panel on Climate Change (T. F. Stocker, D. Qin, G.-K. Plattner, M. Tignor, S. K. Allen, J. Boschung, A. Nauels, Y. Xia, V. Bex, \& P. M. Midgley Eds.). Cambridge, United Kingdom and New York, NY, USA: Cambridge University Press.

Ivy-Ochs, S., \& Briner, J. P. (2014). Dating Disappearing Ice with Cosmogenic Nuclides. Elements, 10(5), 351-356.

Ivy-Ochs, S., Kerschner, H., Maisch, M., Christl, M., Kubik, P. W., \& Schlüchter, C. (2009). Latest Pleistocene and Holocene glacier variations in the European Alps. Quaternary Science Reviews, 28(21), 2137-2149.

Ivy-Ochs, S., Schlüchter, C., Kubik, P. W., \& Denton, G. H. (1999). Moraine exposure dates imply synchronous Younger Dryas glacier advances in the European Alps and in the Southern Alps of New Zealand. Geografiska Annaler: Series A, Physical Geography, 81(2), 313-323.

Jara, I. A., Newnham, R. M., Vandergoes, M. J., Foster, C. R., Lowe, D. J., Wilmshurst, J. M., Moreno, P. I., Renwick, J. A., \& Homes, A. M. (2015). Pollen-climate reconstruction from northern South Island, New Zealand $\left(41^{\circ} \mathrm{S}\right)$, reveals varying high-and low-latitude teleconnections over the last 16000 years. Journal of Quaternary Science, 30(8), 817-829.

Joerin, U., Nicolussi, K., Fischer, A., Stocker, T., \& Schlüchter, C. (2008). Holocene optimum events inferred from subglacial sediments at Tschierva Glacier, Eastern Swiss Alps. Quaternary Science Reviews, 27(3-4), 337-350.

Joerin, U. E., Stocker, T. F., \& Schlüchter, C. (2006). Multicentury glacier fluctuations in the Swiss Alps during the Holocene. The Holocene, 16(5), 697-704.

Jóhannesson, T., Raymond, C., \& Waddington, E. (1989). Time-scale for adjustment of glaciers to changes in mass balance. Journal of Glaciology, 35(121), 355-369. 
Kaplan, M. R., Schaefer, J. M., Denton, G. H., Barrell, D. J. A., Chinn, T. J. H., Putnam, A. E., Andersen, B. G., Finkel, R. C., Schwartz, R., \& Doughty, A. M. (2010). Glacier retreat in New Zealand during the Younger Dryas stadial. Nature, 467, 194.

Kaplan, M. R., Schaefer, J. M., Denton, G. H., Doughty, A. M., Barrell, D. J., Chinn, T. J., Putnam, A. E., Andersen, B. G., Mackintosh, A., \& Finkel, R. C. (2013). The anatomy of long-term warming since $15 \mathrm{ka}$ in New Zealand based on net glacier snowline rise. Geology, 41(8), 887-890.

Kaplan, M. R., Schaefer, J. M., Strelin, J. A., Denton, G. H., Anderson, R. F., Vandergoes, M. J., Finkel, R. C., Schwartz, R., Travis, S. G., Garcia, J. L., Martini, M. A., \& Nielsen, S. H. H. (2016). Patagonian and southern South Atlantic view of Holocene climate. Quaternary Science Reviews, 141, 112-125.

Kidson, J. W., \& Renwick, J. A. (2002). Patterns of convection in the tropical pacific and their influence on New Zealand weather. International Journal of Climatology, 22(2), 151-174.

Kidston, J., Renwick, J., \& McGregor, J. (2009). Hemispheric-scale seasonality of the Southern Annular Mode and impacts on the climate of New Zealand. Journal of Climate, 22(18), 4759-4770.

Kirkbride, M. P., \& Warren, C. R. (1999). Tasman Glacier, New Zealand: 20th-century thinning and predicted calving retreat. Global and Planetary Change, 22(1), 1128.

Koch, A., Brierley, C., Maslin, M. M., \& Lewis, S. L. (2019). Earth system impacts of the European arrival and Great Dying in the Americas after 1492. Quaternary Science Reviews, 207, 13-36.

Koffman, T. N. B., Schaefer, J. M., Putnam, A. E., Denton, G. H., Barrell, D. J. A., Rowan, A. V., Finkel, R. C., Rood, D. H., Schwartz, R., Plummer, M. A., \& Brocklehurst, S. H. (2017). A beryllium-10 chronology of late-glacial moraines in the upper Rakaia valley, Southern Alps, New Zealand supports SouthernHemisphere warming during the Younger Dryas. Quaternary Science Reviews, $170,14-25$.

Kohl, C. P., \& Nishiizumi, K. (1992). Chemical isolation of quartz for measurement of in-situ -produced cosmogenic nuclides. Geochimica et Cosmochimica Acta, 56(9), 3583-3587.

Kubik, P. W., \& Ivy-Ochs, S. (2004). A re-evaluation of the 0-10 ka 10Be production rate for exposure dating obtained from the Köfels (Austria) landslide. Nuclear Instruments and Methods in Physics Research Section B: Beam Interactions with Materials and Atoms, 223-224, 618-622.

Lal, D. (1991). Cosmic ray labeling of erosion surfaces: in situ nuclide production rates and erosion models. Earth and Planetary Science Letters, 104(2-4), 424-439.

Land-Information-New-Zealand. (2018). LINZ Data Service. Retrieved from https://data.linz.govt.nz/ 
Larsen, S. H., Davies, T. R. H., \& McSaveney, M. J. (2005). A possible coseismic landslide origin of late Holocene moraines of the Southern Alps, New Zealand. New Zealand Journal of Geology and Geophysics, 48(2), 311-314.

Lean, J. L. (2010). Cycles and trends in solar irradiance and climate. Wiley interdisciplinary reviews: climate change, 1(1), 111-122.

Licciardi, J., Kurz, M., Clark, P., \& Brook, E. (1999). Calibration of cosmogenic 3He production rates from Holocene lava flows in Oregon, USA, and effects of the Earth's magnetic field. Earth Planetary and Science Letters, 172(3-4), 261-271.

Licciardi, J., Schaefer, J. M., Taggart, J. R., \& Lund, D. C. (2009). Holocene Glacier Fluctuations in the Peruvian Andes Indicate Northern Climate Linkages. Science, 325(5948), 1677-1679.

Lifton, N., Bieber, J. W., Clem, J. M., Duldig, M. L., Evenson, P., Humble, J. E., \& Pyle, R. (2005). Addressing solar modulation and long-term uncertainties in scaling secondary cosmic rays for in situ cosmogenic nuclide applications. Earth and Planetary Science Letters, 239(1), 140-161.

Lifton, N., Caffee, M., Finkel, R., Marrero, S., Nishiizumi, K., Phillips, F. M., Goehring, B., Gosse, J., Stone, J., \& Schaefer, J. (2015). In situ cosmogenic nuclide production rate calibration for the CRONUS-Earth project from Lake Bonneville, Utah, shoreline features. Quaternary Geochronology, 26, 56-69.

Lifton, N., Sato, T., \& Dunai, T. J. (2014). Scaling in situ cosmogenic nuclide production rates using analytical approximations to atmospheric cosmic-ray fluxes. Earth and Planetary Science Letters, 386, 149-160.

Lorrey, A., \& Bostock, H. (2017). The Quaternary climate of New Zealand. . In J. Shulmeister (Ed.), Landscape and Quaternary Environmental Change in New Zealand (pp. 67-139). Paris: Atlantic Press

Lorrey, A., Fauchereau, N., Stanton, C., Chappell, P., Phipps, S., Mackintosh, A., Renwick, J., Goodwin, I., \& Fowler, A. (2014). The Little Ice Age climate of New Zealand reconstructed from Southern Alps cirque glaciers: a synoptic type approach. Climate Dynamics, 42(11-12), 3039-3060.

Lorrey, A., Williams, P., Salinger, J., Martin, T., Palmer, J., Fowler, A., Zhao, J.-x., \& Neil, H. (2008). Speleothem stable isotope records interpreted within a multiproxy framework and implications for New Zealand palaeoclimate reconstruction. Quaternary International, 187(1), 52-75.

Loulergue, L., Schilt, A., Spahni, R., Masson-Delmotte, V., Blunier, T., Lemieux, B., Barnola, J.-M., Raynaud, D., Stocker, T. F., \& Chappellaz, J. (2008). Orbital and millennial-scale features of atmospheric $\mathrm{CH} 4$ over the past 800,000 years. Nature, 453, 383.

Lowe, J. J., \& Walker, M. (2014). Reconstructing Quaternary Environments (3rd ed.). New York: Routledge. 
Lüthi, D., Le Floch, M., Bereiter, B., Blunier, T., Barnola, J.-M., Siegenthaler, U., Raynaud, D., Jouzel, J., Fischer, H., Kawamura, K., \& Stocker, T. F. (2008). High-resolution carbon dioxide concentration record 650,000-800,000 years before present. Nature, 453, 379.

MacFarling-Meure, C., Etheridge, D., Trudinger, C., Steele, P., Langenfelds, R., van Ommen, T., Smith, A., \& Elkins, J. (2006). Law Dome CO2, CH4 and N2O ice core records extended to 2000 years BP. Geophysical Research Letters, 33(14).

Mackintosh, A. N., Anderson, B. M., Lorrey, A. M., Renwick, J. A., Frei, P., \& Dean, S. M. (2017a). Regional cooling caused recent New Zealand glacier advances in a period of global warming. Nature Communications, 8, 14202.

Mackintosh, A. N., Anderson, B. M., \& Pierrehumbert, R. T. (2017b). Reconstructing Climate from Glaciers. Annual Review of Earth and Planetary Sciences, 45(1), 649-680.

Mann, M. E., Zhang, Z., Hughes, M. K., Bradley, R. S., Miller, S. K., Rutherford, S., \& Ni, F. (2008). Proxy-based reconstructions of hemispheric and global surface temperature variations over the past two millennia. Proceedings of the National Academy of Sciences, 105(36), 13252.

Mann, M. E., Zhang, Z., Rutherford, S., Bradley, R. S., Hughes, M. K., Shindell, D., Ammann, C., Faluvegi, G., \& Ni, F. (2009). Global Signatures and Dynamical Origins of the Little Ice Age and Medieval Climate Anomaly. Science, 326(5957), 1256.

Marcott, S. A., Shakun, J. D., Clark, P. U., \& Mix, A. C. (2013). A reconstruction of regional and global temperature for the past 11,300 years. Science, 339(6124), 1198-1201.

Marrero, S. M., Phillips, F. M., Borchers, B., Lifton, N., Aumer, R., \& Balco, G. (2016). Cosmogenic nuclide systematics and the CRONUScalc program. Quaternary Geochronology, 31, 160-187.

Martin, L. C. P., Blard, P. H., Balco, G., Lavé, J., Delunel, R., Lifton, N., \& Laurent, V. (2017). The CREp program and the ICE-D production rate calibration database: A fully parameterizable and updated online tool to compute cosmic-ray exposure ages. Quaternary Geochronology, 38, 25-49.

Marzeion, B., Cogley, J. G., Richter, K., \& Parkes, D. (2014). Attribution of global glacier mass loss to anthropogenic and natural causes. Science, 345(6199), 919.

Masarik, J., \& Beer, J. (1999). Simulation of particle fluxes and cosmogenic nuclide production in the Earth's atmosphere. Journal of Geophysical Research: Atmospheres, 104(D10), 12099-12111. 
Masson-Delmotte, V., Schulz, M., Abe-Ouchi, A., Beer, J., Ganopolski, A., González Rouco, J. F., Jansen, E., Lambeck, K., Luterbacher, J., Naish, T., Osborn, T., Otto-Bliesner, B., Quinn, T., Ramesh, R., Rojas, M., Shao, X., \& Timmermann, A. (2013). Information from Paleoclimate Archives. In T. F. Stocker, D. Qin, G.-K. Plattner, M. Tignor, S. K. Allen, J. Boschung, A. Nauels, Y. Xia, V. Bex, \& P. M. Midgley (Eds.), Climate Change 2013: The Physical Science Basis. Contribution of Working Group I to the Fifth Assessment Report of the Intergovernmental Panel on Climate Change (pp. 383-464). Cambridge, United Kingdom and New York, NY, USA: Cambridge University Press.

Masson, V., Vimeux, F., Jouzel, J., Morgan, V., Delmotte, M., Ciais, P., Hammer, C., Johnsen, S., Lipenkov, V. Y., \& Mosley-Thompson, E. (2000). Holocene climate variability in Antarctica based on 11 ice-core isotopic records. Quaternary Research, 54(3), 348-358.

McColl, S. T., \& Davies, T. R. (2011). Evidence for a rock-avalanche origin for 'The Hillocks" "moraine", Otago, New Zealand. Geomorphology, 127(3), 216-224.

McColl, S. T., \& Davies, T. R. H. (2013). Large ice-contact slope movements: glacial buttressing, deformation and erosion. Earth Surface Processes and Landforms, $38(10), 1102-1115$.

McGlone, M. (2002). The Late Quaternary peat, vegetation and climate history of the Southern Oceanic Islands of New Zealand. Quaternary Science Reviews, 21(46), 683-707.

McGlone, M. S., Hall, G. M., \& Wilmshurst, J. M. (2010a). Seasonality in the early Holocene: Extending fossil-based estimates with a forest ecosystem process model. The Holocene, 21(4), 517-526.

McGlone, M. S., Turney, C. S., \& Wilmshurst, J. M. (2004). Late-glacial and Holocene vegetation and climatic history of the Cass Basin, central South Island, New Zealand. Quaternary Research, 62(3), 267-279.

McGlone, M. S., Turney, C. S., Wilmshurst, J. M., Renwick, J., \& Pahnke, K. (2010b). Divergent trends in land and ocean temperature in the Southern Ocean over the past 18,000 years. Nature Geoscience, 3(9), 622.

McKinnon, K. A., Mackintosh, A. N., Anderson, B. M., \& Barrell, D. J. A. (2012). The influence of sub-glacial bed evolution on ice extent: a model-based evaluation of the Last Glacial Maximum Pukaki glacier, New Zealand. Quaternary Science Reviews, 57, 46-57. 
Members, E. C., Barbante, C., Barnola, J. M., Becagli, S., Beer, J., Bigler, M., Boutron, C., Blunier, T., Castellano, E., Cattani, O., Chappellaz, J., Dahl-Jensen, D., Debret, M., Delmonte, B., Dick, D., Falourd, S., Faria, S., Federer, U., Fischer, H., Freitag, J., Frenzel, A., Fritzsche, D., Fundel, F., Gabrielli, P., Gaspari, V., Gersonde, R., Graf, W., Grigoriev, D., Hamann, I., Hansson, M., Hoffmann, G., Hutterli, M. A., Huybrechts, P., Isaksson, E., Johnsen, S., Jouzel, J., Kaczmarska, M., Karlin, T., Kaufmann, P., Kipfstuhl, S., Kohno, M., Lambert, F., Lambrecht, A., Lambrecht, A., Landais, A., Lawer, G., Leuenberger, M., Littot, G., Loulergue, L., Lüthi, D., Maggi, V., Marino, F., Masson-Delmotte, V., Meyer, H., Miller, H., Mulvaney, R., Narcisi, B., Oerlemans, J., Oerter, H., Parrenin, F., Petit, J. R., Raisbeck, G., Raynaud, D., Röthlisberger, R., Ruth, U., Rybak, O., Severi, M., Schmitt, J., Schwander, J., Siegenthaler, U., SiggaardAndersen, M. L., Spahni, R., Steffensen, J. P., Stenni, B., Stocker, T. F., Tison, J. L., Traversi, R., Udisti, R., Valero-Delgado, F., van den Broeke, M. R., van de Wal, R. S. W., Wagenbach, D., Wegner, A., Weiler, K., Wilhelms, F., Winther, J. G., \& Wolff, E. (2006). One-to-one coupling of glacial climate variability in Greenland and Antarctica. Nature, 444, 195.

Milankovitch, M. (1941). Kanon der Erdbestrahlung und seine Anwendung auf das Eiszeitenproblem. Royal Serbian Academy Special Publication, 133, 1-633.

Miller, G. H., Briner, J. P., Lifton, N. A., \& Finkel, R. C. (2006). Limited ice-sheet erosion and complex exposure histories derived from in situ cosmogenic 10Be, 26Al, and 14C on Baffin Island, Arctic Canada. Quaternary Geochronology, $1(1), 74-85$.

Miller, G. H., Geirsdóttir, Á., Zhong, Y., Larsen, D. J., Otto-Bliesner, B. L., Holland, M. M., Bailey, D. A., Refsnider, K. A., Lehman, S. J., Southon, J. R., Anderson, C., Björnsson, H., \& Thordarson, T. (2012). Abrupt onset of the Little Ice Age triggered by volcanism and sustained by sea-ice/ocean feedbacks. Geophysical Research Letters, 39(2).

Neukom, R., Gergis, J., Karoly, D. J., Wanner, H., Curran, M., Elbert, J., GonzálezRouco, F., Linsley, B. K., Moy, A. D., Mundo, I., Raible, C. C., Steig, E. J., van Ommen, T., Vance, T., Villalba, R., Zinke, J., \& Frank, D. (2014). Interhemispheric temperature variability over the past millennium. Nature Climate Change, 4, 362.

Nicolussi, K., \& Patzelt, G. (2000). Discovery of early Holocene wood and peat on the forefield of the Pasterze Glacier, Eastern Alps, Austria. The Holocene, 10(2), 191-199.

Nishiizumi, K., Imamura, M., Caffee, M. W., Southon, J. R., Finkel, R. C., \& McAninch, J. (2007). Absolute calibration of 10Be AMS standards. Nuclear Instruments and Methods in Physics Research Section B: Beam Interactions with Materials and Atoms, 258(2), 403-413.

Nishiizumi, K., Winterer, E., Kohl, C., Klein, J., Middleton, R., Lal, D., \& Arnold, J. (1989). Cosmic ray production rates of $10 \mathrm{Be}$ and $26 \mathrm{Al}$ in quartz from glacially polished rocks. Journal of Geophysical Research: Solid Earth, 94(B12), 1790717915. 
Norton, K. P., von Blanckenburg, F., Schlunegger, F., Schwab, M., \& Kubik, P. W. (2008). Cosmogenic nuclide-based investigation of spatial erosion and hillslope channel coupling in the transient foreland of the Swiss Alps. Geomorphology, 95(3), 474-486.

Ochs, M., \& Ivy-Ochs, S. (1997). The chemical behavior of Be, Al, Fe, $\mathrm{Ca}$ and $\mathrm{Mg}$ during AMS target preparation from terrestrial silicates modeled with chemical speciation calculations. Nuclear Instruments and Methods in Physics Research Section B: Beam Interactions with Materials and Atoms, 123(1), 235-240.

Oerlemans, J. (1997). Climate sensitivity of Franz Josef Glacier, New Zealand, as revealed by numerical modeling. Arctic \& Alpine Research, 29(2), 233-239.

Oerlemans, J. (2001). Glaciers and climate change. Lisse: A.A. Balkema.

Oerlemans, J. (2005). Extracting a Climate Signal from 169 Glacier Records. Science, $308(5722), 675$.

Oerlemans, J., Anderson, B., Hubbard, A., Huybrechts, P., Johannesson, T., Knap, W., Schmeits, M., Stroeven, A., Van de Wal, R., \& Wallinga, J. (1998). Modelling the response of glaciers to climate warming. Climate Dynamics, 14(4), 267-274.

Oerlemans, J., \& Fortuin, J. P. F. (1992). Sensitivity of Glaciers and Small Ice Caps to Greenhouse Warming. Science, 258(5079), 115-117.

Ohmura, A. (2001). Physical Basis for the Temperature-Based Melt-Index Method. Journal of Applied Meteorology, 40(4), 753-761.

Owens, M. J., Lockwood, M., Hawkins, E., Usoskin, I., Jones, G. S., Barnard, L., Schurer, A., \& Fasullo, J. (2017). The Maunder minimum and the Little Ice Age: an update from recent reconstructions and climate simulations. Journal of Space Weather \& Space Climate, 7, A33.

Portenga, E. W., \& Bierman, P. R. (2011). Understanding Earth's eroding surface with 10Be. GSA Today, 21(8), 4-10.

Porter, S. C. (1975). Equilibrium-line altitudes of late Quaternary glaciers in the Southern Alps, New Zealand. Quaternary Research, 5(1), 27-47.

Porter, S. C., \& Orombelli, G. (1985). Glacier contraction during the middle Holocene in the western Italian Alps: evidence and implications. Geology, 13(4), 296-298.

Post, A. (1967). Effects of the March 1964 Alaska earthquake on glaciers. Washington: US Government Printing Office.

Prebble, J., Bostock, H., Cortese, G., Lorrey, A., Hayward, B., Calvo, E., Northcote, L., Scott, G., \& Neil, H. (2017). Evidence for a Holocene Climatic Optimum in the southwest Pacific: A multiproxy study. Paleoceanography, 32(8), 763-779.

Purdie, H., Anderson, B., Chinn, T., Owens, I., Mackintosh, A., \& Lawson, W. (2014). Franz Josef and Fox Glaciers, New Zealand: Historic length records. Global and Planetary Change, 121, 41-52. 
Purdie, H., Mackintosh, A., Lawson, W., \& Anderson, B. (2011). Synoptic influences on snow accumulation on glaciers east and west of a topographic divide: Southern Alps, New Zealand. Arctic, Antarctic, and Alpine Research, 43(1), 8294.

Purdie, J., \& Fitzharris, B. (1999). Processes and rates of ice loss at the terminus of Tasman Glacier, New Zealand. Global and Planetary Change, 22(1), 79-91.

Putnam, A. E., Denton, G. H., Schaefer, J. M., Barrell, D. J. A., Andersen, B. G., Finkel, R. C., Schwartz, R., Doughty, A. M., Kaplan, M. R., \& Schlüchter, C. (2010a). Glacier advance in southern middle-latitudes during the Antarctic Cold Reversal. Nature Geoscience, 3, 700.

Putnam, A. E., Schaefer, J. M., Barrell, D. J. A., Vandergoes, M., Denton, G. H., Kaplan, M. R., Finkel, R. C., Schwartz, R., Goehring, B. M., \& Kelley, S. E. (2010b). In situ cosmogenic 10Be production-rate calibration from the Southern Alps, New Zealand. Quaternary Geochronology, 5(4), 392-409.

Putnam, A. E., Schaefer, J. M., Denton, G. H., Barrell, D. J. A., Birkel, S. D., Andersen, B. G., Kaplan, M. R., Finkel, R. C., Schwartz, R., \& Doughty, A. M. (2013). The Last Glacial Maximum at $44^{\circ} \mathrm{S}$ documented by a $10 \mathrm{Be}$ moraine chronology at Lake Ohau, Southern Alps of New Zealand. Quaternary Science Reviews, 62, 114-141.

Putnam, A. E., Schaefer, J. M., Denton, G. H., Barrell, D. J. A., Finkel, R. C., Andersen, B. G., Schwartz, R., Chinn, T. J. H., \& Doughty, A. M. (2012). Regional climate control of glaciers in New Zealand and Europe during the pre-industrial Holocene. Nature Geoscience, 5, 627.

Raper, S. C., \& Braithwaite, R. J. (2009). Glacier volume response time and its links to climate and topography based on a conceptual model of glacier hypsometry. The Cryosphere, 3(2), 183-194.

Renwick, J., \& Thompson, D. (2006). The southern annular mode and New Zealand climate. Water \& Atmosphere, 14(2), 24-25.

Reznichenko, N., Davies, T., Shulmeister, J., \& McSaveney, M. (2010). Effects of debris on ice-surface melting rates: an experimental study. Journal of Glaciology, 56(197), 384-394.

Reznichenko, N. V., Davies, T. R., Shulmeister, J., \& Larsen, S. H. (2012). A new technique for identifying rock avalanche-sourced sediment in moraines and some paleoclimatic implications. Geology, 40(4), 319-322.

Reznichenko, N. V., Davies, T. R., \& Winkler, S. (2016). Revised palaeoclimatic significance of Mueller Glacier moraines, Southern Alps, New Zealand. Earth Surface Processes and Landforms, 41(2), 196-207.

Reznichenko, N. V., Davies, T. R. H., \& Alexander, D. J. (2011). Effects of rock avalanches on glacier behaviour and moraine formation. Geomorphology, 132(3), 327-338. 
Robock, A. (2000). Volcanic eruptions and climate. Reviews of Geophysics, 38(2), 191219.

Roe, G. H. (2011). What do glaciers tell us about climate variability and climate change? Journal of Glaciology, 57(203), 567-578.

Rood, D. H., Brown, T. A., Finkel, R. C., \& Guilderson, T. P. (2013). Poisson and nonPoisson uncertainty estimations of 10Be/9Be measurements at LLNL-CAMS. Nuclear Instruments and Methods in Physics Research Section B: Beam Interactions with Materials and Atoms, 294, 426-429.

Rood, D. H., Hall, S., Guilderson, T. P., Finkel, R. C., \& Brown, T. A. (2010). Challenges and opportunities in high-precision Be-10 measurements at CAMS. Nuclear Instruments and Methods in Physics Research Section B: Beam Interactions with Materials and Atoms, 268(7), 730-732.

Rother, H., Fink, D., Shulmeister, J., Mifsud, C., Evans, M., \& Pugh, J. (2014). The early rise and late demise of New Zealand's last glacial maximum. Proceedings of the National Academy of Sciences, 111(32), 11630-11635.

Rother, H., Shulmeister, J., Fink, D., Alexander, D., \& Bell, D. (2015). Surface exposure age chronology of glacial moraines in the middle Waimakariri Valley, Canterbury, New Zealand: Implications for MIS 2 ice extent and LGM glacial mass balance. Earth and Planetary Science Letters, 429, 69-81.

Rowan, A. V., Schultz, D. M., Jones, M. A., Brocklehurst, S. H., \& Plummer, M. A. (2013). Drainage capture and discharge variations driven by glaciation in the Southern Alps, New Zealand. Geology, 41(2), 199-202.

Ruddell, A. R. (1995). Recent glacier and climate change in the New Zealand Alps. (PhD). University of Melbourne, Australia.

Ruddiman, W. F. (2003). The anthropogenic greenhouse era began thousands of years ago. Climatic change, 61(3), 261-293.

Ruddiman, W. F. (2013). The anthropocene. Annual Review of Earth Planetary Sciences, 41, 45-68.

Salinger, M., Heine, M., \& Burrows, C. (1983). Variations of the Stocking (Te Wae Wae) Glacier, Mount Cook, and Climatic Relationships. New Zealand Journal of Science, 26, 321-338.

Schaefer, J. M., Denton, G. H., Barrell, D. J., Ivy-Ochs, S., Kubik, P. W., Andersen, B. G., Phillips, F. M., Lowell, T. V., \& Schlüchter, C. (2006). Near-synchronous interhemispheric termination of the last glacial maximum in mid-latitudes. Science, 312(5779), 1510-1513.

Schaefer, J. M., Denton, G. H., Kaplan, M., Putnam, A., Finkel, R. C., Barrell, D. J. A., Andersen, B. G., Schwartz, R., Mackintosh, A., Chinn, T., \& Schlüchter, C. (2009). High-Frequency Holocene Glacier Fluctuations in New Zealand Differ from the Northern Signature. Science, 324(5927), 622-625. 
Schaefer, J. M., Putnam, A. E., Denton, G. H., Kaplan, M. R., Birkel, S., Doughty, A. M., Kelley, S., Barrell, D. J. A., Finkel, R. C., Winckler, G., Anderson, R. F., Ninneman, U. S., Barker, S., Schwartz, R., Andersen, B. G., \& Schluechter, C. (2015). The Southern Glacial Maximum 65,000 years ago and its Unfinished Termination. Quaternary Science Reviews, 114, 52-60.

Schilt, A., Baumgartner, M., Blunier, T., Schwander, J., Spahni, R., Fischer, H., \& Stocker, T. F. (2010). Glacial-interglacial and millennial-scale variations in the atmospheric nitrous oxide concentration during the last 800,000 years. Quaternary Science Reviews, 29(1), 182-192.

Schimmelpfennig, I., Schaefer, J. M., Akçar, N., Koffman, T., Ivy-Ochs, S., Schwartz, R., Finkel, R. C., Zimmerman, S., \& Schlüchter, C. (2014). A chronology of Holocene and Little Ice Age glacier culminations of the Steingletscher, Central Alps, Switzerland, based on high-sensitivity beryllium-10 moraine dating. Earth and Planetary Science Letters, 393, 220-230.

Schurer, A. P., Hegerl, G. C., Mann, M. E., Tett, S. F., \& Phipps, S. J. (2013). Separating forced from chaotic climate variability over the past millennium. Journal of Climate, 26(18), 6954-6973.

Shakun, J. D., Corbett, L. B., Bierman, P. R., Underwood, K., Rizzo, D. M., Zimmerman, S. R., Caffee, M. W., Naish, T., Golledge, N. R., \& Hay, C. C. (2018). Minimal East Antarctic Ice Sheet retreat onto land during the past eight million years. Nature, 558(7709), 284-287.

Shulmeister, J., Davies, T. R., Evans, D. J. A., Hyatt, O. M., \& Tovar, D. S. (2009). Catastrophic landslides, glacier behaviour and moraine formation - A view from an active plate margin. Quaternary Science Reviews, 28(11), 1085-1096.

Shulmeister, J., Fink, D., \& Augustinus, P. C. (2005). A cosmogenic nuclide chronology of the last glacial transition in North-West Nelson, New Zealandnew insights in Southern Hemisphere climate forcing during the last deglaciation. Earth Planetary Science Letters, 233(3-4), 455-466.

Shulmeister, J., Fink, D., Hyatt, O. M., Thackray, G. D., \& Rother, H. (2010). Cosmogenic 10Be and 26Al exposure ages of moraines in the Rakaia Valley, New Zealand and the nature of the last termination in New Zealand glacial systems. Earth Planetary Science Letters, 297(3-4), 558-566.

Shulmeister, J., Fink, D., Winkler, S., Thackray, G., Borsellino, R., Hemmingsen, M., \& Rittenour, T. (2018). Evidence for slow late-glacial ice retreat in the upper Rangitata Valley, South Island, New Zealand. Quaternary Science Reviews, 185, 102-112.

Sigl, M., Winstrup, M., McConnell, J., Welten, K., Plunkett, G., Ludlow, F., Büntgen, U., Caffee, M., Chellman, N., \& Dahl-Jensen, D. (2015). Timing and climate forcing of volcanic eruptions for the past 2,500 years. Nature, 523(7562), 543. 
Sommerville, P., Mark, A. F., \& Wilson, J. B. (1982). Plant succession on moraines of the upper Dart Valley, southern South Island, New Zealand. New Zealand Journal of Botany, 20(3), 227-244.

Steinhilber, F., Beer, J., \& Fröhlich, C. (2009). Total solar irradiance during the Holocene. Geophysical Research Letters, 36(19).

Stone, J. (1998). A rapid fusion method for separation of beryllium-10 from soils and silicates. Geochimica et Cosmochimica Acta, 62(3), 555-561.

Stone, J. (2000). Air pressure and cosmogenic isotope production. Journal of Geophysical Research: Solid Earth, 105(B10), 23753-23759.

Sturman, A. P., \& Tapper, N. J. (2006). Weather and climate of Australia and New Zealand. Melbourne, Victoria: Oxford University Press.

Tait, A., Henderson, R., Turner, R., \& Zheng, X. (2006). Thin plate smoothing spline interpolation of daily rainfall for New Zealand using a climatological rainfall surface. International Journal of Climatology, 26(14), 2097-2115.

Taylor, K. E., Stouffer, R. J., \& Meehl, G. A. (2011). An Overview of CMIP5 and the Experiment Design. Bulletin of the American Meteorological Society, 93(4), 485-498.

Taylor, K. E., Stouffer, R. J., \& Meehl, G. A. (2012). An overview of CMIP5 and the experiment design. Bulletin of the American Meteorological Society, 93(4), 485498.

Tovar, D. S., Shulmeister, J., \& Davies, T. (2008). Evidence for a landslide origin of New Zealand's Waiho Loop moraine. Nature Geoscience, 1(8), 524.

Ummenhofer, C. C., \& England, M. H. (2007). Interannual Extremes in New Zealand Precipitation Linked to Modes of Southern Hemisphere Climate Variability. Journal of Climate, 20(21), 5418-5440.

Ummenhofer, C. C., Sen Gupta, A., \& England, M. H. (2009). Causes of Late Twentieth-Century Trends in New Zealand Precipitation. Journal of Climate, 22(1), 3-19.

Ustaszewski, M. E., hampel, A., \& Pfiffner, O. A. (2008). Composite faults in the Swiss Alps formed by the interplay of tectonics, gravitation and postglacial rebound: an integrated field and modelling study. Swiss Journal of Geosciences, 101(1), 223-235.

Ustaszewski, M. E., \& Pfiffner, O. A. (2008). Composite faults in the Swiss Alps formed by the interplay of tectonics, gravitation and postglacial rebound: an integrated field and modelling study. Swiss Journal of Geosciences, 101(1), 223235 .

Vacco, D. A., Alley, R. B., \& Pollard, D. (2010). Glacial advance and stagnation caused by rock avalanches. Earth and Planetary Science Letters, 294(1), 123-130. 
van den Bos, V., Rees, A., Newnham, R., Vandergoes, M., Wilmshurst, J., \& Augustinus, P. (2018). Holocene temperature, humidity and seasonality in northern New Zealand linked to Southern Hemisphere summer insolation. Quaternary Science Reviews, 201, 77-88.

Villalba, R., Lara, A., Masiokas, M. H., Urrutia, R., Luckman, B. H., Marshall, G. J., Mundo, I. A., Christie, D. A., Cook, E. R., \& Neukom, R. (2012). Unusual Southern Hemisphere tree growth patterns induced by changes in the Southern Annular Mode. Nature Geoscience, 5(11), 793.

Vimeux, F., Masson, V., Jouzel, J., Petit, J., Steig, E., Stievenard, M., Vaikmae, R., \& White, J. (2001). Holocene hydrological cycle changes in the Southern Hemisphere documented in East Antarctic deuterium excess records. Climate Dynamics, 17(7), 503-513.

von Blanckenburg, F., Belshaw, N., \& O'Nions, R. (1996). Separation of 9Be and cosmogenic 10Be from environmental materials and SIMS isotope dilution analysis. Chemical Geology, 129(1-2), 93-99.

von Blanckenburg, F., Hewawasam, T., \& Kubik, P. (2004). Cosmogenic nuclide evidence for low weathering and denudation in the wet, tropical highlands of Sri Lanka. Journal of Geophysical Research: Earth Surface, 109(F3).

Walker, M., Johnsen, S., Rasmussen, S. O., Popp, T., Steffensen, J.-P., Gibbard, P., Hoek, W., Lowe, J., Andrews, J., Björck, S., Cwynar, L. C., Hughen, K., Kershaw, P., Kromer, B., Litt, T., Lowe, D. J., Nakagawa, T., Newnham, R., \& Schwander, J. (2009). Formal definition and dating of the GSSP (Global Stratotype Section and Point) for the base of the Holocene using the Greenland NGRIP ice core, and selected auxiliary records. Journal of Quaternary Science, 24(1), 3-17.

Wardle, P. (1973). Variations of the Glaciers of Westland National Park and the Hooker Range, New Zealand. New Zealand Journal of Botany, 11(2), 349-388.

Warren, C. R., \& Kirkbride, M. P. (2003). Calving speed and climatic sensitivity of New Zealand lake-calving glaciers. Annals of Glaciology, 36, 173-178.

Wells, A., Stewart, G. H., Duncan, R. P., \& Yetton, M. D. (1999). Prehistoric dates of the most recent Alpine fault earthquakes, New Zealand. Geology, 27(11), 995998.

Willenbring, J. K., \& von Blanckenburg, F. (2010). Meteoric cosmogenic Beryllium-10 adsorbed to river sediment and soil: Applications for Earth-surface dynamics. Earth-Science Reviews, 98(1-2), 105-122.

Wilmshurst, J. M., McGlone, M. S., Leathwick, J. R., \& Newnham, R. M. (2007). A pre-deforestation pollen-climate calibration model for New Zealand and quantitative temperature reconstructions for the past 18000 years BP. Journal of Quaternary Science, 22(5), 535-547.

Winkler, S. (2000). The 'Little Ice Age'maximum in the Southern Alps, New Zealand: preliminary results at Mueller Glacier. The Holocene, 10(5), 643-647. 
Winkler, S. (2004). Lichenometric dating of the 'Little Ice Age'maximum in Mt Cook National Park, Southern Alps, New Zealand. The Holocene, 14(6), 911-920.

Winkler, S. (2014). Investigation of late-Holocene moraines in the western Southern Alps, New Zealand, applying Schmidt-hammer exposure-age dating. The Holocene, 24(1), 48-66.

Yokoyama, Y., Anderson, J. B., Yamane, M., Simkins, L. M., Miyairi, Y., Yamazaki, T., Koizumi, M., Suga, H., Kusahara, K., Prothro, L., Hasumi, H., Southon, J. R., \& Ohkouchi, N. (2016). Widespread collapse of the Ross Ice Shelf during the late Holocene. Proceedings of the National Academy of Sciences, 113(9), 2354.

Zemp, M., Frey, H., Gärtner-Roer, I., Nussbaumer, S. U., Hoelzle, M., Paul, F., Haeberli, W., Denzinger, F., Ahlstrøm, A. P., \& Anderson, B. (2015). Historically unprecedented global glacier decline in the early 21 st century. Journal of Glaciology, 61(228), 745-762. 


\section{APPENDIX 1: Lab-user activity log}

The following table documents the lab-user activity that was logged during the seven-day airborne contamination experiment described in Section 3.3.1.

\begin{tabular}{|c|c|c|c|}
\hline Date & Duration in lab & $\begin{array}{l}\text { Working in right- } \\
\text { hand fume hood } \\
\text { (Yes/No) }\end{array}$ & Brief description of work \\
\hline $13 / 07 / 18$ & $\sim 1 \mathrm{hr}$ & Yes & Adding $\mathrm{HCl}$ to beakers \\
\hline $16 / 07 / 18$ & $\sim 3 \mathrm{hr}$ & Yes & $\begin{array}{l}\text { Decanting } \mathrm{HCl} \text { from } \\
\text { beakers; adding } \mathrm{HNO}_{3} \text { to } \\
\text { beakers; adding } \mathrm{HF} \text { to } \\
\text { samples }\end{array}$ \\
\hline $16 / 07 / 18$ & $\sim 30$ mins & Yes & $\begin{array}{l}\text { Put closed beakers on } \\
\text { hotplate; neutralising } \mathrm{HNO}_{3} \\
\text { and } \mathrm{HCl} \text { waste }\end{array}$ \\
\hline $16 / 07 / 18$ & $\sim 1 \mathrm{hr}$ & No & $\begin{array}{l}\text { Prepping Be columns; some } \\
\text { diluting in left-hand fume } \\
\text { hood }\end{array}$ \\
\hline $17 / 07 / 18$ & $\sim 3 \mathrm{hr}$ & No & Be columns \\
\hline $17 / 07 / 18$ & & Yes & $\begin{array}{l}\text { Decanting } \mathrm{HNO}_{3} \text {; adding } \\
\text { HF to beakers }\end{array}$ \\
\hline $17 / 07 / 18$ & $\sim 2 \mathrm{hr}$ & Yes & Decanting $\mathrm{HCl}$ \\
\hline $18 / 07 / 18$ & $\sim 1.5 \mathrm{hr}$ & No & $\begin{array}{l}\text { BeOH precipitations and } \\
\text { acid dilutions in left-hand } \\
\text { fume hood }\end{array}$ \\
\hline $18 / 07 / 18$ & $\sim 3.5 \mathrm{hr}$ & Yes & $\begin{array}{l}\text { Decanting HF into waste; } \\
\text { adding HF to samples }\end{array}$ \\
\hline $19 / 07 / 18$ & $\sim 45$ mins & Yes & Decanting $\mathrm{H}_{2} \mathrm{O}$ \\
\hline $19 / 07 / 18$ & $\sim 2 \mathrm{hrs}$ & No & Decanting $\mathrm{HCl}$ \\
\hline $19 / 07 / 18$ & $\sim 45$ mins & Yes & Adding HF to samples \\
\hline $19 / 07 / 18$ & $\sim 20$ mins & Yes & $\begin{array}{l}\text { Move clean beakers off hot } \\
\text { plate; half fill large beakers } \\
\text { with } \mathrm{HCl}, \mathrm{HNO}_{3} \text {, oxalic }\end{array}$ \\
\hline $20 / 07 / 18$ & $1 \mathrm{hr}$ & No & Cleaning beakers/tubes \\
\hline $20 / 07 / 18$ & $1.5 \mathrm{hr}$ & No & Decanting HF ( $1^{\text {st }}$ leach $)$ \\
\hline $20 / 07 / 18$ & 10 mins & Yes & $\begin{array}{l}\text { Took big beakers off } \\
\text { hotplate }\end{array}$ \\
\hline
\end{tabular}



APPENDIX 2: Geomorphological map of the upper Dart valley

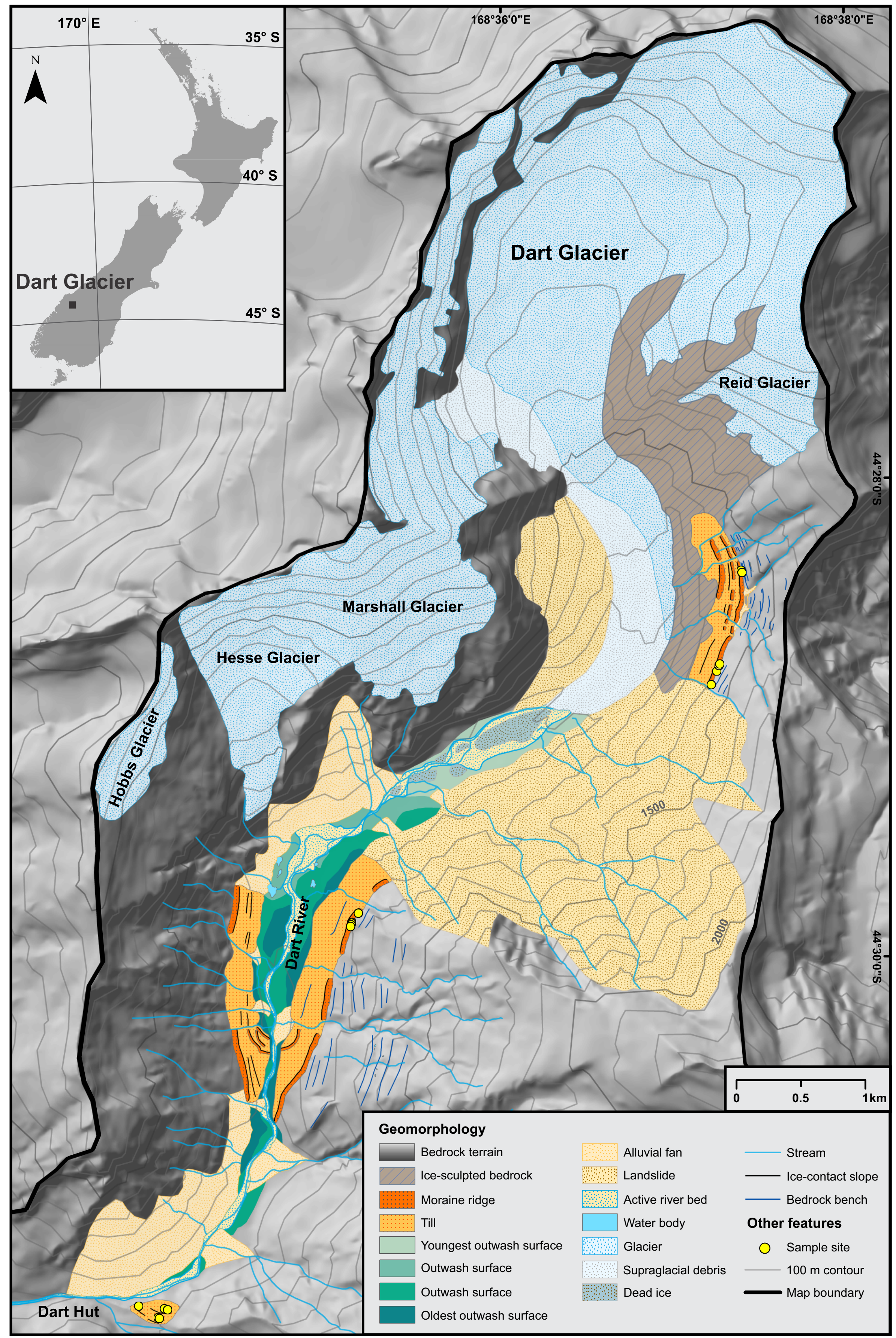

